\title{
Teacher videotaping as a method of self -assessing questioning skills in secondary public schools
}

\author{
Stephen Alan Alberts II \\ West Virginia University
}

Follow this and additional works at: https://researchrepository.wvu.edu/etd

\section{Recommended Citation}

Alberts, Stephen Alan II, "Teacher videotaping as a method of self -assessing questioning skills in secondary public schools" (2000). Graduate Theses, Dissertations, and Problem Reports. 2374.

https://researchrepository.wvu.edu/etd/2374

This Dissertation is protected by copyright and/or related rights. It has been brought to you by the The Research Repository @ WVU with permission from the rights-holder(s). You are free to use this Dissertation in any way that is permitted by the copyright and related rights legislation that applies to your use. For other uses you must obtain permission from the rights-holder(s) directly, unless additional rights are indicated by a Creative Commons license in the record and/ or on the work itself. This Dissertation has been accepted for inclusion in WVU Graduate Theses, Dissertations, and Problem Reports collection by an authorized administrator of The Research Repository @ WVU.

For more information, please contact researchrepository@mail.wvu.edu. 


\title{
Teacher Videotaping as a Method of Self-Assessing Questioning Skills in Secondary Public Schools
}

\author{
Stephen Alan Alberts II
}

\author{
A Dissertation \\ Submitted to the College of Human Resources and Education \\ at West Virginia University \\ In partial fulfillment of the requirements for the degree of \\ Doctor of Education \\ Perry D. Phillips, Ed.D., Chair \\ Robert Bickel, Ph.D. \\ Scott Bower, Ed.D. \\ C. Kenneth Murray, Ph.D. \\ Phyllis Durden, Ed.D.
}

Department of Curriculum and Instruction

$$
\text { Morgantown, WV }
$$

2000

Keywords: Teacher Videotaping, Self-Assessment, Questioning Skills 


\title{
$\underline{\text { Abstract }}$ \\ Teacher Videotaping as a Method of Self-Assessing Questioning Skills in Secondary Public Schools
}

\author{
Stephen Alan Alberts II
}

Primarily this action research project was designed to hone my ability to Socratically question students by reflecting on my teaching through the lens of a videocamera- while reconciling my own paradigm with as many outside assessment devices as possible. The paramount consideration of my questioning/framing references was to incite students to think critically (see Pedagogical Skills Honed in chapter seven). The higher priorities of the outside assessors, on the other hand, were more political than instructional in nature (see Reconciling Multiple Assessments in chapter seven).

Scrutinizing and improving my questioning skills (the focus of the research) led to the epiphany that the larger issue at stake was not just the sequencing of questions up and down the progressive levels of the taxonomy, but the sequencing of foundational skills needed for students to operate at higher abstract thinking/skill levels as they mastered each grade level; this was accomplished by reflecting daily on the videotaped lessons within the larger educational constructs (building, district, state and national edicts).

From my gestalt that students were having trouble answering difficult analysis level questions, came the strand that was followed through my running commentary; students were simply having problems mastering progressively challenging levels of the English Language: reading, writing, critical thinking and speaking.

When eleventh grade students could demonstrate abstract knowledge by providing examples (at the synthesis level), beginning the course- it was clear that they could think about complex issues in terms of cause and effect as well as part to whole relationships.

As the course progressed, and new, more unfamiliar vocabulary began to be layered into the literary selections, it became clear that these students didn't have the skills to assimilate the new terms, the within context of the line/story (through knowledge of root words or pre/suffixes, nor could they phonetically sound them out); the whole language programs move away from these skills. The goal of Socratic inquiry, however, is critical thinking that leads to a differentiation of specifics (words representing ideas).

Empirical thought means proving specifics- and these students could only muster generalities (like, "stuff, things, and you know"). The focus of my questioning then became toward textual evidence to support their statements; herein, the second major stumbling block to critical thinking was uncovered. These students couldn't/wouldn't comprehend what they had read, since previous teachers bought into their, "I don't know's" and simply told students which facts to memorize for the test.

The third major roadblock wasn't blatantly obvious from the tapings- until the student essays' were contrasted with the way they spoke; they didn't write in complete sentences, only clips of vague phrases made it onto the paper (instead of concrete evidence). Therefore, grammar needed to be remediated - in a literature oriented course designed to teaching critical thinking skills and advanced written composition skills.

Since, advanced skill levels of the language are all inexorably tied together, and thinking skills can't advance without these sequential reading and writing foundations, my implications sections of chapter seven address this breakdown of foundational skills that are out of the secondary curricular alignment picture.

The conclusions to this study reveal that not only can questioning skills be honed and improved via videotaping, but also that larger educational concerns can be tied to individual classroom practices recursively. 
Dedication:

To my maternal grandmother Pauline who instilled a love of knowledge in me 


\section{Acknowledgements}

First and foremost, I wish to thank my students for allowing me to undertake this metacognitive endeavor within the confides of their home environment.

Secondly, I would like to express my gratitude to Cynthia Butcher for assisting me in "norming" the questioning levels (as well as the tedium of continually revising the mechanics of this document); this aided me enormously in defining exact interpretations of questioning difficulty- the essence of the study.

Overall, all of my doctoral committee members, I owe a debt of gratitude to for their incremental nurturing and conceptualization of this project:

The chronological genesis and initial conceptualization of quantifying where teaching actually happens, as well as the actual production and refinement of measuring that teaching growth (within the body of this text), was due in large part to Dr. Robert Bickel, whose ability to find the educational truths through a mountain of minutia- while never losing sight of those small morsels of truth gleaned- is of inestimable value.

Likewise, Dr. Perry Phillips' continued sensibilities regarding the bigger educational/political picture, both with this project (as my committee chair) and other subsidiary career choices, garnered my respect early on, and maintained it. Throughout my doctoral program, Dr. Phillips, by arbitrating many sensitive internal and external issues of educational value, and grounding the program in real world career choices, has shown consistent professional character in all decisions of educational importance.

Dr. Scott Bower's pragmatic approach and affable demeanor, from the conceptualization of constructing the research instrument, to be used through the collection of data to be manipulated- down to interpreting the results and meaning of those results- proved itself a boon to avoiding the pitfalls of ill-conceived research and thus results at every stage of development.

Dr. Phyllis Durden, whenever approached, always managed to take the time out of her busy schedule to relate instruction level questions to administrative level considerations; those considerations, in addition to being useful, have proven insightful and have subsequently been inculcated into my administrative conclusions. 
Dr. Kenneth Murray, in terms of the format and layout of this document, also provided strategic information in terms of the preliminary layout of information in this study.

Most of all, I would like to thank all of my political, philosophical, psychological, and educational predecessors for leaving me a roadmap to follow in my pursuit of attaining educational (and life) truths and the methodological results that reflect this growth. 


\section{Table of Contents}

$\begin{array}{ll}\text { ABSTRACT } & \text { ii } \\ \text { LIST OF TABLES } & \text { xi }\end{array}$

CHAPTER

TITLE

PAGE \#

CHAPTER 1

Rationale

Introduction 1

Purpose 2

Pilot Study 2

Statement of Problem 3

Research Questions 4

Significance 5

Reconstructing the Project 5

Limitations 6

$\begin{array}{ll}\text { Definitions } & 6\end{array}$

CHAPTER 2 Review of Literature

Introduction $\quad 10$

$\begin{array}{ll}\text { Teacher Values } & 10\end{array}$

Standards of Assessment 12

Videotaping as Assessment 14 
Questioning Strategies $\quad 16$

Self-Evaluation $\quad 19$

CHAPTER 3

CHAPTER 4
Methodology

Theoretical Framework 21

Qualitative Research 22

Paradigmatic Constructs 22

Triangulation of Assessment 22

Data Collection 23

Data Analysis 24

Course Demographics 24

Participants 25

Course Pedagogy 26

Lesson Planning 26

Daily Itinerary 27

Interpreting the Taxonomic Levels

Introduction 28

Inter-rater Reliability 28

Taping Criterion 28

Labeling the Taxonomic Level 29 
Introduction $\quad 30$

One: Paraphrasing “The Declaration...” 30

Summary $\quad 40$

Two: "Franklin's Autobiography" 41

Summary 52

Three: “Dr. Heidegger's Exp.” 52

$\begin{array}{ll}\text { Summary } & 60\end{array}$

Four: "Poe's Biography" 60

$\begin{array}{ll}\text { Summary } & 67\end{array}$

Five: “A Cask of Amontillado” 68

$\begin{array}{ll}\text { Summary } & 79\end{array}$

Six: Emerson/Transcendentalism $\quad 79$

$\begin{array}{ll}\text { Summary } & 87\end{array}$

Seven: Emerson (continued) 88

Summary 93

Eight: Poetry Terms/Whitman 94

$\begin{array}{ll}\text { Summary } & 102\end{array}$

Nine: Whitman's Poems 103

Summary $\quad 110$

Ten: Explicating Dickinson 111

Summary 117

Eleven: Authors' Compare/Contrast 117 
Summary

CHAPTER 6

CHAPTER 7

\section{Daily Reflections}

Introduction

Framing the Context 136

Question Distribution

Level of Taxonomy Addressed

Authors/Texts (for course)

138

Lesson Design

138

Lesson Modifications

Findings and Implications

Introduction

Reconciling Multiple Assessment Rubrics 140

Multiple Assessment Implications $\quad 150$

Education Administrational Aims $\quad 150$

Educational Administration Implications 154

Pedagogical Skills Honed 155

Pedagogical Implications $\quad 159$

Videotaping Considerations $\quad 159$

Reconstructing the Project 161 
WORKS CITED 162

APPENDIX A: Pilot Study 166

APPENDIX B: Am. Lit. Course Guide 173

APPENDIX C: Sample Lesson Plans 178

APPENDIX D: Participant Consent Forms 182

APPENDIX E: Reflection Guide 187

APPENDIX F: Assessment Review 190

APPENDIX G: Staff Development: Videotaping 215

RESUME 222 


\section{LIST OF TABLES}

TABLE

1. Student Response Elaborations

2. Instructional Emphasis of Lesson

3.

4.
Male Pilot Study Responses

Female Pilot Study Responses
PAGE \#

149

170

171 


\section{Chapter One: Rationale}

\section{Introduction}

Given the dearth of research on teachers in public schools using self-assessment tools in their classrooms, offset by the state (report cards) and national edicts (The National Teacher Exam/Praxis III) designed to hold schools (teachers) to a higher standard, it only makes sense that teachers assess themselves and modify and improve instruction towards specifically stated standards before the opportunity is taken from them.

What we, as a profession, need to keep in mind about the future of instruction, is how our current milieu relates to past external changes brought into the classroom through internally administrated teacher evaluations. According to Perry Zirkle's The Law of Teacher Evaluation: A Self-Assessment Handbook citing Harvard's (1996) Institute on School Law, the following are administratively enforceable areas of a teacher's job performance as have been upheld through case law over the past two decades:

1. Student mastery of concepts as evidenced by tests (mastery is defined as $80 \%$ of the class scoring at $80 \%$ or better on exams).

2. Clearly defined classroom rules, including concise instructions given on assignment instructions and grading criterion

3. Identification of students for remediation (usually 9 mos. behind or more)

4. Identification of illegal student behaviors, violations such as bringing a weapon, drugs, or physical violence into the school setting (as defined by safe school laws)

5. Compliance with school district (and building) policies

6. A well known teacher evaluation process (i.e. school district appraisal forms)

7. Respecting students rights (as defined by constitutional and case law)

8. Any action that could be construed as insubordination

These standards of evaluation made manifest by laws, federal, state and local, define our job description. The teacher, however, is afforded the latitude of interpreting how best to perform the actual task of teaching. Aside from any specifics mentioned in one's individual contract, and the broad legal areas aforementioned, teachers choose the teaching style and method of delivery in achieving their stated lesson plan objectives.

So, if we, as teachers, know that we're expected to perform specific educational and legal tasks- that through student success, or administrative approval, must be considered- what specific 
tasks do we resist being evaluated on, and why? A small study that I conducted in December 1998 will help elucidate attitudes towards these specific tasks - and using videocameras to these ends (a description of the pilot study directly follows the purpose section).

\section{Purpose}

The teaching skill focused on, during the tenure of this project is questioning/framing knowledge. The primary purpose of this study however, is to explore videotaping oneself in action as a viable method of metacognitive assessment (in contrast to either reflective note taking or administrative assessment- which do not take a teacher's methodological style or personal value structure into account).

The secondary purpose of this study is to illustrate the responsibility of a motivated teacher, as a professional, to monitor, set goals and achieve those classroom performance improvements with little help from outside assessors.

Thirdly, this study will act as an individually initiated staff development project, which, when completed, can be workshopped, debriefed and ultimately recreated- using other teachers' similar personal classroom performance improvement goals as a model.

Lastly, upon the fruition of this project, the published conclusions and findings can be shared with the educational community at large, as part of a larger academic concerns regarding the current educational reform movements happening nationally on multiple regional, local, and individual fronts.

\section{Pilot Study}

The results, from the 46 teacher sampling survey, reflecting local attitudes towards videotaping are here broken down by task being evaluated. The number of positive (defined as a 4 or 5 answer on the Likert Scale) responses to each question regarding a particular application are expressed as a percentage:

1. Raising standardized test scores - $23 \%$

2. Creating consistent classroom standards $-59.5 \%$

3. Improving an administrator's future evaluation - $62.5 \%$

4. Ability to accurately describe illegal behaviors $-85 \%$

5. Quantifying (making concrete) subjective practices $-85 \%$

6. Identifying discriminatory practices $-79.5 \%$ 
7. Your ability to defend your classroom practices - $85 \%$

8. Targeting students for remediation $-51.5 \%$

9. Further individualizing instruction $-50.5 \%$

10. Workshopping “best teaching practices" - $86.5 \%$

*The complete survey is included as APPENDIX A.

From this survey, quantifying certain basic areas of teacher performance, describing illegal behaviors, identifying discrimination, defending classroom practices, and workshopping "best teaching practices" are areas receiving very positive approval. Raising test scores, identifying subjective practices, and further individualizing instruction may only receive tertiary gains from videotaping classroom instruction. However, creating more consistent classroom standards, improving administrators' future evaluations, and targeting students for remediation seem to be clear cut areas that having immediate daily feedback on could substantially benefit the receptive teacher.

Since the purpose of this informal pilot study was to confirm and verify teacher intrepidation as reported by Rita Jensen, Doug Smith, and Martin and Mayerson-and was not considered a telling measure in and of itself, explication of the specific areas of resistance to this technological application became the guiding objective to be met out through a real world application.

In addition to political-philosophical value misalignment with tangible assessment of student skills mastered, the "Boyer Commission Report", along with every major longitudinal study done on teacher education programs over the past ten to fifteen years, with my suggestion to lengthen the student teaching apprenticeship to include, at minimum, a one year mentoring term. From a qualified veteran educator mentoring weaknesses in 'rookie teacher' skills, these beginning deficiencies could be identified via videotaping then remediated before bestowing the rank and status of a full faculty member/ professional educator upon them. (This identification of skill deficiencies, in fact, is the aim of the Praxis III classroom performance assessment now being tooled up by ETS for national implementation for the 2001-2002 school year.)

\section{Statement of the Problem}

The problem is, even though teachers are afforded a great deal of latitude in choosing the course materials (text selection) for their respective subject areas, they feel pressured by the outcome oriented learning skills and objectives prescribed by most school districts without feeling enfranchised. This problem is best addressed by understanding the expectations of the individual school district where each educator is employed. 
This, for me, means: Reconciling Praxis III (ETS) national standards of assessment with state and local district rubric while keeping the objectives of the course guide in mind. (All three performance standards, as well as the course guide for American Literature I, are included as APPENDIX B.)

Conversely, every teacher brings a multitude of personal autonomy to the classroom, in terms of philosophical beliefs and their own classroom teaching styles. Before remediating their own skills, each

teacher needs to be metacognitive with regard to their own philosophy and practices or mis-alignment of methodology will result in frustration of the administrator and teacher.

Every practicing teacher today must be aware of their own paradigms and methodologies through inventories (which I will briefly synopsize in my review of literature section) or interactive reflection with pedagogical texts. For this study, through self-assessment and introspection through videotaping, my personal pedagogical ends- improving my questioning/framing skills, are best served through my NeoThomistic Philosophy and Socratic Methodology.

\section{Research Questions}

1. Can Pathwise (district), the State of Ohio (proficiency tests/learning outcomes), and PraxisIII standards be reconciled into one functional cover-all assessment device that can be reflected upon daily? Addressed from pp. 146-163 (specifically answered on page 163). The follow up research suggestion is on p. 164.

2. Is public school teacher videotaping an effective method of self-assessment documentation with regard to administrative educational aims? Addressed from pp.

164-170 (specifically answered on pages 165-167). Further research considerations appear on page 173.

3. Can my own questioning and framing skills be honed and improved to target higher order thinking skills, in light of the constraints that the assessment and outcome rubrics (\#1\&2 from above) place on my lesson plan designs? Addressed from pp. 173-179 (specifically answered on page 178).

4. What physical ways will I have to amend my teaching (e.g. classroom movement and voice projection) in order to work effectively within this video medium? Addressed from pp. 179-181 (specifically answered on page 180).

5. What technical problems will I face/troubleshoot that might be beneficial to other educators wishing to replicate my research undertaking? Addressed from $\mathrm{pp}$. 180-181 (specifically answered on page 181).

6. How will my conclusions affect my administrator's plans to implement this 
technology as a staff development project? Addressed from pp. 170-172 (specifically answered on page 172).

\section{Significance}

The significance of this study is to build on the existing body of educational research in teacher values, by illustrating the role that values play out in everyday educational practices in the public school classroom through the lessons planned. Existing standards of assessment will be inculcated, by connecting the national, state and district criteria to the personal improvement aims of a representative teacher (as a research subject). Videotaping, as assessment, will be the medium of self-assessment, rather than relying solely on reflective notes or outside assessors. My hypothesis then is- can questioning strategies be improved by recursively categorizing and examining their effectiveness in aiding students (and teachers) in the development of critical thinking skills.

Likewise, my further query is- can self-evaluation skills, as well, be improved upon by linking this aspect of self-directed instruction to the growing body of site based faculty development plans (in essence this project is a blueprint for a teacher guided, on site, staff development workshop allowing 'best teaching practices' to be shared). That philosophy (personal beliefs) mediates methodology (teaching style) and is then reconciled with national, state and local edicts provides a rationale for this study. If individually applied, this will benefit the teaching profession by allowing teachers themselves to creatively, based on their own observations, improve their performance in conjunction with meeting tougher and tougher outside standards being imposed upon the profession.

\section{Reconstructing the Project}

The following are the progressive levels of this project's development:

1. Ibecame interested in improving classroom instruction via questioning/framing.

2. I collected background information through my graduate level professors.

3. I researched Questioning/framing and related areas (see chapter two).

4. I began to reconcile my own educational beliefs and methods with the research.

5. I conceived a hypothesis that included my beliefs and the existing research.

6. I created a short questionnaire to test my hypothesis on a small sample group.

7. From the pilot study, I conceived a study to measure the intangibles in question.

8. The conceptual paradigm (prospectus) was refined and modified by committee.

9. The appropriate approvals were garnered and consent was given via Institutional Review Board (IRB). 
10. The lessons were strategically videotaped to illustrate all facets of the study.

11. I continued to research, reconcile my beliefs and practices throughout,

12. While outside assessors were brought in to triangulate (validate) my paradigm.

13. Upon completion of the information gathering stage, I began to review my journal.

14. Daily journal entries were stitched together to create emergent patterns.

15. From the patterns, categories for my concluding discussion were fashioned.

\section{Limitations}

The limitations of this study will be the small sample size of my class (only five students) and myself as a research subject representative of a larger community of secondary teachers and students found in public schools today. Conversely, since this is a qualitative ethnographic study, I was graced with both a small class size (only five students), that all represent a different socio-economic status (SES) cross section of the class structure present in many similar communities across the U.S.

Additionally, an almost endless array of teaching skills could be identified and focused on as perspective areas isolated for research and remediation. For this researcher, however, only outcomes associated with videotaping and improving questioning/framing strategies shall be discussed. Also, subjectively confined, will be to operationally define the progressive levels of questioning that I will employ while videotaping my lesson segments according to the levels of Benjamin Bloom's Taxonomy.

It is important to emphasize that this research is based on a qualitative case study. In contrast to usual surveys, breadth of coverage has been sacrificed for depth of meaningful assertions and future applications/implications of this research.

Once the levels of questioning are defined, the requisite steps will be taken to progressively improve my teaching ability via continuous self-evaluation/metacognition- referencing the appropriate methodological texts (on Socratic Questioning) and modifying instruction accordingly. The only outside validation devices used to identify questioning deficiencies that will be employed are the use of the three outside assessors (named in the methods section).

\section{Definitions}

- Action research- teacher initiated research designed to solve/explain real world instructional problems

- Bloom's Taxonomy- Benjamin Bloom's ordering of objectives from simple learning tasks to more complex ones; the elements from lowest to highest cognitive function are:

1. Knowledge- name, define, memorize, repeat, record, list, recall, know, state, \& write 
2. Comprehension- discuss, describe, give examples, explain, find, tell, \& summarize

3. Application- translate, interpret, apply, solve, show, practice, use, $\&$ demonstrate

4. Analysis- classify, distinguish, categorize, differentiate, compare, examine, \& test

5. Synthesis- originate, revise, compose, arrange, prepare, construct, develop, \& propose

6. Evaluation- appraise, rate, value, assess, measure, estimate, justify, debate, \& score (Slavin, 1997)

- Conceptual framework- is the philosophical, value laden frame of reference (including a teacher's preferred teaching style) that must be constructively reconciled with any new stimulus affecting teaching practices or beliefs.

- Constructivism- Lev Vygotsky's (1978) conceptual belief that all new information must be connected and made relevant to past information and experiences.

- Critical thinking- is generally considered to be the analysis, synthesis, evaluation levels of Bloom's taxonomy that denote higher cognitive functioning/intelligence, that stresses the ability to make rational decisions that either challenge or confirm an existing belief structure.

- Domains (of teaching)- i.e. content knowledge, learning environment, questioning strategies, and lesson efficacy/future modifications as defined by ETS (in Praxis III), that are considered to be essential components of instruction

- Framing skills- the teachers ability to sequentially frame an idea or question in a manner that provides the student with enough concrete context to be answered from the assisted point of reference

- Reflection- a teacher's ability to metacognitively think about his/her practices

- Standards of assessment- generally are the result of a professional organization reconciling their own agenda with the available research on classroom practices and create a rubric that reflects those values

- Socratic questioning- is a method of teaching wherein the instructor seeks to lead students through a complex series of agreed upon empirical truths in order to reach consensus (Webb, 1996).

- Taxonomy- is the system of classification of interconnected levels of intelligence to the whole.

- Teaching style- is the manner in which a teacher presents information that can 
generally be defined as teacher or student centered in origin; here are some examples of styles according to Grasha and Hicks (1995):

Expert

Formal Authority

Personal Model

Facilitator
Possesses knowledge and expertise that

students need. Strives to maintain status as

an expert among students by displaying

students-knowledge and by challenging

students to enhance their competence.

Concerned with transmitting information

and insuring that students are well prepared.

Possesses status among students because of knowledge and role as a faculty member.

Concerned with providing positive and negative feedback, establishing learning goals, expectations, and rules of conduct for students. Concerned with the correct, acceptable, and standard ways to do things and with providing students with the structure they need to learn.

Believes in "teaching by personal example" and establishes a prototype for how to think and behave. Oversees, guides, and directs by showing how to do things and encouraging students to observe and then to emulate the instructor's approach.

Emphasizes the personal nature of teacher-student interactions. Guides and directs students by encouraging cooperative as well as independent learning activities. Good at questions, exploring options, suggesting alternatives, and encouraging students to make informed choices. Overall goal is to develop in students the capacity for independent action, initiative, and responsibility. Works with students on projects in a consultative fashion and tries to provide 
as much direction, support, and encouragement as possible.

Delegator

$$
\begin{aligned}
& \text { Concerned with developing students' capacity to } \\
& \text { function in an autonomous fashion. Interested in } \\
& \text { having people become self-directed, self-initiating } \\
& \text { learners. Students work independently on projects or } \\
& \text { as part of autonomous teams. The teacher is available } \\
& \text { at the request of students as a consultant and resource } \\
& \text { person. }
\end{aligned}
$$

*It is important to note here that each style is not mutually exclusive to the others. In fact, I believe the most effective instructors move smoothly between each style when the appropriateness of task aligns with the instructional delivery method.

- Teacher Values- are the beliefs a teacher has that manifest themselves in practice

- Thomism (neo)- St. Thomas Aquinas' belief that empirical reasoning ultimately seeks to define the scientifically quantifiable complexities of Christian existence (Webb, 1996).

- Workshopped- a teacher (or student) 'best' practice that is shared with colleagues or any hands on learning experience that teams a mentor and a protégé working together on a task

- Zone of proximal development- John Dewey's explanation of a student's ability to perform only with teacher guided assistance, in a task that is beyond a pupils intellectual ability while working on their own (Webb, 1996) 


\section{Chapter Two: Review of Literature}

\section{Introduction}

The intent of this chapter is to elucidate the focus of this research by reviewing the pertinent literature. Since teacher self-evaluation ultimately must begin with one's own conceptual framework emanating from a philosophy that judges practices as either positively reinforcing and constructing upon existing beliefs or negatively impacting self-image and challenging current beliefs and practices, I will first discuss Teacher Values.

Once teachers comprehend how their beliefs affect their practices, they must make lesson plans that allow administrative assessment: Standards of Assessment (national, state, and local), therefore will be the second section of this chapter.

Though there truly is a dearth of information on Videotaping as Assessment in the regular education setting of public schools, the third foci of this chapter will cull applications of this technology that peripherally relate to this study; collegiate settings, the medical field, and special education in the public schools all peripherally apply.

The heart of this chapter, and the subsequent study, will revolve around Questioning Strategies, specifically strategies that illuminate the desired concept or skill being taught as the object of the daily lesson. The assessment devices discussed in section two (Standards of Assessment) have been developed into a rubric for self-reflection that appear in the appendices; ergo, they are an amalgam of all of the previous sections viewed through my Socratic (videocamera) lens.

Lastly, this chapter will focus on the concept of Self-Evaluation, particularly as it relates to the videotape medium. The breadth and scope of my methodological considerations will be laid as a foundational praxis here.

\section{Teacher Values}

An elusive factor to define, but nonetheless a seminal ingredient in classroom instruction, is teacher values. That is, how do teacher beliefs and interests play out in classroom instruction? In the book Out of our minds: anti-intellectualism and talent development in American schooling, Aimee Howley et al. (1995) speculates on the effectiveness of issues that the national reform agenda now lays on the table, "Teachers who consider the acceptance of established authority to be an integral part of the educational process may feel their own values threatened under such a mandate reform". In other words, teachers don't want to be judged on a value structure that is not of their own design. Yet, the greatest debate in public education today revolves around this idea of focusing on tangible results as witnessed by student mastery of concepts, especially higher 
order thinking constructs. Dobson and Dobson, in Teacher Beliefs- Practice Congruency (1983) likewise argue that, "...values immersed in beliefs and practices are reality", and therefore are discursive of specific educational practices that play out in the classroom every day.

The realization that teachers align their classroom instructional techniques and course material content with their own value structures is the focus of Teachers Goals, Beliefs, and Perceptions of School Culture as Predictors of Instructional Practice (Buck et. al. 1992); this paradigmatic conceptualization has created myriad dichotomies in the face of the national instructional reform; the feminist/multicultural -vs- the traditional conservatives, the outcome-vs- process oriented camps, the postmodernist abstract-vs- modern and concrete cadre, to name just a few.

Bussis and Chittenden, in Open Education: Research and Assessment Strategies (1976) found that when teacher reform agendas emanated from the national or state hierarchy, that were perceived as being inconsistent with personal philosophical value structures, they were either ignored or pressed into service with a great deal of anxiety; changes were deemed to be outside the realm of a true comprehension of student needs (as witnessed by daily interaction/observation).

Bob Butroyd's 1997 piece, "Are the Values of Secondary School Teachers Really in Decline?”, gets to the root of explicating values from content when he delves into the multitudinous facets of subjectively evaluating teacher performance; "Strong values are often divided along political/gender lines...Shared values that can be agreed upon are nothing more than summarily dismissed platitudes". Somewhere in the middle of being politically correct and dogmatic-vs- conservative and enigmatic, Butroyd sensibly asserts, “Teacher values are a personal as well as a public matter”(1997).

James S. Leming's 1995 article, "Reflections on 30 years of Moral Education Research", strengthens my assertion that values must not only be identified as factors that affect instruction, but also as factors to be included as part of the classroom pedagogy. He states, "The current trend is against teaching neutrally about values. Rather the trend is for teaching values in concert with methods of analysis and judgment that yield answers" (Leming, 1995). Thomas Lickona shares similar sentiments about values: “...stress the integration of cognitive development and character development (sometimes called citizenship) through perspective taking, moral reasoning, thoughtful decision-making, and moral self-knowledge" (Educating for Character: How our Schools can Teach respect and Responsibility, 1993). By applying Likona's rubric, integration of classroom pedagogy with beliefs then becomes the sorting device through which all other categories are created and organized.

Perhaps, Weil Veuglers, in his 1995 AERA presentation, Teachers, Value Stimulation and Critical Thinking, describes the progression of integrating values, critical thinking and subject 
matter best in his insightful 415 secondary teacher poll: “... when teachers teach a value -loaded topic they often follow a progression of steps: first not expressing their own values, then stressing differences in values without expressing the values they find important, and finally indicating the values they themselves find important".

R.C. Wylie argued, as early as 1974, that external scales, assessments, and measures seldom really identify a teacher's incipient value structure, in his treatise "The Self-Concept, Revised Edition". Whether using a Likert type rating scale, an exhaustive checklist, or a Q-Sort separating responses into categories, the free-response (self-derived/described) model is the only one that allows the respondent to create their own patterns of response- and thus norms. As long as teachers are allowed to create the delivery method of stated educational objectives for skills and concepts, outside teacher assessment devices will always need to be personally reconciled with actual classroom practices.

\section{Standards of Assessment}

According to the American Federation of Teachers (AFT), every state in our union is in the process (in 1999) of developing or revising their teaching standards. National, subject driven, standards are likewise being published by entities such as the National Council for Teachering of English (NCTE) that reflect the concerns of the field, as well as the National Board for Professional Teaching Standards (NBPTS), that not only develop standards, but creates assessment instruments while providing for professional development opportunities. Moreover, domain driven, pedagogical/methodological/political concerns are being tooled up for implementation by the federal government's US Department of Education (such as Goals 2000) and by testing corporations such as Educational Testing Service (ETS). The aim of this section is to point out the overlap of many of these assessing bodies, the power (or lack thereof) of these referendums, and contrast the aforementioned with the actual classroom assessments that take place in the public schools regularly as administrative concerns.

National teacher unions, such as the AFT or NEA are primarily support oriented. As such, they are great clearinghouses for statistics that quantify teaching; they make available (market) myriad teacher resource materials. They are not, however, either committed to, or capable of censuring teacher behaviors.

The subject/field driven organizations such as the National Council of Teachers of Mathematics (NCTM) or the NTE are also vast clearinghouses primarily dedicated to new methods of teaching course content within that particular field, and occasionally to the logical dissemination of new information to the rank and file teachers in the public schools. These organizations are 
most influential in the writing, developing, and approving of new texts being marketed by publishers. Only at the collegiate level (teacher preparation programs) are these bodies able to affect instruction via their influence over accrediting agencies such as The National Council for the Accreditation of Teacher Education (NCATE).

Accrediting agencies, though powerful in academia, have little formal power in modifying teacher assessment standards in the public schools. NCATE is currently calling for higher academic standards as part of their teacher education graduation requirements. Even though their revised standards have been in effect since 1987, real world changes to teacher education programs have come, most recently, from the Interstate New Teacher Assessment and Support Consortium (INTASC). Principles developed by this governing body now must be evidenced by authentic assessment works in student teacher portfolios at many universities.

With the previously mentioned organizations working towards loftier teacher standards of assessment since the mid-eighties, the federal government made grant monies available with the Goals 2000:

Educate America Act. This program offered federal tax money directly to local school districts in the form of block grants to create rigorous academic standards, to align the curriculum with instruction and teacher education programs, as well as the purchasing of new textbooks if compliance with the new benchmark standards were met.

If the previously mentioned organizational bodies have shaped assessment standards over the past 1520 years, the following have defined teaching standards, and as such, are the focus of my own assessment rubric that will be implemented (to varying degrees) in this study. These are: the National Teaching Examination (NTE-PRAXIS II) created by ETS, the individual state edicts for teacher/student assessment standards, and traditional local school district performance assessments done by building level administrators.

The NTE (now labeled the Praxis Series), in effect since 1993 as a paper and pencil test, directly affects the level of academic preparation needed to pass this national teacher proficiency exam. Both subject matter and pedagogy are tested by this ETS test series. The upcoming Praxis III classroom performance assessment (to be implemented in 2002) will have a direct impact on classroom performance since national certification will hinge on passing this authentic assessment device. Similarly, most states in turn now have raised their standards for entry into the teaching profession either by asking for a higher academic attainments (college grades and NTE scores) or are willing to hold off professional licensure until an outside agency certifies proficiency (such as ETS).

Once in the profession, current standards allow working autonomously in a classroom. Under this model, most novice teachers only have to pass a minimal (read competent/incompetent) 
performance standard for their actual building level administrator, possibly having to show evidence of remediating/amending individual performance deficiencies. These last three assessment standards, along with questioning strategies, will be the basis of my methodology for this self-assessment study.

Since as many as one-fifth of the major teacher education programs of study currently use videotaped lesson segments (of student teacher classroom performance) as the primary method of both student teacher metacognition of their own performance (mini-lessons), as well as the faculty critique assessment of said performance, why not extend this type of analysis to a veteran teacher's performance?

\section{Videotaping as Assessment}

"Videotaping Teachers in Action: A View from the back of the Room" by Martin and Mayerson, looks at the college teaching environment in terms of instructional self-awareness. Feeling that most professors don't accurately judge their own teaching abilities (since research is weighted more heavily in academia), Martin and Mayerson (1992) state, "Formal and informal student evaluations and formal observations by supervisors are rarely used as tools for self-discovery. Instead they must rely on their own intuitive perceptions about what occurs on a regular basis in their classrooms". Getting to the eventual outcome of any student evaluation the authors point out that basically students have a horrible time of extricating the ease/difficulty of a course with an instructors ability. This explains why difficult professional degree programs, such as medical or law, seldom poll students regarding professor efficacy/popularity.

On the other hand, Martin and Mayerson (1992) tacitly state, "Politics and threats to ego also play a part whenever a colleague or supervisor enters your class". The bottom line, these authors say, is, "With current videotape technology, one can effectively and easily see oneself from the student's point of view" (Martin and Mayerson, 1992).

Doug Smith similarly delineates the ego conundrum, when videotaping is introduced, in his article, “Peer Coaches; Problems with Videotape Recording for Teacher Observation". Smith's 1996 query into this medium epitomizes the stand pat dismissals of videotaping teacher performances as being twofold: first, teachers fear administrators' unethical usage of videotaped classroom lessons (primarily), -and- teachers fear their own perceived inadequacies of instructional acumen (secondarily). Unfamiliarity with the video equipment was given superficially as a rouge for these two previous concerns, Smith intimated.

In his summary, Smith offered five areas to be addressed, in an effort to change negative initial misgivings about videotaping as a teacher self-assessment tool: 1 . Ethical issues of control must 
be addressed. 2. An awareness of possible self-image conflict must occur with properly trained instructors. 3. Training to overcome technical problems must be addressed up front. 4. Coaching through human problems and fears must be provided, and 5. Experienced staff, familiar with all aspects and problems inherent in this assessment medium, need to be cultivated and put in place beforehand.

Though no research model is available to compare in the regular education classrooms of public schools, in "Self-Evaluation of Instruction: A protocol for Functional Assessment of Teaching Behavior" by Gunter and Reed, we find teacher videotaping used as a tool for recognizing and modifying teacher behaviors that lead to unwanted student behaviors in special education. Focusing primarily on classrooms for children with behavioral disorders, and the lack of strategies designed to deal with teacher self-improvement, Gunter and Reed state that, “...teachers need to learn to ask questions about their teaching practices" (1993).

Once a lesson has been videotaped, Gunter and Reed suggest watching the video once for each of the seven areas they described to be coded/recorded. After presenting the mathematical analysis for assessing the lesson's effectiveness, they speculate that an $80 \%$ compliance rate of teacher commands given translates into effective instruction wherein the course content (not- off task behavior), is the primary focus of the time spent in the classroom.

For most new topics, they assert, negative and positive reinforcement will need to be adjusted in the form of questioning difficulty; simply stated, when disruptive behaviors are positively enforced, the lesson is derailed and/or incomplete, but when students are experiencing success by positive feedback given from the instructor, the lesson maintains its integrity of focus-and it becomes much more likely than the students will reach concept attainment.

Gunter and Reed conclude that because the teachers themselves are using personally formatted (video) assessment of their own behaviors towards their own needs (and rewards) they are more responsive to positive instructional change. An additional boon to using this tool is that teachers can create tapes to be evaluated by their administrators using lessons of their own choosing. Administrators, in turn, can choose the most exemplary models to workshop during in-service proceedings. Ultimately, Gunter and Reed reflect my sentiments when they recommend, "The protocol presented provides a simple and inclusive format to guide the consistency of self-observation measures with the bonus of providing a functional assessment of child behavior" (1993).

Glenda Clyde likewise made a strong case for incorporating videotaping into daily assessment (for pre-service teachers) when she addressed the 1994 Annual Meeting of the Speech Communication Association; entitled Assessment is Epistemic and Heuristic: The Role of Videotape in the 
Public Speaking Course- basically postulates, “...the process of formulating assessment methods is also a process of researching the learning process".

While all of this research provides the requisite positive backdrop to comprehend videotaping in different environments, they are also illustrative of the same external pressures to change in a predetermined fashion. Conversely, were this technology to be accepted on a widespread basis, as a positively viewed tool for self-improvement, and each individual teacher was allowed to identify his/her own teaching style, outlining the major skill areas to be mastered within their chosen teaching style/ technique, then ethical administrative input could be garnered towards improvement.

\section{Questioning Strategies}

All of the national, state and local assessment evaluation rubric uses Benjamin Bloom's terminology as the idiomatic currency of this sub-genre of education. For this reason, I do not feel it would be a fruitful educational pursuit to significantly deviate from this literature and practice. The remainder of this section of chapter two ergo, builds on, and supports Bloom's venerable taxonomic device, specifically higher order thinking skills such as the analysis and synthesis levels.

Socratic Questioning, the method of instruction predominantly used in law schools in the united states is designed in "... exact opposition to the sophistic reduction of values to arbitrary artifacts established by convention" (Brumbaugh, p,105, 1982). In reviewing Alfred North Whitehead's venerable educational constructs, Brumbaugh goes on to delineate Socratic precepts, “....wisdom comes in part from removing conceit and false opinion...(p,106). Essentially, a shared inquiry mode of operation, the Socratic method seeks to dismiss the facile and superficial attempts at explanation in lieu of consensus concerning agreed upon truths. Brumbaugh extols, Platonists (followers of Plato and Socrates' teachings) “... see no virtue in pretending that philosophical arguments can exist in a vacuum” (p, 102). Dennis gray's 1988 discourse, Socratic Seminars: Basic Education and Reformation perhaps best defines the tenets of the modern public school application as, it, "(1) emphasizes rigorous thinking, not mastery of facts; (2) stresses that a leader's questions should promote serious conversation, not evoke correct answers; and (3) engages students in a collaborative quest for information"

Cathleen Galas' inquiry based (1999) method of engaging critical thinking skills in students is proposed as, "The Never Ending Story? Questioning Strategies for the Information Age". In this model, Galas describes the classroom situation as one where, "The students categorize and explore the questions; explain and hypothesize about the experience; develop a rubric for evaluation; compare to other class discussions; define the intended users; give evidence supporting their research design; articulate their commitment to the question, research plan, and finally visualize and evaluate their own and others' projects" (Galas, 1999). With the focus of this classroom model on open- ended questions and locating resource materials (such as the internet), these strategies may only be appropriate for 
layering depth into the stated course objectives, at, or near, the end of a unit or course that emphasizes process over content knowledge (breadth). Nonetheless Galas' model will be applied to this study when/where time constraints (of material mandated for coverage) permits.

"The Effects of Questions on Visualized Instruction" (1971) by Dwyer involving the most time efficient way of presenting material that must be quickly/accurately memorized and correctly charted on a performance based (visual labeling) assessment. This research uses the 'time is valuable' axiom to define the quandary most public school educators face (yet many of our collegiate counterparts ignore); does internalized student questioning strategy schema greatly aid in the recall of essential (as defined by state/local objectives) information that students will be tested on? Dwyer says no- at least for straight memory recall.

Though a plethora of related studies were drawn in to define the pupil performance -vs- time spent instructing issue, Wager and Mory (1992), in their article, Feedback, Questions and Information Processing-Putting it all Together, came to this conclusion: "Fixing the time frame to restrict the amount of interaction with the questions, or allowing students the freedom of setting their own time frame to interact with questions, showed no differences in achievement". On the other hand, Denner and Rickerts in A Developmental Comparison of the Effects of Provided and Generated Questions on Text Recall (1987) found that, "Questions helped focus students' attention on the important aspects of the message and helped them to use study time more effectively". Again, research can't get away from the issue of trying to help students internalize a study strategy that is personally meaningful, without spending valuable (sometimes highly restricted) class time helping less receptive/motivated students find the connections and categories, prior to disseminating the information (to be later recalled on standardized performance tests).

The next few empirical studies build on the latest research on the brain's ability to store new information (and the ability to recall said information). These authors all based their conceptualizations on the idea that schema (a pre-existing category) is available in all human brains, in which every individual can construct (Vygotsky's constructivism) relevant connections to/with new facts. In literature there are multiple levels of comprehension available- based on the ability a student possesses to get away from the factual recall and into the realm of reconciling new knowledge with past paradigms. Unfortunately, with regard to lower -vs- higher ability students, Rosenshine's 1976 article Recent Research on Teaching Behaviors and Student Achievement found that lower ability students do better with textually explicit questions that don't stray far from the literal concrete, whereas higher ability students function best in an atmosphere of (Socratic) probing and re-directed questions; real world teaching affirms this truth. Martin's 1979 research, The Effect of Teacher Higher Order Questions on Student Processes and Product Variables in a single Classroom Study, on student attitudes towards high/low level questioning also bears this dichotomy out, “.... negative correlation (exists) between the use of high 
order questions and the (lower functioning) student attitude toward the teacher".

Similarly, Garner and Alexander identified a wide gulf between the ability of students and the benefit of pre -vs- post reading questions to be answered in Strategic Processing of Text: An invitation of the Effects on Adults' Question- Answering Performance (1982). Basically, Garner and Alexander found that higher functioning students who could activate schema (create their own question categories) did better with pre-reading (organizing) strategies. Concomitantly, lower functioning students were overly stressed with trying to activate and create a schematic that was not of their own origin, and they subsequently spent all of their time referring back to the advanced organizer (i.e. post- selection questions were answered from short-term memory rather than an internalized schema connection).

The issue of actively engaging students in the learning process is functionally expressed by Bonwell and Eison in their (1991) article, "Active Learning: Creating Excitement in the Classroom"; “ To be involved, students must engage in such higher-order thinking tasks as analysis, synthesis, and evaluation". The authors, citing Penner (1984) suggest such activities as class time spent on note consolidation (three times per lecture) and simple listening activities (without taking notes) wherein the main ideas and details of the lecture are to be recalled later in a group discussion. These activities, they stress are inestimable in value. Though nothing profound was gleaned from this text, the end note- asking faculty members to self-reflect and explore alternative approaches to instruction, offers sage, time tested advice for improving instruction by targeting higher levels of Bloom's Taxonomy.

According to Cardellichio and Field's 1997 article, "Seven Strategies that Encourage Neural Branching", which specifically delineates questioning strategies designed to overcome the brain's natural tendency to limit information, “...neural branching, or extending the neural networks...” is accomplished by asking students to think hypothetically. The seven specific strategies that the authors advocate are:

1. The use of reversal (putting yourself in the negative situation to resolve the problem)

2. The creation of the student's own symbol system to classify information

3. The use of personal analogies created by students to constructively connect information

4. The completion of unsolved/unresolved problems

5. The web analysis to physically chart the relationship of parts to the whole

6. The creation of point of view charts that explicate factors leading up to beliefs

7. The individual creation of personal hypotheses to explain disparate anomalies

The authors go on to lambaste questioning strategies that never reach these higher levels of the taxonomy, even though essential comprehension of a given concept may have been met. The caveat to not using critical thinking is that, according to Cardellichio and Feild, neural pruning occurs in the brain since not enough data was assimilated to challenge lower order thinking misconceptions (i.e. students continue believing incomplete and inaccurate ideas- or- they simply memorize the new answers without fully 
comprehending their extended implications).

\section{$\underline{\text { Self-Evaluation }}$}

This self-evaluation discourse (conceptualized for this study), in addition to meeting the criteria specified in the "Standards of Assessment" section of this chapter, also draws its strength from the growing body of teacher self-empowerment literature that is emergent in defining deficit to competency based teacher self-improvement. This approach stresses professional growth through metacognition of ability and the commensurate self-reliance needed to improve one's teaching delivery.

In the document, "Changing Conceptions of Teaching Influence: The Future of Staff Development", Smylie and Conyers (1991) suggest this advice to perspective administrators: "Providers of inservice programs need to consider, however, that teachers have little time during the school day to pause, reflect on practice, or conduct research. Ways need to be found to provide practicing teachers with such time". Smylie and Conyers go on to say, “...experiences are perceived as professional resources...This paradigm shift addresses one of the most pervasive conditions of the classroomteacher isolation, or the inability to learn and communicate with colleagues in the place where it counts the most- the school" (1991). The decentralization movement in public education, these authors report, has given impetus to, “...professional development, inservice in particular, increasingly being conducted in, and by, school systems rather than in colleges and universities" (Smylie and Conyers, 1991), where greater personal meaning can be discussed in an open forum.

In " Self-Evaluation of Instruction: A Protocol for Functional Assessment of Teaching Behavior"(1996), by Gunter and Reed (previously discussed in the "Videotaping as Assessment" section of this chapter) we find a useful guide for self-assessment, particularly of the video medium: First, our authors suggest that the initial recordings be used simply as a baseline for technical adjustments having to do with camera angles and sound quality. The bonus here is that this time also acts as a buffer to desensitize students to the presence of the equipment in their environment.

Next, Gunter and Reed recommend isolating periods of academic instruction, based on the function of that time allotment. Logically, instructional time breaks down into administrative concerns such as the taking of role and anything else that has nothing to do with didactic concerns. Once these concerns are addressed, new concepts introduced, skills to be mastered, individualized instruction (seat work), and discussion of the text, in addition to concept attainment (of the unit) can all be broken down into meaningful instructional segments according to their particular function.

Finally, these authors (Gunter and Reed) advocate coding specific areas of concern (for this study, I have created a list of questions to be reflected upon). They note that while observing these areas of particular concern, careful attention should be paid to the time immediately pre/proceeding these endeavors. After the coding has been defined, Gunter and Reed believe that grouping like items together 
for schematic/topical purposes will yield the best (read, least time wasted). These categories, in turn, can be viewed as separate areas of concern to focus on in each sitting (tape review). A further breakdown, in this study, might be to first mark/note the specific question (and answer) that fits the criteria, and then follow up with a second viewing with the road markers in place. For more specifically coded research, a final quantification of on/off task ratio of student or teacher behaviors may be developed as an interfacing device with quantitative research; for the purposes of this study, the patterns that emerge from the qualitative research will be discussed as part of my conclusions section, once the study is brought to fruition.

With the exception of not being a pre-service teacher, trying to internalize a rubric for self-assessment, but rather a professional wishing to improve/fine tune his own performance, this study roughly follows the research model utilized by Rita Jensen et. al. as described in their 1994 presentation to the ATE. In, Fear of the Known: Using Audio-Video Technology as a Tool for Reflection in Teacher Education, Jensen set up a study and control group of student teachers and successfully showed that the study group, “... demonstrated they were better at assessing their interpersonal skills and instructional management competencies than at assessing their use of questioning strategies". 


\section{Chapter Three: Methodology}

\section{Theoretical Framework}

The theoretical foundation of this study rests upon the values of the teacher instructing; these incipient values either allow modification to instruction (or block improvement) that take into consideration the philosophical outlook and teaching style of the instructor. The teacher, given educational objectives to perform in the classroom, based on national, state and local assessments- in turn, either performs up to expectations or modifies objectives to meet their own value laden paradigm of operation according to Blumberg and Jonas' (1987) article Permitting Access: The Teacher's Control Over Supervision.

Teachers themselves are the best judge of their own instructional effectiveness (if they are made aware of their own beliefs and have a specific outcome to improve upon in mind)- not outside administrators, that may have divergent ideas about how to meet the same objectives. The University of Michigan's Institute for Social Research identifies three distinct models for reconciling "Individual Goals and Organizational Objectives" in Barrett's (1970) synopsis of the study of the same name. They are: The "Exchange Model" that operates on a reward system for teachers doing their jobs according to a supervisor's view. The "Socialization Model" wherein a teacher is expected to accept and internalize the organizations objectives in order to fit into the existing social strata. The most effective model identified by the study however was labeled the "Accommodation Model" because it takes the teacher's philosophy and teaching style into account first and then amalgamates those preferences with the organization's standards and objectives.

Videotaping pressed into service in lieu of an administrators outside (of a teacher's philosophical realm of) assessment then makes the most empirical sense. In the privacy of one's own home, after the instructional day has ended, a teacher can, according to their own rubric, assess their own performance. Arther Blumberg (1980) defines the following as integral to teacher/administrator collaboration: a) both teacher and administrator should reach agreement on objectives that are consistent with both teacher and district goals for instruction, then, $b$ ) decide what data is necessary for a teacher performance evaluation.

Once a specific area of instruction has been targeted, such as questioning strategies, a conscientious teacher, motivated to personally improve their own performance can begin to collect information regarding the changes they wish to bring about. From literature on teacher performance, categories can be created for specific analysis (as described in the self-analysis section). After improvements have been targeted and specifics for improvement have been discussed with a building administrator, these tapes can be evaluated based on a shared criteria checklist that meets both the district standards as well as the particular areas that the teacher values. Ultimately, if the teacher and administrator agree upon the 
performance criteria to be evaluated then, tapes can be workshopped as part of a faculty development process. The findings section of this completed study, denoting exact quotational references and specific phrases may aid greatly in the workshopping phase.

\section{Qualitative Research}

Since qualitative research, to a great extent, rests upon the extant sensibilities of the researcher, to not only have reasonable constructs comparable to other similar work in the given field, throughout the tenure of this project, I will continue to discuss, review and consult outside sources for methodological input. However, the actual reflection upon my classroom teaching practices will be limited to my own arrangement of information and perspectives discussed in the proceeding section. Though I do not have statistical weighting to convince novice educators of the validity of this action-research project, the seminal points made and means of explanation made are likely to ring true to the professional educator currently dealing with the issue of personal assessment as it relates to personally defined teaching effectiveness.

In this connection, it is useful to acknowledge that all research is interpretative, and that all interpretations are subjective in the sense that they are produced by people who are culturally distinctive, rooted in a particular time and place, and inevitably imbued with a socially acquired frame of reference. The frame of reference, moreover, is both illuminating and distorting. Without it, however, interpretation is impossible, because there's nothing to use in the interpretative process - there's nothing to think with.

\section{Paradigmatic Constructs}

Student teacher preparation programs routinely use videotaping as a method of improving pre-service instructional techniques, either in a university classroom, or in actual student teaching placements; I will likewise use this technology to evaluate my teaching techniques weekly (for at least 12 consecutive weeks).

Furthermore, administrators sporadically observe both novice and veteran teacher alike (even less frequently in the case of the latter), in order to insure instructional proficiency. I will focus on the rubric of not only my building administrator, but also the assessment criteria my Pathwise mentor in my school, as well as the criteria set forth in the Praxis III (ETS) NTE standards (to be evaluated by an outside, of the building/district assessor).

\section{Triangulation of Assessment}

Teachers seldom receive any metacognitive feedback regarding specified areas they want to improve, other than briefly reflecting on their own lesson plans. Therefore I will ask the three aforementioned outside assessors to specifically evaluate, and discuss 'questioning' improvement strategies with me. 


\section{Data Collection}

Additionally, it is incumbent upon teachers to continually improve instruction. With this weekly videotaping self-assessment tool (a tangible, accurate, all inclusive recording- not based on memory or notes) it will be easier to focus on and track ongoing performance improvements; which I will keep as a running commentary ( as a summary at the end of each lesson) based on the "Master List of Criteria to be Reflected Upon".

Given the aforementioned considerations, it follows that:

1. Videotaping as a method of self-improvement can be implemented in public school classrooms as a means of supplying daily/weekly qualitative feedback.

2. Likewise, much of the standard teacher assessment rubric used by administrators is seldom addressed on a daily basis, yet is expected to be part of the teaching repertoire. For instance, unless an administrator was coming to observe at the beginning of a unit, he/she probably would not get a clear, student oriented, overview, nor would a casual observer know the effectiveness and totality of any alternative teaching methods, such as cooperative learning (followed through to fruition). In short, much of the daily observable teaching behaviors are only a part of a larger weekly, bi-monthly, or monthly unit plan and truly can not be holistically scored/evaluated without that context.

3. With specifically identified instructional goals set forth by the teacher, multiple domains (the focus of Praxis III) of learning can be focused/improved upon over longer periods of time using daily/weekly/monthly video feedback.

4. Ultimately, teacher research indicates that real teacher improvement only comes from internally valued criteria that has been chosen for reflection upon \& remediation thereof.

Therefore, my methodology follows my own paradigmatic model of construction. Since I am selfaware of my philosophical and methodological perspectives, and wish to improve my instruction though this lens, I have created a self-assessment checklist to reflect upon during the tenure of my videotaping project.

This model is an amalgamation representing different foci and interconnected strands of the educational model. The national Praxis III and district Pathwise rubric are similar models that are derived from sound teacher preparation practices (written and supported by educators wishing to quash both the political and pedagogical pundits of our current licensing and certification system); these two, nearly synonymous models are broken down into four domains that the district (and therefore, building) level criteria are layered upon. For this study, I have culled specific criteria from the existing assessment 
devices that my teaching performance will be evaluated on which particularly focus on questioning strategies- since this is the area of instruction I most wish to improve.

The building level teacher appraisal assessment likewise wishes to thwart criticism, but these criteria are geared more towards minimal levels of competency that can either be defended in court or dealt with through district policy guides. Either way, the intent here is to prevent educational lawsuits from bankrupting the district, while trying not to create an adversarial polarity between administrators and their representative teacher unions. Nonetheless, some of these criteria have likewise been inculcated into my reflection criteria.

The last set of criteria to be inserted into the multi-faceted nature of this coverall self-assessment reflection guide, is coming from the parents/prospective employers/ tangible- skills-mastered camp. The state of Ohio requires that reading and writing proficiencies be mastered by high school seniors. As part of my course guide (which will be reflected on separately in my daily lesson plan book) for American Literature I, these skills must be integrally included as part of my regular repertoire of fundamental skills taught that students must show proof of mastery.

\section{Data Analysis}

In order to triangulate my self-assessment skills, I will be: a) Reconciling my scripted lesson plan questions with b) my journal based on my own perceptions of what actually happens in the classroom, after viewing the weekly tapes and c) asking the three outside assessors to specifically focus on my questioning strategies using their own evaluation rubric-in order to gain outside perspectives that validate my own metacognition (five cumulative scheduled outside visits). *The actual "Self-Assessment Reflection Guide appears as APPENDIX E.

With the fundamental empirical backdrop to this project's constructs in place, I will focus on the specific implementation of this project:

From Jan. 17th, 2000 in my American Literature I (a junior/senior level) course that met daily from 8:25-9:15 AM I videotaped myself twice a week -in an effort to improve my own instructional abilities. The entire project will took place within the confides of a High School in Ohio and ended concomitantly with the course and school year on May 28, 2000.

After this raw data had been gathered and reflected upon, I immediately began categorizing and grouping the annotated data into segments of meaningful information in order to address my tacitly stated research questions.

\section{Course Demographics}

This American Literature I (American authors up to circa 1860) course is offered by the High School to mostly junior (some seniors) level students. It is a one semester English elective course designed to be 
taken in conjunction with American Literature II to round out the American/English Literature requirements. Though the course enrollment has theoretically been set since the inception of the school year (early August, 1999), experience with other required electives tells me that over ten students will be initially enrolled and fewer than five will comprise the class roster after the liberal two week class change period has ended.

The students themselves are coming from a more and more diverse family environment since Pataskala, Ohio (located 12 miles due East of Columbus) is slowly being engulfed by the suburban sprawl of the ever burgeoning growth of the greater Columbus area. However, a small majority of these 15-18 year olds will still be operating from a rural farming community upbringing (paradigm) that has a decidedly conservative value structure; whereas the remainder of the student population will either be comprised of professional commuter families, who are decidedly more liberal, (wishing to avoid the crime and congestion of Columbus) or the urban poor (also liberal in thought, but for other reasons altogether) that have migrated for many of the same reasons (including taking discipline problem children out of the greater Columbus schools); these are the same sort and type of real world students that most any suburban public school system in the United States, regardless of regional idiosyncrasies, would service.

\section{Participants}

Though the primary participant in this study is myself (a 35 year old doctoral student in Curriculum and Instruction), the life experiences and current academic ability of the five, 16-18 year old, students does have a bearing on the line and level of questioning pursued daily-in terms of comprehension of abstract concepts. Plus, on a the macro level they are effected in terms of the student learning curve that occurs when higher order thinking constructs become internalized and anticipated as both part of the written and spoken language. In this section, I am speculating on student background in order to anticipate each student's paradigmatic point of view (for appropriate analogies during this project).

Student "A" is a 16 year old junior student used to making A's and B's. She spends much of her time with friends, outside of school, that also have poor home lives. She does not participate in any extracurricular activities, but she is an avid reader of poetry (which explains her willingness to tackle difficult texts) and does plan on attending a four-year university.

Student "B", a 17 year old junior is likewise taking the course to fulfill her English requirement in the prescribed sequence. At 6'4", she is an outstanding athlete in volleyball; her work ethic is the product of her home life (father a former NBA player) and her own sense of accomplishment. Though not always able to handle abstract questioning during the initial explication of difficult literary works, her affable demeanor and tenacity to succeed academically show in her grades (which she knows are all- 
important in her scholarship quest for collegiate athletics).

Student " $\mathrm{C}$ " is an 18 year old senior who is active in her church youth group and is the assistant manager of a local video rental store. An interesting anomaly is the fact that she misses a third of her classes, yet still managed to graduate on time with honors. Moral issues embraced by the authors in the classical canon often draw this student into the issues and concepts thematically discussed. Though able to operate at a slightly higher level of abstract reasoning, than the other two girls, her excellent study skills and ability to memorize seminal ideas explain her academic success.

Student "D", an 18 year old senior, takes on the persona of the "grunge" group wearing the clothes, piercings and ever-changing hair colors, but is a member of the school's "Quiz-Bowl" team and is genuinely interested in knowledge. He takes pride in his ability to relate trivial information about historical figures to other students. While both of his parents hold degrees, his father's suicide and mother's alcoholism force this youth into peer relationships that do not foster traditional values. Nonetheless, this student is able to work with abstract concepts with very little framing or grounding in a contemporary issue.

Student "E", on the other hand, a product of two professional parents, thrives on the contemporary analogy to (classical canon) traditional literary themes. An 18 year old senior who plans on majoring in English Literature and going on to law school, this student is very willing to judge and analyze literature on an abstract level, but lacks the articulatory ability of student "D".

\section{Course Pedagogy}

The course itself will be taught Socratically, focusing on the issues that many of the founding (read, American Revolutionary Leaders) fathers faced, along with the historical background and origins of the genres later developed and solidified by great American fictional authors. The focus of this course, while attempting to meet all of the objectives listed in the course guide, will be to traditionally illuminate the intent of the great authors in the canon, since a) I feel these authors are seminal in comprehending American thought in literature/government and b) the ethnically diverse population, that might oppose traditional authors, in this school system (Southwest Licking Local Schools) is less than 3\%. For additional information about the breadth and scope of the course.

\section{Lesson Planning}

Lesson plans, questioning strategies and consensus on issues reached, were limited by available space (a sample page is included as APPENDIX F), and specific, pre-planned, minute by minute, scripted out questions were not prepared prior to daily lesson segments (class periods) being taught. However, as a general daily maxim, review questions usually began with analysis (level four) or evaluation (level six) 
and were sustained, or the level of abstraction was raised, until a student was either unable to comprehend the concept, didn't understand the question as it was originally posed, or was simply unable to articulate a salient response.

\section{Daily Itinerary}

The following represents a typical progression of daily events:

1. Daily journal prompts are written on the board, while-

2. Roll is taken, then...

3. The journal prompt is discussed.

4. A brief review of yesterday's concepts and skills are covered.

5. Homework is checked.

6. Homework is related to prior lesson content and today's activities.

7. A student is asked to read from the text.

8. Students then paraphrase passages pertaining to thematic unit.

9. Students are asked to generate possible essay thesis statements.

10. Students are asked to review key supporting ideas from the text.

11. Another student reads.

12. Additional essay topics are discussed.

13.Upon completion, the post-text analytical questions are discussed.

14. Key concepts and unfamiliar vocabulary are reiterated.

15.The progression of the current writing process is defined.

16. Previously graded papers are handed back.

17.Individual essays are workshopped at my desk.

18.I Recap tomorrow's assignment(s).

19. Students are dismissed at bell.

Though there were a few quizzes to confirm basic comprehension of concepts as well as homework (usually text questions hitting the analysis level), the primary mode of formative assessment was the inclass Socratic discussion and the essay draft -whereas the summative assessment was usually in the form of a letter grade assigned on the essay final drafts (which had been individually workshopped in class) plus test grades. 


\section{Chapter Four: Interpreting the Taxonomic Levels}

\section{Introduction}

In the following section, each lesson segment's (approximately 40-45 minute class periods) questions are labeled according to Bloom's Taxonomy. As is often the case in the classroom, specific contextual references are needed. Likewise, the contextual frame of reference is also here included to lend situational clarity. Furthermore, since this was an exceptionally small class (only five students), I have also included designations (letters A through E) indicating to whom each question was addressed.

By labeling each question at its corresponding level of comprehension and cross-referencing the number of correct student responses falling under levels 4,5, and 6 (analysis, synthesis, and evaluation), the researcher wishing to target higher order thinking skills should be able to learn how affective his/her questioning/framing strategies were during any given class period, unit, or even semester long analysis.

\section{Inter-rater Reliability}

Though I, the researcher and subject of the study, was the primary stenographer, interpreter, and rater of the taxonomic levels of questions that appear in the proceeding section, care was taken to norm the interpretation of the data; Cynthia Butcher, a 25 year old English/Math/Education undergraduate familiar with Bloom's Taxonomy also labeled each question posed from the first three lesson segments. The reliable outcome of 232 questions classified was $85 \%$. This was accomplished by simply reconciling the 197 questions that both she and I labeled as falling in the same taxonomic level Primarily semantics and syntactical interpretations were ferreted out as nebulous differences in interpretation that that would occur during a norming session wherein there is a question of strict semantical definitions and syntactical meanings.

\section{Taping Criterion}

Three primary considerations were taken into account in deciding when and what lesson would be taped, since the beginning of the project was delayed due to IRB considerations. The priori consideration was, were all of the students present on the planned day of taping. Given that the class size was exceptionally small, the researcher felt that the audience dynamic could change by losing members. The next factor considered was the methodological nature of the lessons; for instance, were 'essay development' to be the focus of the lesson, individually workshopping student papers is geared more toward teacher directed (student) skill remediation through suggestion than Socratic 
questioning- and would therefore yield data much harder to quantify. Lastly, the read throughs (of literary selections form the text), though some were taped, obviously do not yield the volume or variety of questions that unit over/re-views do. Therefore, when possible, unit and semester long themes were taken into consideration as part of the subject matter to be explicated vis a vis videotaping.

\section{Labeling the Taxonomic Level}

Comprehension, though only one step above memory recall, also can be seen as the end result of Socratic questioning - which seeks consensus (i.e. commonly agreed upon interpretations). Therefore, before going on to greater levels of syntactical student awareness, some modicum of authorial intent must be agreed upon by the group by using referential (within text) and historical (common historical knowledge of the era) context.

Likewise, if students are merely repeating what the teacher or another pupil has just said - or are simply reading from their notes - this will be labeled at the knowledge level.

When differentiating between application and comprehension levels of questioning, application has been used preferentially over comprehension in cases where the students are still struggling with translating and interpreting the query or having difficulty solving and demonstrating internalization of the concept being embraced.

Comprehension, on the other hand, is being labeled in cases where one or two students have thoroughly defined the concept yet comprehension (internalization) has not been checked with the remaining students (i.e. if students are only layering examples onto an already defined list - this is only comprehension not application). The more critical analysis moniker will be placed at any point where some type of classification or comparison is implicitly/explicitly evident.

Synthesis, or the creating anew by internalizing abstract criterion, likewise can present a problem when coveted as an end result in a literature survey course - since the stated overarching objectives seek student comprehension of concepts, themes and ideas as the end result of literary analysis while concomitantly seeking the application of epistolary skills in composing an articulately phrased lucid essay. 


\title{
Chapter Five: Question Transcription
}

\author{
$\underline{\text { Introduction }}$
}

This chapter transcribes all of the twelve videotaped lesson segments labeling the taxonomic level of each question to the left, the question verbatim, the frame of reference, as well as indicating which student was being addressed- by letter designation (all in 14 pt. bold type), followed by a running reflective commentary below each question in italics (12 pt. type). In the case of two questions appearing together, without a space in-between, I have simply re-directed (rephrased) the question to the same student. Each lesson is also immediately proceeded by a lesson summary indicating the most noteworthy events that transpired, what was gleaned from the lesson, and the direction I am headed in for the subsequent session.

Taxonomic Questions Transcribed Student Addressed Level Intended

Lesson One: Paraphrasing the Declaration

Analysis $\quad \begin{aligned} & \text { What are the key ideas there (if you had to come up } \\ & \text { with a very short list of three key things said)? } \\ & \text { (Student B) } \\ & \text { Since the prior three weeks of introductory material, and the } \\ & \text { first reading of the Declaration, had previewed several } \\ & \text { categories for an analytical breakdown of the categories } \\ & \text { Jefferson was delineating, I was hoping the student could } \\ & \text { transpose and overlay those themes onto the actual text (i.e. } \\ & \text { inductively place particular phrases in pre-existing categories). } \\ & \text { She had, in preliminary discussions given modern examples that } \\ & \text { fit each of Jefferson's particular referents. }\end{aligned}$ 
Frame: "Which is not the kind of government that represents the people as much as a government that controls the people."

Student "B" has accurately described some of George's transgressions against the colonials, after identifying two of Jefferson's implicit categories, without actually describing a tyrannical oligarchy as the type of government.

Comprehension

2. ....and what would another category (do you think) be? (S.B)

Frame: "He (King George) was suppose to be protecting us..."

Application

3. ...but in reality he was doing what? (S.B)

The student, after waiting two full minutes for a reply, does not follow the abstraction from example to appropriate categorical placement (i.e. she cannot label George's behavior).

Frame: "He was bending us to his will."

Knowledge

4. O.K. who has the next section?

Frame: "I didn't notice a whole lot of changes there (paraphrased)..."

Knowing that this student comprehends the majority of the vocabulary used in the original text, the challenge here is to get this student to break down the complex issues into root issues that have been layered upon (through paraphrasing).

Analysis $\quad 5$. ...but if you had to break that down into the things that Jefferson was writing about as a specific complaint against George, what would you say they are? (Student D) 
Again the student tries to comment upon the category rather than vivisecting it into meaningful smaller terse specifics.

Application $\quad 6$. Now, why is hiring these mercenaries a problem? (S.D)

The student is starting to see the cause and effect nature of mercenaries as agents taking away basic freedoms.

Application

7. (Absolutely) Is there any other reason to have foreign soldiers on our soil? (S.D)

Frame: "None, whatsoever unless they were going to be fighting a war against us; that's one."

Frame: "O.K., O.K., O.K., after student breaks down causes."

Knowledge $\quad 8$. Who has the next section?

Analysis

9. If we had to narrow that down into a couple of key ideas, what would we say out of that paragraph? (Student A)

This student, being somewhat introverted, has trouble creating categories for analytical breakdown without receiving incremental "Zone of Proximal Development" feedback (her first essay illustrated this need for continuing reinforcement).

Comprehension 10. What does he (Jefferson) start out with? (S.A)

Knowledge 11. What is the key verb that he starts out with, there in the second sentence? (S.A)

Frame: “ 'Warned' right? (S.A nods). Jefferson is saying that Britain has been warned over, over, and over again - and they (the British) have done nothing, 
nothing to try to get around, to circumvent, this problem of going to war with the colonists; they have been warned over and over again."

Application

Application

Comprehension

Analysis
12. What would be another key idea? (S.A) After demonstrating the skill of looking for the key verbs, I expected the student to apply my model to the next segment of the selection she was assigned.

13. What were "the circumstances" (when the Europeans came over? (S.A)

Frame: "For the most part these people (early settlers) had to get their rights of passage from the King himself. The King told them that they could come over here and run this country anyway they saw fit. ...that is why Jefferson's family paid, whatever they paid, for their property and plantation; because King George was saying: This is a frontier, a chance for you to be your own boss. That was the situation that George set up, they were going to have. Especially the Aristocrats thought that they had a deal..." After repeated attempts to nudge the student into paraphrasing, the problem, replete with situational context, it was simply laid out.

14. ...but did it work out that way? (S.A)

Frame: "There wasn't much we could do about it (George's taxes) because we were held hostage by the British soldiers."

15. So, what are the key ideas here? (Student E) 
This student, from previous in-class discussions, showed an ability to recognize, label, and break down seminal conceptsand predict outcomes based on facts and the tone of charged language.

Application

16. What is he (Jefferson) saying, as he's wrapping up this document? (S.E)

Comprehension

17. What part of the document is it, according to our introduction? (S.E)

Knowledge

18. Where is this (section) in the layout of it? (S.E) Although the student is able to give an extended dissertation on the topic of the section he has been asked to explicate, I am shifting his focus to the role it plays within the entirety of the text.

Frame: "This is formal, we the people have agreed to it."

Application Analysis

Application
19. This is a what? (S.E)

20. What are the key ideas here? (S.E)

Frame: "Good point, yes exactly we're only going to answer to God, we're not going to answer to the King."

Frame: "Yes, because we know we are good people and we don't need your permission."

21. What's this about "contract alliances" and "establishing commerce"? (S.E)

At this point, the student has internalized the schemata (categories) and is able to draw macro inferences from the implications of the language used by Jefferson. 
Application

Comprehension

Analysis

Application

Knowledge

Comprehension

Knowledge
22. "...and contract alliances", how does that go along with it? (S.E)

Frame: "You got it, he (Jefferson) says, from here on out, we're going to build our own alliances. If we want to deal directly with France, we're going to deal directly... we're going to have our own (independent) business and..."

23. We're not going to give you any ? (S.E) At this juncture, the student is clearly following the author's intent; thereby allowing the Socratic discussion format to take on a new dynamic that questions underlying assumptions which clarify theories and perspectives that undergird the text.

24. Any other key ideas there? (S.E)

Frame: "Yeah, exactly we're pledging to ourselves, because we believe in divine providence..."

25. ...by whom? (S.E)

Frame: "because we believe in divine providence..."

26. Remember, we talked about this yesterday? (S.E)

27. ...by who's authority? (S.E)

Frame: "He (Jefferson) says that as long as we are all together on this, and we all believe in God..."

28. How much time do we have left? (All students)

Frame: "Let's start a brief discussion here. On page 158, let's try to work through these questions." 
Evaluation

Knowledge

Knowledge

Knowledge

Evaluation

Comprehension

Application

Analysis

Application
29. What's your reaction to this document? (S.B) At this point, realizing the student's articulatory reticence, I am satisfied just to get her to speak at length though prodding her into increasingly more sophisticated logical disseminations of detailed descriptions.

30. What was Jefferson's occupation? (S.A)

31. What was he trained to do? (Student D)

32. What did he make his living at? (S.E)

33. Do you think that he (Jefferson) did a good job of preparing this case? (S.E)

This student's desire to attend law school is being focused on as a method of motivation in order to get the student to explicate the text in terms of the laws that are being questioned.

34. Does he have concrete evidence here? (S.E)

Frame: "Everything that the King has ever done; he's saying, here is a list of all of his transgressions."

35. Why do you think that he would have gone through the trouble (of preparing the case)? (S.B)

Though able to transcribe cause and effect relationships after the relationship has been defined, he doesn't initially see the connection.

36. Why would, if they know that they (the colonies) are going to go to war, send this document off to Great Britain? (S.A)

37. What would have happened if we had lost the war? (S.A) 
Frame: "...lots of reasons for writing this document out, not the least of which was to keep the colonists pumped up."

Application

Comprehension

Comprehension

Application

Synthesis

Synthesis
38. How would you define a "self-evident truth"? (S.D)

Frame: "Remember they were living in the age of enlightenment 'scientific reasoning' was prevalent. ...Locke, Rousseau and Bacon."
39. When he (Jefferson) says, "self-evident truth" what is he talking about? (S.D)

40. ...more than that if something is a self-evident truth, how do we know it's a self-evident truth? (S.A)

41. (It's instinct) but is it provable? (S.E) Asking the student to separate sociocentricity from universally grounded empiricism here does not lead to insight into each side's (British-vs-Colonials) egocentric behavior and belief structure.

Frame: "Exactly, so we're talking about the idea of consensus ...it's so basic and fundamental, that you can't even argue with it."

42. Under what circumstances today would Americans elect to change their system of government? (S.D)

43. What would have to happen? (S.B)

Contributing factors and spurious relationships are being sought.

Frame: "So we would have to go through the same procedure that he (Jefferson) went through." 
Comprehension 44. First we would have to $?$ (All students)

Comprehension 45. Then we would have to do what? (S.A)

Comprehension 46. Well, what did they do? (S.E)

Here, I have chosen to review the factual recollection of events presented in the text, in an effort to reach consensus regarding the sensible and logical progression of events that unfolded (i.e. facts are connected to the principle impetus here).

Frame: "Well they waited for a while to see if anything was going to get better."

Comprehension 47. Did it get better for them (the colonists)? (S.B)

Frame: "...things (the situation) got worse because..."

Comprehension 48. What happened after they waited for a while? (S.A)

Frame: "Soldiers taxes, and unjust laws... and finally when they knew things weren't going to get better, but worse..."

Comprehension 49. ...they finally __ ? (S.D)

Evaluation 50. Which reason for breaking away from British rule strikes you as most important? (S.D)

Comprehension 51. Over our daily lives you mean? (S.D)

Comprehension 52. Soldiers in citizens' houses would have been the final straw wouldn't it? (S.D)

Comprehension 53. People are going to stand up and say that's it; is that what you're telling me? (S.D) 
Frame: "Jefferson's complaints are against George - not the British people."

Analysis

Application

Comprehension

Analysis

Comprehension

Application

Comprehension

Comprehension

Comprehension
54. In what ways does the declaration emphasize this difference? (S.A)

55. Why do you think that this distinction was made? (S.A)

56. So you think the British people, had they known about some of these things (George's transgressions), may have been just as upset as the colonists? (S.A)

57. How does he (Jefferson) make it clear that it was just George and not the British people that they had a problem with? (S.E)

Now that the motivation for action (causes) have been reviewed and the effects have been explicated, I am asking the student to separate individual actions from sociocentric behavior (i.e. carte blanche hatred of unlike groups).

58. Cite examples from the Declaration that shows it's a fair minded reasoned approach: (S.E)

59. So what was very "fair-minded" about this document? (S.E)

60. Why was that "fair-minded"? (S.E)

61. Who was it fair to? (S.E)

This line of questioning was designed to elucidate the principles, moral and ethical, of the democratic civilization conceptualized by Jefferson (based on equality and merit).

62. They (the British troops) were not interested in our 


\section{well-being; is that what you are saying? (S.E)}

Again the students gives an at length list of transgressions without grounding his thoughts (and case) in the principle (law) not followed. I was trying to cajole a closing argument (synopsis) from him.

Application

Comprehension 64. Is that fair-minded? (S.B)

63. How do you consider that to be fair? (S.B)

Comparison and contrast of the literal dead ends with the points we've already discussed in class. Creating anew the abstract examples does not come easily for this student.

\section{Frame: Reading of the preamble... "causes of separation..."}

\section{Summary of Lesson One:}

The purpose of this lesson, in the larger scheme of this project, was to create a set of dialectical notes that could be referred to as student roadmarkers of progress. As such, it contains many more annotations documenting students' current cognitive abilities than do the subsequent sections that seek to mark specific student critical thinking abilities that are burgeoning into a new abstract skill mastered. My technique here, as stated in my daily reflections summary, was to begin each individual line of student questioning with a sufficiently difficult open ended query and provide a contextual frame only as the student showed clear signs of difficulty breaking the task into meaningful answers that demonstrated part to whole relationships (which at times also meant heading off a generality heading away from empirical thought). What I learned here was twofold: 1) Students have been groomed by society (including educational settings) to generate gross generalities- these new critical thinking skills will not come easy since students also recoil at, 2) new vocabulary; this reticence to tackle new vocabulary, I feel is an outcropping of, a) feeling disenfranchised in the public school system and-b) a fundamental lack of skills necessary to effectively assimilate new words within their respective contexts.

A long held suspicion of teaching quality, methods, and accountability at the middle school level is starting to congeal; has whole language and "quiet" reading time subverted secondary education? Is the elementary school setting the last time most of these students were asked to 
sound out words and come up with, at least, tentative conclusions on their own? I'm already wondering, early on, how much of the gap I can bridge when students lack essential reading and vocabulary skills.

Since reading comprehension facilitates vocabulary assimilation and vocabulary assimilation leads to new schematic categories in which to place new knowledge (according to Vygotsky, Dewey, Benjamin, et al...), I'm wondering how critical thinking can be fostered in this environment. What I want to know is how far can these students be weaned from their comfort zone (easy language and simplistic over- generalizations) into Dewey's "Zone of Proximal Development"?

Taxonomic Questions Transcribed Student Addressed Level Intended

\author{
Lesson Two: \\ Franklin's Autobiography (in class reading)
}

Knowledge $\quad 1$. Where did we leave off, somewhere around page 133? (All students)

Frame: Discussing "temperance as a virtue".

Comprehension 2. What does he (Franklin) say about temperance? (S.E)

Frame: "No excess of anything in life."

Application 3. The very first thing you need to do to be effective, is have a clear what? (S.E)

Frame: "The virtues must be done in progression as they appear."

Knowledge 4. What's his plan for the year? (on page 113) 
Comprehension 5. What's his plan and how is it going to go?

Knowledge $\quad 6$. What does he say? (S.B)

Frame: Referring to Franklin's own usage of his virtues chart.

Application

7. We see he had no dots under "T" in the chart on page 113, what will that tell him? (S.C)

Knowledge

8. He (Franklin) goes on to the next thing, which we can see he had a little more of a problem with; which was ? (S.C)

Frame: "Now he's mastered temperance and he's moving on to silence."

Knowledge 9. What is the vocabulary word we have there? (S.D)

Frame: "Every 13 weeks Franklin creates a new chart to eliminate faulty virtues by identifying them."

Comprehension 10. Does that sound like a reasonable plan of attack? (S.D)

Frame: Discussing with (S.E): Franklin as a printer.

Comprehension 11 ....or better yet, what might he have done since he had access to it? (S.E)

Frame: "The precept of order"

Knowledge $\quad$ 12. O.K. who had order? (S.E)

Application 13. What do some people carry around with them, especially business men? (S.D) 
After providing a modern day analogous situation, students were able to recognize the evolution of the planner.

Application

Application

Comprehension

Knowledge

Knowledge

Application

Comprehension

Comprehension

Comprehension

Analysis
14. Do you think there were many daily planners around during this time period? (All students)

15. How does he break this down? (S.E)

16. What does he cover? (S.D)

Frame: "He gets up at 5am."

17. The first thing he does when he wakes up, is asks himself what? (S.A)

Frame: "Yes, what good shall I do today."

18. What's our (daily) quote today?

Frame: "Yesterday we discussed science, religion, and morality."

19. How would we define "great" in this instance? (S.D)

20. O.K. in general terminology how would we define great? (S.A)

21. Who is somebody that you think is great? (S.A)

22. What else could we add to this description? (S.D)

Frame: Virtues of greatness (public figures) discussed.

23. Do you think Franklin had that as a politician and businessman? (S.E) 
After reaching consensus on a universal value structure based on merit, I am asking the student to reconcile actions (and results) with stated objectives (from Franklin's Autobiography) as they relate to "greatness".

Comprehension 24. Anything else we could add to the definition of greatness? (S.B)

The student is here beginning to synthesize the abstract examples of concepts internalized.

Frame: A synopsis of the complete of traits is now given.

Knowledge

25. ....and what was the one you just said? (S.B) Positively reinforcing previous abstractions (answers given), upon later review of the videotaping, yields a greater level of enfranchisement in the student (i.e. posture \& attentiveness improved).

Comprehension

26. Are all of these things (just discussed) covered by Franklin's list of virtues? (All students)

Frame: "If someone could make it to greatness, Franklin probably did, but he says you have to be good first."

Comprehension 27. So what does "good" mean? (S.E)

Comprehension 28. Decent, wholesome, what else describes a "good" person? (S.C)

Comprehension

29. Honest right? What else? (S.B)

Though still sticking close to the text, the student is beginning to deductively infer new extended implications.

Comprehension 30. (S.A)? 
Frame: "The first thing he (Franklin) does, when he gets up each day, is say 'What good will I do on this day?"”

Knowledge

31. Well what good does he plan to do on this particular day? (S.C)

Frame: "He doesn't really define work, but he says he's going to work from 7:30 to 11am."

Knowledge

32. Now what was his business? (All students)

Knowledge

33. Then sometime around noon, what would he do? (S.A)

Comprehension

34. Do you think that people who get up at five o'clock in the morning and work until at least five o'clock in the evening have a great chance of being successful? (S.D)

Comprehension

35. What's one of the sayings (from "Poor Richard's Almanac) that Franklin had; "early to bed, early to rise ... ? (S.C)

Comprehension 36. So then around six o'clock in the evening, what does he ask himself? (S.E)

Comprehension

37. So what does he do before he goes to sleep? (S.B)

Frame: "Yesterday, we defined Franklin as a renaissance man."

Comprehension 38. What did we define as traits of a renaissance man? (S.D) 
Comprehension

39. A renaissance man is somebody who

Frame: At this point, a recap of Franklin's accomplishments is postulated and then the discussion is refocused on "order."

Application

40. O.K. so what's he talking about? (S.E)

Frame: "Referring to his daily chart"

Comprehension

41. When he is saying, "scraping out the marks" what does he mean there? (S.D)

Frame: Again, referring to the durability of Franklin's reusable chart.

Application

42. When do you think the dry erase board was invented? (S.D)

Frame: "Yeah, it's hard to say,..."

Comprehension 43. ...but do you think it was around in Franklin's time? (S.D)

Application

44. Paraphrase that for me; what is he saying (here)? (S.D)

Comprehension

45. O.K. well what are the things that he wants to change about himself? (S.E)

Frame: "When he's talking about self-examination and becoming a journeyman printer..."

Comprehension 46. What kind of a system is he talking about? (S.A) 
Application

47. Does anybody know about the apprentice system at all, or how it works? (S.D)

Frame: The apprentice system (of the trades) is explained.

Comprehension 48. In this day and age, if you're a journeyman, you carry what kind of a card? (S.E)

Application

49. What kind of a group do they (trades men) belong to? (S.C)

Frame: "He (Franklin) says that most people learn by Somebody watching and critiquing them."

Comprehension 50. That makes sense, right? (S.C)

Application

51. In order for him (Franklin) to improve any more than he already has, he has to critique what? (S.D)

Frame: "He gives us a word (footnoted) here, vex."

Knowledge 52. To vex something is to ___? (All students)

Frame: $\quad$ Franklin on metacognition

Comprehension 53. Do you get this analogy here? (S.E)

Frame: Discussing tradeoffs/mediocrity

Comprehension 54. What are we doing, according to your example?

Comprehension 55. What are we really saying? (S.B)

Comprehension 56. ... and we're also settling for __ ? (S.C) 
Frame: "It's human nature, but..."

Application

Application

Application

Knowledge

Knowledge

Comprehension

Application

Comprehension
57. Why do we do that? (S.E)

58. How much effort does it really take to reach perfection at some level? (S.E)

Frame: In comparison to Franklin's "speckled ax" being imperfect.

59. Do we do that? (S.C)

Frame: Discussing the vocabulary word "fop".

60. Have you ever seen a Shakespeare play where he has some kind of a fool? (S.D)

Frame: Franklin is discussing public relations.

61. Does anybody know the name of the book written by Machievelli, in the 1500's? (S.E)

62. Ever hear of, know anything about,... what was Machievelli like? (S.A)

Frame: "The thing that Machievelli said that always kept Franklin's interest was;"

63. If you appeared to be too perfect, what would people say about you? (S.B)

64. Anybody who appears to be too perfect, is not (S.B)

Feelings and thoughts are not about the text are still not leading to personal interpretations of the text (but is coming 
out in the general class discussions).

Comprehension 65. Franklin realizes, if he gets to the point of moral perfection, how will people perceive him? (All students)

Comprehension 66. Are other people morally perfect? (S.C)

Application 67. What do we think about people who don't appear to have any faults? (S.D)

Analysis

68. So what kind of a conclusion is he (Franklin) coming to here? (S.A)

Application

69. Even if he could (achieve perfection), would he act like he's perfect around other people? (S.A)

Frame: "Franklin sees perfection as a never-ending process."

Comprehension 70. Do you think that's true? (S.D)

Frame: "We all know that we can't reach it, but..."

Application 71. Do you think you would feel better about your life, if you would at least try to (reach perfection)? (S.B)

Comprehension 72. Do you ever wake up in the morning and say, today I'm going to improve on this thing? (S.C)

Comprehension 73. Do we do that? (S.D\& S.B)

Comprehension 74. We don't talk about it, but we think about it don't we, from time to time? (S.A) 
Frame: Quotes from Poor Richard's Almanac

Comprehension

Application

Application

Comprehension

Application

Application

Comprehension
75. Who did we say was his primary audience? (S.A)

76. The only other book that was more widely read, in America in the 1780's, was the ? (S.C)

Frame: "He that cannot obey cannot command" (Franklin).

77. What does that mean? (S.A)

78. Are we going to follow the rules that somebody else makes up if they themselves don't follow the rules? (S.B)

Frame: "He that lies down with dogs, shall rise up with Fleas" (Franklin)

79. What does that mean? (S.D)

80. So what's he talking about when he says "a dog"? (S.B)

Frame: “Love your neighbors, but don't pull down their Hedge" (Franklin).

*(S.C) answers without prompting

Frame: "A mob's a monster, heads enough but no brains" (Franklin).

81. Would he (Franklin) have seen "mob" type mentality in his day? (All students) 
Knowledge

Comprehension

Comprehension

Application

Comprehension

Application

Analysis

Comprehension

Application
82. During what time period have we just been talking about? (S.D)

83. What happened in Boston that was so famous? (S.A)

Frame: "There were hundreds of men that boarded those ships."

84. Do you think all of them understood exactly why they were doing that? (S.C)

Frame: "Lost time is never found again" (Franklin).

85. How would you interpret that? (S.A)

86. Anything that you wished that you would have done, in the past, that you didn't get a chance to do? (S.D)

87. It tells us that we need to take advantage of (S.D)

Frame: "Early to bed, early to rise..."(Franklin).

88. Do you think anybody can get rich by only working a few hours a day? (All students)

89. ...but in order to get to the point that you were making \$800 an hour, what kind of training would you have to have?

Frame: "Be slow in choosing a friend, slower in changing" (Franklin).

90. What does that mean? (S.B) 


\section{Summary of Lesson Two:}

Having a firmly entrenched baseline of student ability, based on in-class and videotaped observations, I am now starting to work the fringes of student ability while nurturing student confidence by strategically pinpointing a student's ability to articulate a salient answer while concomitantly gauging a student's emotional reticence to delve into heretofore uncharted abstract cognitive realms of thought.

What I'm learning, en media res, is that Skinnerian axioms regarding positive and negative reinforcement are needed at critical junctures to either ferret out negative student willingness (which I chide) or bolster students' willingness to attempt the new and unfamiliar (which I praise).

The real test of my questioning and framing skills becomes the accuracy of my instantaneous prognosis of student ability as orchestrated and directed towards a student's own metacognitive epiphany of innate ability (I want to push them, but the climax of their ability, I want to come during the last week being videotaped).

Taxonomic Questions Transcribed Student Addressed Level Intended

Lesson Three: Dr. Heidegger's Experiment (Character Analysis)

Frame: Discussion of Heidegger's (Fountain of Youth) water

Comprehension 1. So how long did this potion last? (S.A)

Frame: "Earlier on, the narrator describes what happened to the rose."

Comprehension 2. What happened to the rose? (S.A)

Frame: Student reading Heidegger's epilogue.

Application 3. So what does Heidegger learn there, in the end? (S.C) 
Working inversely, I'm here hoping to link the moral

platitude to the axialogical rubric for virtuous behavior- which in turn- can be contrasted with actual character behaviors and actions.

Application

4. You had (were assigned Heidegger's character) Heidegger, what did he learn? (S.E)

Comprehension

5. Did they (the other characters) learn anything from this (experiment)? (S.B)

Frame: "Using the chart (in the book) on page 193, let's see if we can describe accurately the characters' traits."

Knowledge

6. Who had Mr. Medbourne? (S.D)

Comprehension

7. We said that he had lost what? (S.D)

Comprehension

8. When he was given a second chance, what does he do with it? (S.D)

Knowledge

9. What does he do 'specifically'? (S.D)

Comprehension

10. What do we learn about his greed? (S.D)

Comprehension

11. What are the decisions that he makes in the story? (S.D)

Comprehension

12. O.K., he lusts for 'things' doesn't he? (S.D)

Comprehension

13. What are the things that he tries to do, just in the short time that he's at Heidegger's? (S.D)

Comprehension

14. What was his (Heidegger's) idea to do to help these 
characters? (S.E)

Frame: “...ice to the East Indies..."

Comprehension 15. How was he going to make money at it? (S.D)

Application 16. So what are we going to discuss about him (Mr.

Medbourne) when we're writing an essay? (S.D)

Synthesis 17. What are we going to use as a thesis statement?

(S.D)

Application $\quad 18$. What's our synopsis? (S.D)

Application 19. What's our overview of this character? (S.D)

Certain obvious benefits arise from following an idea from inception to fruition; the student was forced to carefully

craft his character analysis via interpretation of particular actions that illustrated identifiable traits.

Comprehension 20. When Mr. Medbourne was given an opportunity to change his old life ___? (S.D)

Frame: Referring to Medbourne lusting after widow Wycherly.

Application

21. How did he know that it was a mistake to chase after her? (S.A)

Comprehension 22. Was she true (monogamous) to one person? (S.A)

Frame: "Let's see if we can learn more about Colonel

Killegrew."

Knowledge 23. Who had Killegrew? (S.C) 
Application

Comprehension

Comprehension

Comprehension

Comprehension

Analysis

Application

Analysis

Knowledge

Application

Comprehension

Comprehension
24. What is Killegrew's story? (S.C)

25. What's his background? (S.C)

Frame: 'gout' as a euphemism for venereal disease

26. So, does he change? (S.C)

27. Right, isn't that his character? (S.C)

Frame: "He wants to dance with her (widow Wycherly)"

28. What else does he do as the story progresses? (S.C)

29. How are we going to break this (information listed on the chalkboard) down into three body paragraphs? (S.C)

30. How can we break this down to show that he doesn't change? (S.C)

31. What are three things that Killegrew does, during the story,that he tells us that he hasn't changed? (S.C)

Frame: "Let's talk about Mr. Gasciogne."

32. Was that one yours? (S.B)

33. What characterized Gasciogne? (S.B)

34. What is the primary characteristic of Gasciogne? (S.B)

35. What do politicians do? (S.B) 
Comprehension 36. They manipulate right? (All students)

Frame: "They do things to gain power."

Comprehension 37. Does he lie and cheat? (S.B)

Comprehension 38. When he's in Heidegger's study with the others, what does he do? (S.B)

Knowledge 39. What does he do there? (S.B)

Comprehension 40. What do we know about Gasciogne specifically? (S.B)

Frame: "The phrases that he uses are manipulative."

Application

41. Why does he phrase things the way he does? (S.B)

Frame: A synopsis of Gasciogne's characteristics is given.

Knowledge 42. What other characters do we have? (All students)

Knowledge 43. Who? (S.A)

Knowledge 44. Was that you? (S.A)

Application 45. What are we going to say about the widow Wycherly? (S.A)

Frame: "The men lusting after her..."

Evaluation 46. What was she trying to get them to do? (S.A)

Comprehension 47. She wanted them to fight didn't she? (S.A) 
Frame: "Elaboration on her powers of seduction over men."

Synthesis

48. So what kind of a thesis statement are we going to create describing the widow Wycherly? (S.A)

Analysis

49. What is it about her character that says that one man is not enough for her? (S.A)

Frame: "Now, the one and only character in the story that has an epiphany."

Knowledge

50. What is an epiphany? (S.E)

Application

51. What did Heidegger want to come out of this experiment? (S.E)

Evaluation

52. Did Heidegger have the right idea in mind when he got these people together? (S.E)

Comprehension

53. What did he think was going to come out of it (the experiment)? (S.E)

Comprehension 54. He thought that they would change right? (S.E)

Frame: The rose (dying in the experiment) as a symbol of Heidegger's lost love.

Application

55. How did she (Heidegger's wife) die? (S.E)

Frame: Wrap up of Heidegger's key traits is listed on the board

Comprehension 56. Tell me one more time what your thesis will be:

(S.E) 
Synthesis 57. So what are your three body paragraphs going to be? (S.E)

Frame: After student gives key traits, two ideas are added

Comprehension 58. Does that make sense? (S.E)

Comprehension 59. Does that sound like a good essay? (S.E)

Frame: Discussion of text questions on page 207

Analysis

60. What was your mood as the story ended and why? (S.D)

Evaluation

61. Do you feel sorry for these people (characters) at the end? (S.D)

Comprehension

62. ...but, you do feel sorry for the doctor right? (S.C)

Comprehension

63. So, you feel sorry for them because, in the end, they learned absolutely nothing? (S.A)

Analysis

64. Why do you think Dr. Heidegger chooses these four subjects for his experiment? (S.E)

Though still unsure of the correct terminology to use in creating his categories for analysis, the student is becoming more adept in sensibly labeling, based on authorial intent, the motivations behind character behaviors; intellectual courage is becoming internalized.

Frame: Description of character motives, when they were in their prime is given

Comprehension 65. How were they going after what they wanted? (S.C) 
Application

Application

Analysis

Application

Analysis

Application

Comprehension

Application

Comprehension

66. What qualities do these characters represent? (S.D)

67. All these characters are $?$ (S.B)

68. Which thoughts and actions reveal that the guests have not learned from the mistakes of their youth? (S.E)

69. Do we get any clues, before the last paragraph, about looking for the "fountain of youth"? (S.A)

70. How do the attitudes from the pre-reading (textbook) discussion compare with the attitudes in the story? (S.D)

Frame: "In our society (today)..."

71. How do we feel about old age? (S.A)

Frame: "The moral majority tends to respect old age."

72. They paid their dues, didn't they? (S.A)

Frame: "People in society (the elderly) are concerned about losing physical beauty."

73. What do they end up losing? (S.C)

74. What are the things we have today designed to hide aging? (All students)

Frame: The health and beauty industry

Comprehension 75. It's all attached to what idea? (S.B) 
Comprehension 76. People want to __ ? (S.B)

Synthesis $\quad 77$. What do you imagine is going to happen to these people (characters)? (S.A)

Frame: "They may die trying to find the fountain of youth."

Comprehension 78. What do you think, is that the case? (S.B)

\section{Summary of Lesson Three:}

In this lesson, my Socratic methodology was the vehicle through which I questioned student beliefs while challenging superficial interpretations- as well as reinforcing moral sensibilities.

I learned that strongly held beliefs connected to strongly held convictions- that can't easily be articulated or connected to textual facts, can be a recipe rife with dissent, but worth the risk of student anger if it generates a paradigm shift on the students' part. I'm now taking students down an academic road they don't want to traverse simply because they're emotionally, albeit negatively, connected to the issues. Images of Socrates questioning Glaucon in "The Republic" are also beginning to conjure up images of the pitfalls of this mode of operation.

Taxonomic

Questions Transcribed

Student Addressed

Level Intended

\section{Lesson Four: Poe's Biography}

Frame: Journal topic: "Great minds have purposes, others just have wishes" (Washington Irving).

Analysis

1. What do you think, is that true? (S.E)

A little reticent still, in creating his own organizational schemata as an advanced organizer for all to use, nonetheless, the strength of having a concrete, ever-evolving, dynamic, 
audio-visual record (videotape) is becoming apparent. Judging material based on his own paradigmatic interpretation that takes empirical logic into account as a goal for this student.

Comprehension 2. Elaborate: (S.B)

Frame: "You have a pretty good idea of what you want to do with your life."

Comprehension 3. What do you want to do? (S.B)

Frame: "So you have a purpose and on a daily basis know what to do."

Comprehension 4. You have some plans right? (S.D)

Comprehension 5. Do you have a purpose? (S.E)

Comprehension 6. Which is __? (S.E)

Frame: During the checking of student daily journal entries

Comprehension 7 . Where is your elaboration on these (journal entries)? (S.E)

Frame: Beginning the biographical introduction to Poe

Comprehension

8. What was his background? (S.D)

Application

9. What was he like? (S.D)

Frame: Discussing Poe's parents

Knowledge $\quad 10$. The mother's name was? (S.D) 
Comprehension 11. What were his parents, we talked about this yesterday? (S.D)

Knowledge

12. What else do we know? (S.D)

Application

13. What kind of (life) influences did he have? (S.E) Student has already read several of Poe's works.

So, rather than looking at character motives as evinced through behaviors described in the text, I am asking the student to begin to attribute the actual themes developed by the author to his own life situations (Constructivist ideology and Socratic methodology allow me to move at a different cognitive level of attainment with this student- though still achieving concept consensus with all pupils).

Knowledge

14. How old was he when he went to live with his aunt and uncle? (S.D)

Frame: "So he grew up around the stage."

Application

15. What do you think that explains? (S.B)

Frame: Referring to yesterday's quote (Washington Irving)

Knowledge

16. What was the quote that we had yesterday? (All students)

Frame: "Poe traveled a lot as a child, with his parents."

Comprehension 17. Your formative years are when? (S.D)

Comprehension 18. When are you most susceptible to new ideas? (S.E)

Knowledge 19. What else can you tell us? (S.D) 
Application

Application

Knowledge

Knowledge

Comprehension

Application

Application

Application

Comprehension

Knowledge

Knowledge

Application
20. What do you think he read a lot of? (S.D)

21. Who would be some of the people (authors) that Poe would have read? (S.D)

22. In fact, what's the date of Poe's death? (S.D)

23. What's the date of Hawthorne's death? (S.B)

24. So who do you think that he tried to emulate as a writer? (S.E)

25. Do you want to pick up there? (S.D)

26. What kind of people do you think his aunt and uncle were?

27. What were they like? (S.B)

Frame: "Poe's uncle expected a lot from him (rules to be followed), but his aunt doted incessantly on him."

28. So what happened when Poe went to the University of Virginia? (S.B)

Frame: "Thrown out because of his gambling debts that his uncle wouldn't pay..."

29. What did he do then? (S.D)

30. He did what next? (S.D)

31. What kind of qualifications do you have to have in order to get into West Point? (S.A) 
Comprehension 32. Such as __ ? (S.C)

Application 33. Again, what kind of qualifications do you need to get into West Point? (S.E)

Heretofore left as an abstract (imagining oneself in another

time period), I am now tacitly asking students to

compare their own modern world knowledge to situational

equivalencies from the past - in an effort glean emotional insight into lifestyle choices that affected Poe. Both student readiness and a more contemporary social situation permit this change in methodological tactic.

Comprehension 34. Who do you think he got the recommendation from? (S.D)

Application

35. Who do you think gave him the other recommendations? (S.E)

Here, the student is working from his own schemata of personal experience wherein he himself needed recommendations for a scholarship nomination.

Frame: "After West Point, Poe settled down a little."

Knowledge 36. Who did he marry? (S.A)

Frame: "His 14 year old cousin - first cousin."

Comprehension 37. Do you think it was common even in the 1800's? (S.A)

Frame: "For the first time, Poe accepted some responsibility."

Knowledge $\quad 38$. What kind of work did he find? (S.A)

Application 39. As a magazine editor, what were the benefits? (S.A) 
Frame: "So Poe now had an income, and was starting to get published."

Application

Analysis

Application

Application

Comprehension

Application
40. Why do you think Poe didn't stay at his editing jobs for long? (S.C)

Insight into her own perspective of Poe's character reveals a host of opinionated judgments that cast Poe into the same negative light as some of her subordinates at the video store. Separating limited knowledgelexperience from fact, while still keeping the emotional connection is my challenge here.

41. What factors contributed to Poe's inability to stay at a job? (S.B)

Frame: "So Virginia's sickness and Poe's drinking and drug addiction..."

42. What were some successes, however, that came out of Poe's work as a magazine editor? (S.D)

Frame: "At least other authors came to know Poe's work/name."

43. How, in what context, did most of his contemporaries know of Poe? (S.E)

44. So, during Poe's life, what was he best known for? (S.D)

45. After his death, what contributions to Romantic Literature was he revered for? (S.C) After holding such strong negative conceptualizations of Poe's character, I am asking the student to now step back into a more sensible/logical viewpoint in order to appropriately label clear categories of achievement (along with the failures). 
Comprehension

Comprehension

Application

Comprehension

Application

Application

Application

Analysis
46. According to Poe, how long should it take to read a short story? (S.E)

47. Poe is often called the father of the modern story? (S.B)

48. What genres did Poe work in? (S.D)

Frame: "So poetry, short stories were fiction and literary criticism was non-fiction."

49. What was the only genre Poe didn't tackle? (S.D)

50. Where did Poe get his story ideas from? (S.B)

After discussing Poe's life as a source of thematic

motivation(affects manifested in literature)- she is able, through empathy, to vaguely show their manifestations in his work.

51. How did Virginia's death effect Poe? (S.A)

Frame: "So Poe's poetry was written with Virginia as the intended audience."

52. What common theme do Poe's poems all have? (S.C)

A less value laden category is now inductively created to get the student to think stoically rather than emotionally, in order to bring about a meaningful discrimination between the author's life and his contribution to literature.

53. How does this theme relate to the Romantic body of literature? (S.D)

Though a few generalized descriptions come, relating to "man vs. nature", the student vaguely encircles the theme. 
Analysis

Analysis

Knowledge

Application

Knowledge
54. How does Poe's work relate and fit in with previous Romantic authors covered, such as Irving and Hawthorne? (S.C)

Now judgments based on externally agreed upon criterion are meaningful and rational in nexus (though the emotional connection-albeit negative- remains neutral).

55. What difference do you expect to see between Hawthorne and Poe, given their family and educational backgrounds? (S.B)

Now confident in her thought processes, she connects the socio-economic educational paradigm to level of attainment reached by the respective authors.

56. Other than "A Cask of Amontillado" and "The Raven," which are in our text, what other works of Poe have you read or heard of? (All students)

57. Why do you think Poe is still well known and appreciated, especially by high school students today? (S.E)

58. Has anyone already read "A Cask of Amontillado"? (All students)

\section{Summary of Lesson Four:}

The analytical skill tantamount to empirical operational efficiency is here shown to be of cause and effect origin. Likewise, if the student ethos is connected to the cause- then the pupil pathos must be connected to the effect. Moving from the emotional connections of cause to the cognitive connections of effect always requires a great deal of student trust in the facilitator (framer) while never losing the tangible connection to this endeavor (as mental gymnastics that prepare students to explicate the complex issues they will be faced with later in life). What I'm hoping is 
that, even though students are yet to recognize the rubric associated with questioning critically (i.e. the taxonomic progression), they will nonetheless employ it.

Taxonomic

Questions Transcribed

Student Addressed

Level Intended

Lesson Five: Essay development based on "A Cask of Amontillado"

Frame: "It is more dangerous that even a guilty person should be punished without the forms of law than that he should escape" (Thomas Jefferson).

Application

1. How does this quote relate to, "A Cask of Amontillado"? (S.C)

Comprehension

2. You didn't understand "A Cask of Amontillado" or, you didn't understand the quote? (S.C)

Application

3. So what is the quote saying (stating)? (S.D)

Comprehension

4. Who takes the law into his own hands in "A Cask of Amontillado"? (S.B)

Application

5. So once again, what is Jefferson saying here? (S.B)

Comprehension

6. This is called what kind of justice? (S.D)

Frame: "In this essay, we are going to focus on all the elements of the story as they work together."

Application

7. What is one of the literary elements that we can identify in this story? (S.E)

Frame: Student says "time frame"” 
Analysis $\quad$ 8. O.K. so that is part of what? (S.E)

Comprehension 9. Plot, characterization, or setting? (S.E)

Frame: Setting as first body paragraph of the essay.

Comprehension 10. What evidence, from the text, can we give that supports setting as helping to create the (end result) mood? (S.B)

Application $\quad 11$. What are we going to say about setting? (S.E)

Knowledge 12. Where do we find that (passage) in the text? (S.E)

Comprehension 13. What do we know about the catacombs? (S.E)

Application 14. Dead bodies are housed in the catacombs and what else? (S.D)

Knowledge $\quad 15$. Where do we find that information? (S.D)

Comprehension 16. What did these catacombs look like? (S.D)

Comprehension 17. 'Really' describe what these catacombs look like: (S.C)

Since she obviously didn't read the text carefully, I am layering facts into the in-class explication in order to reach the revenge theme (which in turn can be related to vigilante justice- Jefferson's fear).

Knowledge $\quad$ 18. ...damp ground, what else does it say? (S.A)

Comprehension 19. Anything else about smell? (S.A)

Knowledge 20. What page do we find that information on? (S.E) 
Frame: "We know there are dead bodies (in the catacombs)."

Application 21. What stage of decomposition are they in? (S.B)

Application 22. Where would the most recent dead bodies be found? (S.E)

Comprehension 23. Where does Montressor take Fortunato? (S.D)

Application 24. I'm walking through these catacombs, 'at first', what kind of things do I see? (S.B)

Frame: "First I'm going to see some skeletons..."

Comprehension 25. Do you think they're going to be recently deceased? (S.B)

Comprehension 26. Would that bother you to some extent? (S.B)

Comprehension 27. Would that make you uneasy? (S.B)

Frame: "We're traveling onward (into the catacombs), the further we go..."

Application 28. The more it's going to be __ what? (S.B)

Comprehension 29. Didn't he (Poe's narrator) mention the mold in the air? (S.B)

Application

30. What kind of effect did the nitre (on the walls) give; look at the illustration? (S.D)

Frame: "So then we're talking about the look of it (the Catacomb). 
Comprehension

31. Did you ever go through a haunted house ride and see lights come up out of nowhere? (S.B)

Frame: Referring to the notes listed on the board.

Comprehension

32. Based on what we have here, could you write a decent paragraph describing the setting? (S.C)

Now that concrete textual comprehension is in place, the initial comparison/contrasting of the anagram (Jefferson) can be disseminated and overlaid upon the Poe conceptualization.

Frame: "Furthermore we need to include specifics..."

Comprehension Application

Comprehension

Comprehension

Comprehension

Evaluation
33. Where does Montressor live? (S.B)

34. What kind of home is it? (S.B)

35. How are we going to describe that? (S.B)

36. Remember the family motto; what was it? (S.E) Capable of deductively explicating behaviors in patterns that predict events, after watching this student firmly grasp abstract critical thinking skills, I now am asking the student to sense the intimate connection between reason and emotion (both propel Montressor's actions). I decide to wait, however, for other students to develop more concrete evidence in coming to this Gestalt before actively dichotomizing this incongruency.

Frame: "I know you don't remember Latin, but..."
Frame: "So we now have setting." 38. Is this complete? (S.C) 
Comprehension 39. Do we want to add anything else to this? (S.C)

The concept attainment of theme comes here.

Comprehension 40. Any questions about setting? (All students)

Application 41. Why was I talking about this walk, this voyage, down the catacombs? (S.D)

Frame: "I mentioned three different elements that contribute to mood...."

Knowledge $\quad$ 42. Besides setting, what else did we discuss? (S.E)

Frame: (When talking about characters) "Let's start with the antagonist."

Comprehension 43. Who is the antagonist in this story? (S.A)

Comprehension 44. Do you think so? (S.E)

Frame: "Usually, the protagonist is the good guy, but..."

Comprehension 45. Are we saying that "Fortunato" is the bad guy? (S.B)

Application

46. I'm confused, can you help me out with this one? (S.B)

Application

47. Is Montressor the good guy? (S.B)

Frame: "I don't know"

Application 48. Is this written from the antagonist or protagonist's point of view? (S.B) 
Frame: "We have our antagonist."

Comprehension 49. Which is ? (S.A)

Comprehension 50. What do we know about Montressor? (S.C)

Comprehension 51. What do we learn about him (Montressor), in the beginning? (S.E)

Comprehension

52. What other items does Montressor talk about in the beginning? (S.C)

Frame: Renaissance Italy's import/export tradesmen (merchants) discussed.

Comprehension 53. What, besides wine, does Montressor mention, that he sells? (S.C)

Comprehension

54. When he (Montressor) is describing "Fortunato", what does he say Fortunato is an expert at? (S.D)

Comprehension 55. What does Montressor say Fortunato is a "quack" at? (S.E)

Comprehension 56. A "quack" at__ ? (S.E)

Frame: Discussing gemstones

Comprehension 57. Generally we would translate that as $?$ (S.D)

Application

58. Montressor would own the equivalent of what kind of store today? (S.B)

Application

59. What kind of store would sell these types of items? (S.C) 
Frame: The list of items Montressor sells is written on the board.

Application

60. If we take the cheese out (of the list), what kind of store can we envision? (S.E)

Frame: An exhaustive list of details known about Montressor is created

Evaluation

Application

Comprehension

Comprehension

Application

Application

Comprehension
61. What kind of a character is Montressor? (S.A)

62. How do we know that? (S.A)

63. Why was he "unhappy"? (S.B)

Frame: "He (Montressor) is set on revenge."

64. How do we know that? (S.C)

Now that the revenge motive has been disclosed, the concept of equitable justice can be Socratically discussed.

65. What specifically, is he holding against Fortunato? (S.A)

Frame: "He says, this is the one thing that Fortunato did that went too far..."

66. What's the revenge for, that's the question I want answered? (S.A)

67. What did Fortunato do to him (Montressor)? (S.C) Implicitly, at least I'm asking for commentary on justification.

Frame: "We don't know what kind of insult, but..." 
Application

Comprehension

Comprehension

Comprehension

Application

Application

Comprehension

Application

Comprehension

Knowledge

Application

Comprehension
68. What does he pride himself on being an expert at? (S.A)

69. What else can we say about Montressor? (S.D)

70. When he (Montressor) sees him (Fortunato), does he (immediately) try to kill him? (S.D)

71. What else could we say? (S.A)

72. What other trait could we ascribe to Montressor? (S.A)

Frame: Discussing Montressor's intelligence and patience.

73. Why do we say that? (S.A)

74. So could we say, he's in control? (S.A)

Frame: "This would be a good place for a quote in your essays."

75. What's the quote we could insert here? (S.C)

76. What did he say about the best kind of revenge? (S.C)

77. What page is that on? (S.E)

78. How are we going to put that (explain) in our own words? (S.D)

79. What kind of revenge did he say was the sweetest? (S.C) 
Frame: "Unexpected, well-planned, revenge"

Application 80. What else can we say about Montressor? (S.B)

Application $\quad 81$. How do we know that he has a sense of humor? (S.B)

Comprehension 82. What does he say to show us that he has a sense of humor? (S.B)

Knowledge 83. O.K. where do we see that? (S.C)

Knowledge 84. What page is that on? (S.C)

Comprehension 85. It's toward the end right? (S.C)

Comprehension 86. What does he (Montressor) do while he's walling him in? (S.A)

Comprehension 87. What does he do to get him (Fortunato) down there for? (S.A)

Comprehension 88. What was the premise...? (S.A)

Application 89. Somebody who likes somebody else to suffer is called a what? (S.E)

Frame: All of Montressor's traits are reviewed here.

Application 90. What is the ironic thing, that we see along the way, that foreshadows Fortunato's demise? (S.E)

Comprehension 91. What was the guild that Fortunato belonged to? (S.A)

Application 92. How does that relate to the Mason's trowel? (S.A)

Comprehension 93. What does he say to Fortunato when he pulls out the 
trowel? (S.A)

Comprehension 94. "To your ___ ? (S.A)

Frame: The irony with the trowel

Knowledge 95. What page is that on? (S.E)

Frame: "If we dedicate this long paragraph to

Montressor, we certainly would want to dedicate, at least a short paragraph to Fortunato, but before we do that..."

Knowledge 96. Does everybody have all of these notes (on the board) down? (All students)

Application 97. So what are we going to say about him (Fortunato)? (S.A)

Comprehension 98. Who to, and why is Montressor telling this story now? (S.B)

Comprehension 99. ... and how much time after the fact is it? (All students)

Application 100. He's telling it to _ ?

Comprehension 101. Why do we say, maybe his priest? (S.C)

Application 102. What (religious) denomination was he probably? (S.D)

Application 103. What do Catholics tend to do, especially when they are dying? (S.A)

Frame: "We're saying that Fortunato is the protagonist, 
but he may have been just as bad a character as Montressor, because..."

Comprehension 104. What does Montressor say about him, in the beginning? (S.C)

Comprehension 105. What does he say? (S.C)

Comprehension 106. How does Montressor describe Fortunato early on? (S.E)

Knowledge 107. What page is that on? (S.D)

Frame: "Montressor says that, Fortunato was a man to be respected and even feared."

Application 108. He admired him for what quality? (S.D)

Application 109. He disrespected him for what trait? (S.D)

Application 110. What does the word "Fortunato" mean? (All students)

Comprehension 111. Was he fortunate? (S.E)

Comprehension 112. How about before Montressor got to him? (S.D)

Analysis 113. What was the big difference between Montressor and Fortunato's businesses? (S.A)

Comprehension 114. What else could we say about Fortunato? (S.C)

Analysis $\quad 115$. Who is the more trusting, Fortunato or Montressor? (S.C)

Here I leave the student, after a brief monologue, focused on the might vs. right issue. 
Comprehension 116. Fortunato is somewhat gullible isn't he? (S.B)

Application 117. How was Montressor able to deceive Fortunato?

(S.D)

Comprehension 118. What does he say to him to keep him going down the catacombs? (S.A)

\section{Lesson Five Summary:}

In this lesson, I set out to prove that the students did, in fact, know a great deal about the characters' actions and motivations in this story- since all of the students found both Poe and his tales interesting and were therefore engaged. What I learned, by using this rapid-fire questioning technique, was that if students could be orchestrated into a crescendo- they themselves would inductively draw their own conclusions. Perhaps even more importantly, many of the descriptive terms that I used such as deceive, gullible, disrespect, etc... were picked up on by students and inculcated into their own descriptive repertoire. I will use this rapid paced questioning technique again to build student confidence during a later lesson.

Taxonomic Questions Transcribed Student Addressed Level Intended

Lesson Six: Transcendentalism/Emerson (reading)

Frame: "It's the way we live our lives."

Application 1. What kind of a philosophy is this that Emerson is talking about? (S.A)

Knowledge 2. Starts with a T? (S.E)

Frame: "Emerson is talking about a personal relationship with God based on deeds and actions, not words." 
Application

Comprehension

Comprehension

Application

Application

Application

Application

Application

Application
3. What's he saying here? (S.D)

4. What did Shakespeare say, "Be true to "? (S.D)

5. We said the Romantics were primarily concerned with what? (S.E)

6. What theme was Hawthorne working with in his "mad scientists"? (S.E)

Frame: "Yes, man trying to improve on man, and ..."

7. The answer to that folly is always what? (S.E)

Frame: Emerson's definition of right

8. Constitution, in this case, means? (S.B)

9. According to Emerson, who is it that should be able to tell you what's right and what's wrong? (S.C) Here, I am drawing on her internalized sense of morality, ethics and virtuosity; her self-esteem comes from the same didactically oriented pedagogy as Emerson.

Frame: "Independence of solitude..."(Emerson).

10. Do we know anything about Emerson or Thoreau that relates to this idea of solitude? (S.D)

11. What did Thoreau do with Emerson's idea of solitude? (S.B)

Frame: "Solitary man not contaminated by society, but simply applied God's ideas..." (Emerson). 
Comprehension 12. What do you think about that idea, solitude? (S.A)

Comprehension 13. Do you think you're more or less pure a person?

Highly sensitive to issues of moral platitudes, student " $A$ " begins to disclose her biases and prejudices that limit her own humility. Wishing to expose the limitations of her thought processes, I move on to other students more cogniscent of their own metacognitive limitations- in hopes of her achieving the epiphany without directly cross-examining her logic.

Comprehension 14. Do you think that's true? (S.C)

Frame: "Not being forced, but deciding to go out and live on your own for awhile."

Application

15. Do you think you would be a better person for doing that? (S.C)

With a highly developed internalized value structure in place, this student begins to enumerate the benefits of being a "free-thinker" unencumbered by pop-culture (MTV \& egocentric values).

Comprehension 16. Do you think that's true; would it help? (S.D)

Application

17. What kind of things would you tend to eliminate if you were in solitude? (S.E)

Comprehension

18. So who are you held accountable to? (S.E) Now my Thomistic philosophy manifests itself in the Socratic method in that the Christian code of ethics roots scientific (including self-reflexive) truths as being firmly entrenched in the belief that your conscience (soul) must transcend the temporal world and answer directly to God; this concept (self-accountability) is readily understood 
by all students (thanks to middle school pedagogy)- though untempered by humility, civility or logic. The challenge here is to build upon an incomplete conceptual frame of knowledge.

Analysis

Analysis

Analysis

Comprehension

Knowledge

Application

Comprehension
19. Why do monks and sometimes nuns live a life of solitude? (S.B)

20. Why do they do that? (S.B)

21. Why would somebody go to the heart of the Himalayas in Tibet and climb 10,000 feet up a mountain, with nothing but the clothes on their back, and then maybe not even talk to anybody for ten years? (S.C)

Frame: S.C discusses the hardships of going it alone. She hits close to home, discussing her moral upbringing (family life/belief structure) as contrasted daily with her liberal, mostly amoral, peers dealt with daily.

22. Do you think that's true? (S.D)

Frame: S.A is reading.

23. Our footnote on "countenance" says? (S.A)

Frame: "That's pretty heavy commentary on the masses."

24. What's he saying there? (S.E)

Frame: "That's part of it - what else..."

25. What's he saying? (S.E) 
Application

Comprehension

Analysis

Application

Application

Comprehension

Application

Application
26. So he is speaking positively about the mass of people around him? (S.E)

Frame: Just follow the rules on MTV and no one gets hurt.

27. Is that right, just follow the rules on MTV? (S.E)

Frame: In Emerson's day it was the newspaper.

28. What media pressures do we have that influence us today? (S.B)

Frame: He's saying something about people that conform.

29. What's he saying there? (S.A)

Frame: ...that people just do it.

30. Because they don't $?$ (S.A)

31. So then, they are not thinking for ? (S.B)

Frame: Emerson's views on habits.

32. What did (Ben) Franklin say about habits? (S.A)

I now come back to this student's lack of questioning habitual modes of operation. She sees how theory applies to Franklin, but still fails to see her own mis-alignment.

33. What is Emerson saying about habits here? (S.B)

Frame: People have a hard time breaking bad habits. 
Comprehension 34. Why? (S.C)

Frame: Emerson says others expect you to perpetuate bad habits to make them feel good.

Comprehension 35. Is that true? (S.A)

Now forced to apply her own value structure, the student begins the process of evaluating the tenets of the concept of conformity-yet is still unwilling to elaborate. Though the facial expression of this student was considered minutia during the lesson (I didn't respond to it), the videotape here greatly enhances my ability to follow a particular student, at her developmental level, and modify my instructional strategy to accommodate the diverse levels of abstract cognition present within this group.

Comprehension

36. Did you ever get involved with a group of people, where you know that they're making some bad decisions and you've grown out of it and decided, hey, I don't need this anymore? (S.D)

Comprehension 37. Have you ever been in that situation? (S.D)

Frame: They only want your friendship, if it meets their needs...

Comprehension 38. And then you're left with $?$ (S.D)

Frame: “...words as hard as cannonballs"

Application

39. What's he saying? (S.D)

Frame: "To be great is to be misunderstood." 
40. Is that true? (S.A)

Now feeling confident that she has internalized the immediate schemata, the pupil gives examples illustrating the point. Had I paid more careful attention (i.e. caught her facial expression from the previous round of questioning), $I$ may have opted to invest greater time and energies into nurturing this student into a more intricate analysis. Clearly, in this instance, videotaping captured a subtle nuance that later could be identified as part of a larger developmental picture (though it was not uncovered while making instructional adjustments "on the fly").

Frame: Referring back to Galileo, Copernicus, etc...

Knowledge

Knowledge

Knowledge

Knowledge

Knowledge

Comprehension

Knowledge

Knowledge
41. Now, you've heard of most of these names once I said them , right? (S.C)

42. Franklin said, "Imitate Jesus and ? (S.D)

Frame: Discussion of Emerson and Franklin emulating Socrates.

43. How about Pythagoras? (S.B)

44. Has anybody had any advanced math classes? (S.B)

45. What is it called? (S.B)

Frame: "Yes, his theorem."

47. Who was Luther, as in Martin Luther? (S.E)

48. Copernicus was the first one to say that $?(\mathrm{~S} . \mathrm{D})$ 
Comprehension

Comprehension

Knowledge

Analysis

Knowledge

Comprehension

Application
49. What did Sir Isaac Newton discover and label? (S.E)

Frame: All of these people were great thinkers that in Their day were misunderstood. So, Emerson is saying, if you want to be great you've got to break away from the crowd.

50. Does that make sense? (S.A)

Frame: Handed student a dictionary.

51. Somebody tell us what the word "aphorism" is? (S.E)

Frame: S.A is reading Emerson's aphorisms.

52. What do these remind us of? (S.D)

53. Franklin's sayings that came from what publication? (S.B)

54. So what's an "aphorism"? (S.E)

Frame: "Aphorisms", maxims, words to live by

55. Is there anything we take issue with here (Emerson's quotes)? (S.E)

While aware of his own belief structure, the student only has a vague sense of why some of Emerson's aphorisms didn't reconcile with his own beliefs; articulatory fluency (the actual labeling of abstract concepts) later turned out to be the primary source of this inconsistency. Subsequent discussions would yield a reference back to a couple of Emerson's ideas later disputed when discussing Thoreau. Review of the videotaped lesson segment 
posthumously led me to the conclusion regarding

articulation of the student's ideas as the quandary-not, in

fact, comprehension of Emerson's maxims, as I had

initially supposed.

Comprehension 56. Which one did you like the best? (S.B)

Comprehension 57. What about you? (S.D)

Comprehension 58. S.C?

Because she had reached concept attainment early on (sometimes a negative in terms of teacher focus), I now touch base with her to show the value of her input.

Comprehension 59. Which one did you say you liked? (S.E) Aware of the student's previous inability to accurately describe problematic ideas, I wanted to make sure that the pupil didn't associate irreconcilable beliefs with the author's ability to generate acceptable platitudes that were appealing (i.e. I didn't want the student to tune out to the author's larger message[forest] based on minor disagreements[trees]). Moreover, since the student was intellectually engaged, and Thoreau would continue to bring Emerson's ideas through to fruition, my intent was to instill patience in working through obstacles and difficulties toward a rational unification of a personal philosophy of his own.

Knowledge $\quad 60$. How much time do we have left? (S.D)

\section{Lesson Six Summary:}

In this lesson, I was beginning to separate students' underlying beliefs from, empirically proven, observable facts accepted while not losing the emotional connection to the underlying social issues being discussed. What became very clear during this lesson was- the dynamic effect that my extended questioning of one student, to the exclusion of others- they were tuning out, since 
they were not receiving personal attention; though schools have allowed this self-centered pupil egocentrism to occur, the fundamental devaluation of 'the golden rule' being reinforced in the homes and churches also goes a long way towards explaining why we, as a society, have a national problem with ignorance being bliss; they (children) don't value anything not of their own origin.

What, amongst myriad other goals, I hope to cultivate over the next few lessons is the conditioning of students to value the origination of any ideas that may expose the roots of sophistic (hearsay) rather than philosophic (empirical) reasoning.

Taxonomic Questions Transcribed Student Addressed Level Intended

Lesson Seven: Emerson's ideas (oral quiz)

Analysis

Application

Knowledge

Evaluation

Evaluation

Evaluation

Application
1. How does this (quote on board) relate to Emerson? (S.B)

2. How does Emerson say that you should live your life? (S.C)

Her extensive diatribe reinforces her confidence in mastering the subject matter.

Frame: While checking journal entries

3. Have you been here every day? (S.B)

4. Which ideas in this essay did you find the most meaningful? (S.C)

5. (S.B)?

6. (S.E)?

7. So put that in your own words: (S.E) 
Comprehension 8. What does that mean? (S.E)

Evaluation 9. (S.A)?

Evaluation $\quad 10$. (S.D)?

Comprehension 11. Ultimately, you only answer to ___? (S.D)

Analysis 12. What are the advantages of being a "nonconformist"? (S.D)

Analysis

13. Any other advantages, to being a "nonconformist"? (S.A)

Application

14. Can you think of anything other than not being influenced by other people? (S.E)

Economics, authority and social status are prematurely brought out as disadvantages, indicating a clear preference for prestige resulting from conformity. A balanced treatment of this issue is abandoned for fear of being too heavy-handed in guiding the student to a point of view that lucidly weighs the consequences and rewards. I decide to let the other students dispel the preconceived notions regarding disadvantages of dogmatic thought.

Application 15. Any other advantages that we can think of? (S.B)

Frame: The other side of the coin are the disadvantages.

Analysis

16. What does that say about great people needing support? (S.B)

Application 17. Can most people make it in life without some kind of serious support group? (S.B) 
Application

Application

Comprehension

Application

Comprehension

Application

Application

Comprehension
18. What other disadvantages do we have in being a non-conformist? (S.A)

19. You are not getting any quality feedback right? (S.E) Reviewed approximately a week after the taping, I now ironically see the student's actions as being nonconformist, for here he is also playing the devils advocate in discussing the merits of being free of outside influences.

Frame: Discussing Emerson defining man as alone.

21. Why? (S.C)

22. Is that what you were going to say? (S.B)

Frame: "Envy is ignorance, imitation is suicide" (Emerson).

23. How about that one (S.E)?

Frame: "What I must do is all that concerns me, not what people think" (Emerson).

24. (S.A)?

Frame: "To be great is to be misunderstood" (Emerson).

25. What did we just say about this (S.C)?

Frame: reference to Galileo, Copernicus, etc...

Comprehension 26. What was Emerson saying about these people (S.D)? 
Analysis

Comprehension

Comprehension

Application

Comprehension

Comprehension

Analysis

Application

Comprehension

Application

Comprehension
27. What kind of ridicule do "different" kids have to endure (S.D)?

28. What can we add to this (S.A)?

29. (S.B) Do you get mis-judged a lot?

30. Based on what? (S.B)?

31. Do people mis-judge you at times? (S.C)

32. Has nothing to do with your brain though does it? (S.C)

Frame: Discussion turns to cliques

33. What happens when you get out of high school when everybody goes a different direction? (S.C)

34. So then what? (S.C)

Frame: Analogy: Henrik Ibsen's "Enemy of the People" is synopsized.

35. What do you do in this situation? (S.B)

36. What do you think happened to this character? (S.D)

Frame: The towns people tried to deny the problem and...

37. Labeled him a $?$ (S.D)

Frame: Then people started dying 
Application

Application

Comprehension

Comprehension

Analysis

Knowledge

Application

Application

Comprehension
38. Then what happened? (S.A)

39. In the end (of "Enemy of the People") what do you think that he (the protagonist) learned? (S.A)

Frame: When people that you counted on turn their backs.

40. Were they your real friends to begin with? (S.A)

Frame: Favorite aphorisms are recapped here.

41. What can we say about enthusiasm? (S.C)

The student rightfully defines, as does Aristotle, motivation as the most essential ingredient in the learning process.

42. Although Emerson's ideas might work for a few people, would they work for an entire nation? (S.D)

43. Did you ever read Plato's Republic? (S.D)

Frame: "The Republic" -and its citizens are explained.

44. Would these ideas work for everybody in this Country? (S.E)

45. Do you think everybody is capable of thinking for themselves? (S.C)

Frame: (S.C) is explicating

Disparate levels of cognitive ability are finally defined as the deciding factor second only to motivation. 
Application

Comprehension

Comprehension

Analysis

Application

Application
47. Is everybody intellectually able to do what Emerson is suggesting? (S.A)

48. Aren't there people that have trouble just functioning independently? (S.D)

49. They wouldn't understand these concepts right? (S.E)

50. The question is, who are these people going to follow? (S.A)

Consensus is here reached after following the "anybody can be anything” pop-culture platitude to fruition; a dead end.

51. If everybody in the United States became a nonconformist ? (S.D)

52. Without rules and laws who would be left? (S.B)

*The lesser volume of questions here is due in great part to greater elaboration on each question by the students.

\section{Lesson Seven Summary:}

In this lesson, I was more concerned with students taking their own thought processes to fruition than using specific terminology-at first. However, once the students showed a willingness to explicate their own value structure (steeped in the hypothetical realm), I then pointed them in the direction of the connection to the text. Once this textual connection was established, the specific word choices and phrases of Emerson were propondered.

What I learned here is that, generally speaking, teenagers are able to contemplate and even quantify to some extent, the intricacies of issues that they themselves deal with every day are themselves difficult to articulate, but again have trouble seeing from another's abstract perspective. Could it be that Kohlberg's studies showing adolescent egocentrism up until age 30 (and beyond) is also the product of a public school curriculum that doesn't lay the foundations of said critical thinking? 
After all, learning is incontrovertibly sequential. Therefore, if that sequence breaks down, as Piaget and Erikson suggest, and several essential sequences are skipped (read middle school, and in many high school courses) then how can this mature adult thinking be taught in a vacuum?

The next lesson, along with previous less encompassing attempts, seeks to define particular literary terminology as the currency of thought to be bartered as ideas expressed. Unlike past attempts, the next lesson will focus on the language first-followed by the incipient idea, rather than the inverse posthumous labeling (i.e. I return to deductive logic now).

Taxonomic Questions Transcribed Student Addressed Level Intended

Lesson Eight: Preparation for Whitman/poetry terminology

Frame: "Peace is always beautiful" (Walt Whitman).

Application $\quad$ 1. Is that true? (S.A)

Application 2. Is it always beautiful? (S.D)

Frame: Other than if you are an anarchist.

Application $\quad 3$. Is it true or not? (S.A)

Application 4. O.K. so what is your idea of peace? (S.E)

Comprehension 5. So you're talking about a state of relationships with no drama going on? (S.E)

With only minor prompting, the student is able to follow his own, off the cuff knee-jerk, reaction to its' proper underlying assumptions that illustrate his egocentric desires untempered. 
Frame: If you open this up to a national or international level...

Comprehension $\quad$ 6. In that case, would we agree with this? (S.E)

Frame: At this point, Whitman is being discussed within the context of the other writers read thus far in the semester.

Knowledge

7. In the beginning, what were the early writers writing about? (All students)

Comprehension 8 . What kind (genre) of writing was it? (S.B)

Analysis $\quad$ 9. Based on what kind of ideas? (S.E)

Frame: From Jefferson to Franklin (the revolutionaries)

Analysis $\quad 10$. What kind of topics did they move from to? (S.D)

Comprehension 11. By the end of that colonial period, what was Franklin writing about? (S.E)

Comprehension 12. The next group of writers that we get into is ___? (S.D)

Frame: Writers of mostly fiction.

Analysis

13. Why is it possible that they're able to write about something other than real life at this point? (S.D)

Frame: Social turmoil has subsided-farming is productive...

Application 14. What kind of fictional topics did these authors write 
of? (S.D)

Frame: Generalizing about Romantic themes.

Application 15. Basically the theme is man in what kind of setting? (S.A)

Comprehension 16. Man who wants to change what? (S.B)

Frame: First we go through short stories.

Application 17. According to Poe, what is the definition of a short story? (S.C)

Frame: At this point, poetry terminology is defined on the board.

Knowledge

18. Does everybody have the journal copied from the board? (All students)

Frame: A list of romantic poets (previously discussed) is given.

Application

19. What kind of subject matter do they generally write about? (S.D)

Not one to miss an emergent pattern, the student here is being asked to hone his articulatory abilities using content specific literary terminology as his medium.

Frame: "In order to understand poetry, you need to under- stand some central terms that are used to describe poetry."

Comprehension 20. What is theme? (S.E) 
Application

Application

Comprehension

Knowledge

Knowledge

Comprehension

Comprehension

Knowledge

Comprehension

Knowledge

Comprehension

Knowledge
21. All poetry works on what kind of a basis? (S.D)

22. What's the function of all poetry? (S.D)

23. In almost all poetry, we see what device? (S.E)

24. A metaphor is $?$ (S.E)

25. The definition of a metaphor is what? (S.E)

Frame: Theme and metaphor (concepts) are reviewed.

26. Give me an example of a theme and a metaphor: (S.D)

Frame: "Instead of saying love, love, (theme), the poet is talking about the parts and components of the rose."

27. Does that make sense to you? (S.A)

28. What other terms do we have from our poetry notes? (S.A)

29. When we're talking about rhythm, what are we talking about? (S.C)

30. The meter is what? (S.C)

31. When we have a "Shakespearean sonnet" it is written in iambic pentameter - which means what? (S.E)

32. "Penta" means what? (S.A)

Frame: S.D and S.E are cajoled to remember these terms from creative writing class. 
Comprehension 33. Rhyme scheme has to do with what? (S.E)

Frame: We're looking at the last syllable and...

Application

34. How it what? (S.D)

Frame: A short poem is written on the board.

Application

35. How are we going to label this (rhyme scheme), we're going to start with what? (S.E)

Frame: Rhyme scheme is labeled on the board example.

Application

36. Could you label a rhyme scheme like this on the test? (S.B)

Comprehension 37. Could you do that for me on Monday if we have a quiz? (S.A\& S.C)

Frame: Still discussing rhyme scheme

Comprehension

38. We don't necessarily get a lot of that though, if we have what kind of poetry? (All students)

Comprehension 39. What does "free verse" mean? (S.D)

Analysis

40. What's the down side to rhyming poetry? (S.E)

Comprehension

41. What else? (S.A)

Once able to experience a modicum of success, she now feels confident (partially due to her outside of class readings) to make some broad based generalizations regarding the subject at hand (the effect of the language pattern on the reader). 
Analysis

Synthesis

Application

Comprehension

Knowledge

Application

Comprehension

Application

Comprehension
42. For instance, if our theme was death, do you think it would be all that appropriate to have a rhyming poem? (S.A)

Frame: Theme example on board is changed to death and the metaphor for love is erased.

43. What would be a good metaphor for death? (S.B)

44. Who wrote about these concepts? (S.C)

45. What author's poetry is very similar to Poe's, that we're going to get to after Whitman? (S.B) Outside interests are here gleaned as a method of drawing another heretofore passive learner into an active analysis of stylistic comparison of somewhat similar author.

Frame: All terminology on board is briefly reviewed.

46. What other terminology did we mention last week? (S.C)

Frame: "When we read 'The Raven' though we didn't apply it much..."

47. "Sensory details" describe what (term)? (S.D)

48. When we talk about sensory details, what are we talking about? (S.B)

49. Based on the ? (S.B)

50. How many senses do we have? (S.B)

Frame: So we're using our senses to create a mental picture. 
Comprehension 51. Give me an example: (S.E)

Knowing the student has internalized this concept (and its commensurate application), I now draw him into the fray.

Frame: 'I'm going to give you a word; you're going to give me a sensory detail to describe it."

Synthesis 52. "Rock"? (S.E)

Comprehension 53. Can you see, feel, touch, smell, or hear that word? (S.E)

Synthesis

54. "Tree"? (S.D)

Application

55. Can we see, feel, touch, smell, taste "shade"? (S.D)

Frame: There is a mental picture that is associated with these words.

Synthesis

56. Try for me "water": (S.A)

Frame: Yes to "cool".

Application

57. Refreshing is a little more abstract, can you think of anything else? (S.A)

Though this is the first time I have tacitly differentiated

between concrete and abstract phraseology, she inductively

comprehends that the abstract must be defined concretely.

Synthesis

58. “Grass"? (S.B)

Application

59. "Soft," O.K. but what else could we say about "grass"? (S.B)

Comprehension 60. What other terms do we really need to define and 
work with poetry? (All students)

Frame: Alliteration is a "literary device."

Application 61. What does alliteration mean? (S.E)

Application 62. What would be an example of that? (S.C)

Comprehension 63. What's the sound being repeated? (S.B)

Comprehension 64. Questions about alliteration? (S.A)

Comprehension 65. Can you think of one? (S.A)

Tempted to give an example and non-example from which to choose, I wait; it works!

Comprehension 66. (S.B)?

Comprehension 67. (S.C)?

Frame: In prose we have paragraphs...

Application 68. What's the equivalent in poetry? (S.A)

Frame: Personification is another literary device.

Comprehension 69. Personification is where we take $?$ (S.D)

Frame: "This is especially addressed to you girls, since the guys have had these terms before."

Application

70. Will we be able to take these literary terms, that we've had so far, which have to do with describing poetry - and apply them? (All girls) 
Comprehension 71. Can we do it? (All girls)

Comprehension 72. If I ask you to identify, say stanza three, in a poem we're looking at tomorrow - can you do it? (All girls)

Comprehension 73. Does that sound easy? (S.A)

Comprehension 74. Would you be able to find the alliteration? (S.A)

Comprehension 75. Could you do that? (S.B\& S.C)

Comprehension 76. If I ask you to cite examples of "Imagery" from a poem that we read tomorrow, could you do that? (S.E)

Comprehension 77. Could you find "Imagery" in the poem? (S.E)

Comprehension 78. If I asked you to simply define for me "free verse" could you do that? (S.A)

Comprehension 79. What doesn't it necessarily have? (S.A)

Comprehension $\quad 80$. If I asked you to label rhyme scheme, could you do that? (S.B)

Comprehension 81. Could you pick out what the "metaphor" (in the poem) is, Given that you have had lots of guided practice? (S.D)

Comprehension 82. S.A?

\section{Lesson Eight Summary:}

More than anything else, here I was trying to draw in each students interest in a particular facet of an issue (connected to past classroom situations) to create the emotional connection to the revisited topic- hoping new student insights would be articulated in a refined oratory using 
the appropriate vocabulary. I learned that students really do need to have a high level of comfort with the terminology to break out of old speech patterns (that fall back on vagaries that lead to eventual student frustration). Next, I will try to synthesize the vocabulary and personal connection to the issues in the upcoming taping.

Taxonomic Questions Transcribed Student Addressed

Level Intended

Lesson Nine: Whitman's Poetry

Frame: Students are taking turns reading "When I Heard the Learned Astronomers".

Analysis $\quad$ 1. First define the theme here, then try to relate this back to Emerson and Thoreau: (S.D)

He guesses, "self-reliance" without making the connection.

Frame: "That's part of it."

Application 2. What do you think the theme is? (S.D)

Frame: "Your on the right track, it's about being alone."

Comprehension 3. What did Emerson say? (S.D)

Previous criteria is now used to define the current analogy.

Frame: "Self-reliance"

Application 4. So what is Whitman saying about the way that this astronomer is interpreting the stars? (S.D)

Working through the "zone of proximal development", the student is finally able to lucidly quantify the correlation.

Frame: S.A says the speaker is relying on the astronomer. ...but there is more to it than that... 
Application

5. Add to that: (S.E)

Examining the text closely, his initial oversimplification is now layered upon to validate the complex variables affecting the speaker of the poem's theme.

Comprehension 6. Is that what you're getting from this? (S.B)

Comprehension 7. It's an individual thing right? (All students)

Comprehension 8. So it is individualism right? (S.D)

Frame: "So our theme is individual interpretation."

Application

9. So what's the metaphor here? (S.B)

Frame: "Let's discuss what kind of poem this is..."

Application 10. Why do we say it's "free verse"? (S.A)

Frame: Students discuss free verse.

Application 11. What is the meter or rhythm? (S.C)

Comprehension 12. How many syllables do we have in the first line? (S.A)

Comprehension 13. How many do we have in the second line? (S.E)

Application 14. What do you think? (S.C)

Comprehension 15. How many beats do we count? (S.C)

Comprehension 16. How about the third line? (S.D)

Comprehension 17. How many syllables do we have there? (S.D) 
Application

Application

Application

Comprehension

Comprehension

Comprehension

Application

Application

Application

Analysis

Analysis

Application
18. Do we have an even meter to this poem? (All students)

19. What do the stanzas look like? (S.A)

20. Does there seem to be any kind of set grouping? (S.A)

21. How many stanzas are there? (S.A)

22. Where does the first stanza start? (S.E)

23. How about the last stanza? (S.C)

Frame: "This is definitely a free verse poem. How about literary devices..."

24. Do we have any literary devices that, as we go through, we could pick out? (S.D)

25. Do we have any kind of internal rhyme scheme (alliteration)? (S.E)

Frame: Other literary devices...

26. Do we see any kind of personification here? (S.A)

27. What is your impression of the speaker of this poem? (S.B)

The recall and synthesis of complex variables orchestrated into a singular theme- still does not come without prodding.

28. How would we describe this person? (S.C)

29. Anything else we could say about this speaker/narrator? (S.A) 
Comprehension 30. Anything else we could add? (S.B)

Application 31. Why do you think the speaker in this poem leaves the lecture room? (S.D)

Application

32. Where are the roots of Whitman's ideas? (S.D)

Comprehension

33. What other literature did we just read? (S.D)

The student is now able to recount the strands of selfreliant ideology as they historically relate to Whitman.

Frame: Scientific or naturalistic approach to seeing things

Analysis

34. Which approach do you favor - and why? (S.E)

Frame: Student says "natural."

Comprehension

35. ...but on the other hand, aren't you planning on going to law school? (S.E)

Comprehension

36. ...but aren't there some things that you will need to break down and understand the component parts of? (S.E)

Again, the grasp of the generalization does not lead to the analogy of building a legal case based on empirical fact.

Analysis

37. Which one (viewpoint) do you appreciate most? (S.D)

Frame: The speaker in the poem

Comprehension 38. Anybody disagree with that? (S.C)

Comprehension 39. Could we improve our volleyball game if we didn't look at the specific statistics... and videotapes once 
in a while? (S.B)

Frame: Just going out and having fun.

Application

40. Would that give you the kind of results (improvement) that you wanted? (S.B)

Frame: In reference to (S.E's) previous commentary on Whitman:

Comprehension

41. Do you now agree more with his point of view? (S.E)

Comprehension

42. You still think you're going to have a difference in philosophy with him? (S.E)

Frame: Students read “One’s Self I Sing”.

Application

43. How does this particular poem relate to the (daily journal) quote? (All students)

Comprehensive

44. Would it surprise you to learn that we have an abbreviated version of this poem in our text and that the quote is another line of the original complete poem? (All students)

Comprehension

45. Now we have some language here; what does "en masse" mean? (S.B)

Comprehension

46. When we're talking about "physiology" we're talking about __? (S.A)

Application 47. Who were the muses? (S.C)

Comprehension 48. What is immense? (S.D) 
Comprehension 49. If it is immense it is ? (S.B)

Knowledge

50. Do we have a (foot) note on that? (S.A)

Frame: "The modern man I sing" (Walt Whitman).

Comprehension 51. Is he talking just about the man? (S.A)

Comprehension 52. What's he talking about? (S.D)

Application 53. So what's the theme of the poem? (S.D)

Comprehension 54. Equality right? (S.A)

Comprehension 55. So he's talking about what kind of appearances? (S.A)

Evaluation

56. What's the most memorable line in this poem? (S.E)

Evaluation

57. S.C?

Frame: "The female equal to the male..." (Walt Whitman)

Application

58. That line is most illustrative of what, theme or metaphor? (S.C)

Application

59. Is there any real metaphor that he's using here? (S.B)

Application

60. What are some of the topics that Whitman will "sing" about? (S.C)

Comprehension 61. What else? (S.A)

Application 62. What was the idea (theme) from the last poem, and 
where do we see that again in this one? (S.E)

Comprehension 63. What was the theme of the last poem? (S.D)

Frame: "Individualism"

Comprehension 64. Where do we see that (here)? (S.D)

Application 65. "Simple and separate" is also an example of what literary device? (S.B)

Comprehension 66. How many stanzas do we have here? (S.C)

Analysis 67. Any particular reason you think he grouped these the way he did? (S.A)

Application 68. He's talking about what topic in the first stanza? (S.C)

Frame: "Yes, individualism and..."

Comprehension 69. At the same time, you are part of what? (S.E)

Application 70. Second stanza, what's the idea he's trying to convey here? (S.C)

Application 71. Third stanza? (All students)

Application 72. What do you think Whitman means by the phrase "modern man"? (S.B)

Comprehension 73. "Modern man" in his estimation, also takes into account, what (other group)? (S.C)

Analysis $\quad 74$. So what were some of the ideas that Whitman was talking about, and is this a follow-up of Emerson and 
Thoreau? (S.E)

Correctly assessed, the student rightly differentiates between Whitman's social issues and the transcendentalist's focus on free thinking through a personal locus of moral operation.

Application

Application

75. How does he, Emerson and Thoreau want to interpret things? (S.B)

Frame: Emerson - in terms of non-conformity...

76. Felt that it was important that you figure out what? (S.A)

Comprehension 77. I gave you a term called free $?$ (S.D)

*For the rest of the period, the students are asked to apply the poetry terminology (a written self-directed activity) used to a new, previously unread, poem by Whitman.

\section{Lesson Nine Summary:}

Though I do feel that I am finally working in these students' respective "Zones of Proximal Development", the apathy towards thoughts not of their own origin (immediate interest) combined with the intricacies of language precision also not present (in their heretofore untapped cognitive abilities) and a genuine lack comprehending the value of these higher-order thinking skills, are all exceptionally difficult disparate factors to overcome without an incredible amount of trust and showmanship. It is no wonder so few teachers attempt to take students to this level of thought (even if they themselves could conceive of teaching it).

I can't help wondering if it would be an infinitely more accessible endeavor for the high school teacher if more middle school teachers would genuinely force (force in middle school?) students to attempt difficult reading material on their own before generating a list of answers for students to memorize before each test.

Of course that would also mean moving away from whole language (which incidentally is NEVER EVER used to remediate reading skills) to facilitate students assimilating new vocabulary based on their working knowledge of phonetics, spelling rules, root words and pre/suffixes. Even if given these edicts were in place, would any of these (mid-level) teachers attempt to meet 
these standards without more stringent standardized testing at each and every grade level?

Taxonomic Questions Transcribed Student Addressed

Level Intended

Lesson Ten: Explicating Dickinson

*Abbreviated class period (only 30 minutes) due to an assembly

Frame: "That such have died enable us the tranquiller to live" (Emily Dickinson)

Application 1. What's the interpretation on that? (S.A)

Application 2. (S.D)?

Comprehension 3. Anything you could add to that? (S.E)

Comprehension 4. Anything to add? (S.B)

Comprehension 5. (S.C)?

Comprehension 6. What did we say Dickinson was preoccupied with and wrote about all the time? (S.A)

Application 7. This all falls under the heading of what genre of writing? (S.D)

Comprehension 8. What other authors' (ideas) is she building upon? (S.B)

Frame: Brief Dickinson biographical introduction (lecture) here

Comprehension 9. Are you taking notes on this, it may be on the test? (S.E) 
This comment is particularly appropriate to the student since he tends to rely upon concept generalizations that capture the gist of the information internally- yet when asked to write an essay or justify an in class opinion, the student falls back on poorly articulated vagaries.

Application 10. Who else is living at this time? (S.E)

Comprehension 11. What about the authors that we've already read that were living during this time? (S.B)

Frame: Poe was already dead by the end of this time period.

Comprehension 12. Hawthorne, does this work for him? (S.D)

Comprehension 13. Who were the two transcendentalist authors we just read? (S.D)

Frame: "Dickinson would have known the work of all the authors we have read."

Application

14. Why would those authors have not known her work?

(S.C)

Again, I here rely upon outside interest in the author to draw this introverted student into the discussion.

Application

15. Why did she withdraw from society? (S.D)

The abstraction from yesterday's short introduction describing her affair with a married man doesn't register as a fact that can be extrapolated and applied.

Comprehension 16. What problem did she deal with in her daily life? (S.D) 
Application

17. Do you think she was a happy person? (S.D)

Frame: She had an affair with a married man who moved away.

Comprehension 18. Apparently, what happened here? (S.B)

Cause (jilted) and effect (seclusion) is correctly

hypothesized here.

Comprehension

19. What's that? (S.C)

Frame: "Yes, self-exile"

Application

20. Why would she dress exclusively in white? (S.A)

Application

21. What do you think she was trying to prove? (S.A)

Thinking that having read Dickinson's Biography would prove a boon to speculatory prowess, I try to get the very concrete thinking student to speculate.

Application

22. Any thoughts on why she would have dressed exclusively in white? (S.D)

Frame: "Think about this for a second."

Comprehension

23. What if the guy came back from California and ask around about what Emily had been up to? (S.A)

I really don't want to let this student off the intellectual hook (confidence in her thought process needs to be bolstered) so, I add a narrower frame.

Application

24. ...but what else, if we said that white is a symbol of ? (S.B)

Frame: "With most authors no, but with Dickinson her 
life influenced her work."

Application

25. What did Poe's poetry look like, in terms of the way he laid it out on the page? (S.C)

Frame: Poe's poetry layout is contrasted with

Dickinson's stanzas and lines.

Comprehension 26. What did we say a stanza does? (S.D)

Comprehension 27. What did we say a metaphor was? (S.A)

Comprehension 28. So what is that? (S.D)

Comprehension 29. Personification, we said, is what? (S.E)

Comprehension 30. A simile is a comparison using _ or__? (S.B)

Frame: Student reading of Dickinson excerpt "My letter to the world".

Analysis

31. What are we seeing in this poem, that we didn't see in Whitman? (S.A)

Here she is willing to make the physical comparison.

Comprehension 32. So, if we're going to label the rhyme scheme here, how are we going to do that? (S.C)

Frame: "So we do have a definite rhyme scheme."

Application 33. How about meter or rhythm? (S.B)

Frame: The first and third lines, etc...we see a repetitive pattern. 
Application

Application

Application

Comprehension

Comprehension

Application

Application

Comprehension

Application

Comprehension

Comprehension
34. What kind of an effect does that create? (S.E)

35. Does it make it more or less memorable, the poetry? (S.B)

36. Why do you think so? (S.B)

37. If that's the case, do you think you'll remember more of the text and the words? (S.B)

Frame: "Well, let me ask you this."

38. How long does it take you to remember words to a new song that you like? (S.D)

39. Now, how long does it take you to remember a paragraph that doesn't rhyme and your not that interested in? (S.D)

Frame: "This is my letter to the world that never wrote to me" (Dickinson).

40. How does she feel about the world? (S.A)

41. Do you have something to add? (S.E)

Frame: "Simple mood of nature told with tender majesty" (Dickinson).

42. What do you think she is speaking of there? (S.C)

43. What does the word "romance" mean? (S.B)

44. Do you think it was a love that was returned? (S.C) 
Frame: "her message is committed to hands I cannot see" (Dickinson)

Application

Application

Application

Analysis

Application

Application

Application

Application

Analysis
45. Who's the "her"? (S.B)

46. Who's hands do you think she might have been referring to? (S.A)

47. So, what's the overall theme that she's working with? (S.D)

48. What is your impression of the speaker in this poem? (S.C)

All of the speaker's character traits are correctly synopsized, based on her intuition.

49. What are her feelings at this point? (S.B)

Paraphrases synonyms for sadness.

50. What can you infer, from her statement "no-one wrote back"? (S.A)

Frame: "Simple news that nature told" (Dickinson).

51. What does this suggest about Dickinson's feelings for nature? (S.D)

52. Does she appreciate the beauty of nature? (S.A)

53. What does she want her readers to think about nature? (S.B)

Language (vocabulary) used by the poet still cannot be correctly asserted as a specific necessary to the full unencumbered message of the writer. *Fear of new words begins in the middle school (whole language). 
Application

Analysis
54. What does she expect her readers to get out of this? (S.A)

Frame: Since only a handful of Dickinson's poetry was was published in her lifetime.

55. Do you think she expected to become famous after her death? (S.D)

Already asked in a previous lesson, this query is designed to layer new factors into the students broader comprehension of the affects on the author while testing his ability to accurately convey those ideas.

\section{Lesson Ten Summary:}

As much as possible, I tried to keep this lesson at the analysis level of cognitive operation. Students were, in fact, able to break down complex issues and ideas into subsets; my hard work is paying off, in terms of thinking skills- but is extremely limited in terms of getting students to internalize new terminology that conveys the specifics of our in-class explications. Plus, cognitive ability change is almost non-existent in terms of applying these new higher order skills to their essay assignments. Next, I will delve deeper into the criteria used to judge previously read authors' worth (contribution to the literary canon).

Taxonomic Questions Transcribed Student Addressed Level Intended

Lesson Eleven: Comparison \& Contrast of Authors (layout of final essay)

Frame: Ultimately, we're going to compare and contrast.

Application $\quad 1$. ...but what's another type of layout that we can use? (S.A)

Comprehension 2. How are you going to lay yours out? (S.A) 
Analysis

Analysis

Analysis

Analysis

Comprehension

Comprehension

Analysis
3. What are the commonalties between these authors?

(S.A)

Students have been conditioned by teachers to quip "I don't knows" almost as a reaction to anything that's not blatantly obvious. I realize that the language, not the question (as is most often the case) is the problem.

4. What kind of things are the same, that we can group? (S.A)

I give her a look that says, "this test of wills will not get you off of the hook". Based on previous class discussions and a knowledge of her introverted tendencies, I know today is one of those days when she is on the verge of getting angry, which sometimes will draw her out.

Frame: Students' three authors (chosen) listed on board.

5. What kind of similarities are we going to look at here? (S.A)

Finally she creates categories.

Frame: Daily quote on "Duty" (Robert E. Lee)

6. How did these three authors feel about duty? (S.E)

Frame: Doing the things you don't want to do.

7. Is that true? (S.B)

8. Do you ever get that (sublime) feeling when you've done your duty? (S.E)

9. What are some other similarities that we can discuss between Hawthorne and Poe? (S.D) 
Student goes into the similar story settings and character motives.

Frame: The notes on the board about similarities (schooling).

Application

10. This is also going to spur what? (S.A)

Frame: Geographic region as an influence on these authors

Knowledge

11. Didn't we talk about this one (factor) too the other day? (S.A)

Knowledge 12. Hawthorne was from? (S.D)

Knowledge 13. Poe was from? (S.B)

Frame: Poe $-\mathrm{v}-$ Hawthorne

Application 14. Who do you think probably did more traveling though? (S.E)

Based on his remembrance of Poe's tumultuous life he recounts many of Poe's travels.

Comprehension 15. As a child his (Poe's) parents were what? (S.C)

Comprehension 16. What else are we going to talk about, similarities and differences? (S.A)

Frame: "For those of you covering other authors (in your essays)...

Application 17. Who else spent a lot of time in isolation? (S.C) 
Application

Comprehension

Comprehension

Knowledge

Comprehension

Application

Comprehension

Application

Comprehension

Application

Knowledge
18. What do you think this created for theme these authors, spending time in isolation? (S.B)

19. Anything else we could get in and maybe discuss about these two (Hawthorne and Poe)? (S.E)

Frame: Student asks why Hawthorne wrote the number 64 over and over before he died.

20. By the way, how old was Hawthorne when he died? (S.A)

21. So who's our third author here (to be compared in your essay)? (S.A)

22. Where did Twain get a lot of his traveling in; two different time periods in his life? (S.E)

Frame: "Steamship travel in 1830's - 1850's and then..."

23. He traveled a lot again when? (S.B)

24. Did Twain spend much time in isolation? (S.A)

25. If he did, what did it cause? (S.A)

26. What else (other comparison or contrasts) can we get in with Twain? (S.A)

27. How can we take this comparison/contrast of Hawthorne, Twain, and Poe, who all were contemporaries, and apply it to other authors we've read Who weren't alive at the same time? (S.C)

28. Who are we discussing in your essay? (S.C) 
Application

29. How much of this information (listed on the board) can we apply to Emerson and Dickinson? (S.D)

Frame: Dickinson's Education

Comprehension 30. Famous girl's preparatory school was called? (S.D)

Frame: Isolation (on board) as a comparison

Application

31. Does this apply (pointing to board)? (S.D)

Application

32. How about education, what are we going to talk about here? (S.D)

Comprehension 33. Were they all three educated? (S.D)

Application 34. To what extent and how (course of study)? (S.D)

Application 35. How about parents (as a factor in comparison)? (S.D)

Comprehension 36. Wasn't Dickinson a teenager when her parents died? (S.A)

Frame: Discussing Dickinson, Emerson, and Poe

Application 37. When did they become famous? (S.C)

Application 38. What about their life experiences? (S.D)

Comprehension 39. Are those different? (S.D)

Comprehension 40. What geographic regions are they coming from? (S.D)

Frame: The three authors motivation to write... 
Comprehension

Application

Comprehension

Comprehension

Knowledge

Comprehension

Comprehension

Application

Comprehension

Comprehension
Application

41. ... and Emerson didn't have to write for a living because predominately he was making enough money as a ? (S.D)

42. What else can we take (extrapolate) from our brainstorming activities here on the board? (S.D)

43. What other similarities and differences can we work with? (S.D)

44. Do you think you have enough (notes) for three pages there? (S.D)

45. Who are the authors you're working with? (S.E)

46. Jefferson and Franklin, they both lived and were instrumental in what period? (S.E)

47. First of all, where are they from geographically? (S.E)

Frame: "Franklin, on the other hand was from the Boston area, but..."

48. Predominately made his impact when he lived in ? (S.E)

49. What about education? (S.D)

Frame: Franklin as a Renaissance man

50. What were some of the areas where Franklin contributed? (S.E)

51. What were some of the things Franklin did? (S.D) 
Frame: Both Jefferson and Franklin received a lot of respect during their lives...

Comprehension 52. How about Poe? (S.D)

Comprehension 53. Did Poe ever gain a lot of respect in his lifetime? (S.E)

Comprehension 54. What kind of (genre) writing did Jefferson and Franklin do? (S.D)

Frame: All were instrumental in shaping.

Application 55. Instrumental in shaping what? (S.B)

Knowledge 56 . What do you have so far, read it back to me: (S.E)

Frame: Student reads off his notes.

Comprehension 57. How long should a short story be according to Poe? (S.E)

Frame: Franklin's plans and organization

Comprehension 58. How would we say that? (S.E)

\section{Lesson Eleven Summary:}

The comparison/contrasting went well, with students themselves generating many of the categories for discussion. Some (two) of the students are actively trying to manipulate me into believing they do not understand the subject matter in order to avoid writing the final essay. Unfortunately, students believe they have a choice 'not to' here when parents, administrators and sometimes even (pitiful) English teachers facilitate this behavior with statements like, "Well, they just don't do very well with writing, but that's no reason to fail the course". WRONG!

Writing lucidly phrased ideas that are comprehensible to others facilitates critical thinking. Let me rephrase that in another way: If students are never made to be precise with the rules of 
writing (which is a proven schematic boon to organization) or even attempt it, then those students will never be able to operate on the synthesis level when dealing with complex life issues. I know from personal experience that I could not even begin to express complex relationships (part to whole) until I began crafting empirically organized essays as the roadmap for my own learning.

Again, middle school short-sighted mentality here prevails! Even Beethoven who composed entire symphonies in his head had to write his notes down on paper as an organizational device that he, himself, could manipulate and refine, not to mention the loss to all of society had he never written his music for all to see, study and re-create for eons to come. No, writing well is not optional, it is essential to learning!

Taxonomic Questions Transcribed Student Addressed Level Intended

Lesson Twelve: Course recap/final essays discussed

Frame: "The brightest are the tenderest, the loving are the daring" (Longfellow).

Application $\quad$ 1. What do you think about this? (S.A)

Application 2. Was Henry Wadsworth Longfellow correct in making this assertion? (S.A)

Application 3. Why? (S.A)

Application 4. Reaction? (S.B)

Frame: "We're talking about trying to get underneath the surface..."

Application 5. To what? (S.A)

Application 6. What's underneath the surface? (S.A) 
Application $\quad$ 7. What compels somebody to do something? (S.E)

Comprehension 8. What else? (S.D)

Comprehension 9. What's underneath the surface? (S.D)

Frame: In terms of the law

Application 10. What do they look at in crimes? (S.E)

Application 11. And? (S.E)

Comprehension 12. So what's Longfellow saying about motives and intentions here? (S.C)

Comprehension 13. Elaborate? (S.C)

Frame: Student questions the syntax of the quote.

Comprehension 14. You think it would be better the other way (inverted)? (S.D)

Application

15. So why does he say it (write) this way? (S.D)

Frame: Referring to Jefferson's passion for the revolution

Application 16. What did he do for it? (S.B)

Frame: Form the Revolutionary to the Civil War

Comprehension 17. What's the time span? (S.B)

Comprehension 18. How much time are we talking about? (S.B)

Knowledge 19. When, then, is the beginning of the Civil War? (S.E) 
Knowledge 20. Who did the revolutionary authors? (S.C)

Application 21. What were they concerned with in the 1770's80 's? (S.C)

Comprehension 22. What was the central focus of the writings? (S.C)

Comprehension 23. ...free from the oppression of __ ? (S.C)

Frame: "After we win the Revolutionary War, Jefferson helps pen..."

Comprehension 24. What famous document? (All students)

Application 25. By around 1800, how has the mood changed in this country? (S.D)

Application 26. What has changed in that thirty year period? (S.A)

Comprehension 27. They were more relaxed because ? (S.E)

Frame: Student discusses leisure time and agricultural productivity.

Comprehension 28. Is that what you were going to say? (S.B)

Frame: "The next major change in American literature comes in the 1830's."

Comprehension 29. Who was the predecessor of Hawthorne and Poe? (S.C)

Frame: Dealing with another type of oppression

Application 30. What is Hawthorne concerned with in "The Minister's Black Veil" or "Young Goodman 
Brown", you guys read those? (S.B)

Loss of faith is correctly recounted.

Knowledge

Comprehension

Comprehension

Comprehension

Application

Comprehension

Comprehension

Application

Application
31. Has anyone read "Young Goodman Brown"? (All students)

32. Hawthorne set a lot of his stories during what time period, because of his grandfather? (S.B)

Frame: Hawthorne was concerned with religious/ personal freedom as a romantic.

33. What were the romantic authors concerned with generally? (S.D)

34. And ? (S.D)

Frame: Personal freedom

35. What's the tie-in to Jefferson? (S.A) Improving mans' life quality; she gets it.

36. .... and Franklin, Henry, etc...? (S.C)

37. What's the tie-in between Hawthorne and the Revolutionaries? (S.C)

38. How did the revolutionaries deal with freedom? (S.E)

They created it (he sees the big picture).

39. So Hawthorne's writing about what? (S.D) Freedom of choice (viola!).

Frame: Hawthorne's didactic conclusion discussed 
Application

Application

Comprehension

Comprehension

Application

Application

Comprehension

Comprehension

Application

Analysis

Application
40. What happened at the end of "Dr. Heidegger"? (S.B)

41. Hawthorne is concerned with showing man's what? (S.A) Selfishness (she comprehends)

42. What kind of writing, genre did Hawthorne work in? (S.E)

43. Approximately how long were most of Hawthorne's stories? (S.B)

44. Did they fit Poe's definition of short story? (S.D) He correctly recounts Poe's criterion.

45. Hawthorne was writing from what point of view? (S.E)

46. "Omniscient" means what? (S.E)

47. “Omni” means $?$ (S.B)

Frame: Poe influenced by Hawthorne. "Poe comes along and..."

48. What was the situation with Poe? (S.B)

Frame: Hawthorne concerned with man changing man for the worse.

49. What was Poe's overarching theme? (S.C) She guesses death and gloom-again too general.

50. Do you think Poe ever really fit in anywhere? (S.C) 
Frame: Student discusses Poe's fears.

Comprehension 51. ...about what? (S.C)

Application 52. Did he ever really have anything to hang onto? (S.C)

Application 53. What was the one thing that Poe had? (S.A)

Comprehension 54. Before Virginia (his wife) and after her, how did he feel? (S.B)

Application 55. Where was he coming from? (S.B)

Application 56. So what kind of writing did he tend to do? (S.D)

Application 57. Elaborate, when you say "dark" you mean _ ? (S.D)

Comprehension 58. In the beginning of his life he wanted ? (S.D)

Application

59. Why do you think Poe married someone a whole lot younger than he? (S.E)

Application 60. What is he concerned with showing (themes) in his short stories? (S.B)

Comprehension 61. What's "The Mask of the Red Death" about? (S.A)

Application 62. Do you think there were people in Poe's life that he wanted revenge on? (S.C)

Here the Socratic method comes full circle to zero in on the nature of the question (which, when dealing with people, always centers around motivation). 
Comprehension

63. He probably entertained a lot of thoughts of revenge against his uncle, don't you think? (S.E)

Providing a key example spurs his recollection of Poe's nemesis- and his handling of Poe's roadblocks.

Comprehension 64. What was the real life inspiration for "A Cask of Amontillado"? (S.D)

Comprehension

65. Remember, Poe is the father of not just horror, but the modern story? (S.E) Again checking to see if any specific information made it into this student's (normally non-existent) notes.

Application

66. If Poe's horror stories are concerned with revenge; what are the detective stories about? (S.B) Doesn't see the connection and guesses "Who dunnit".

Application

67. If the short stories are about revenge, what are the poems about? (S.A)

Is cognizant of the effect of Virginia's death, but is unable to open it up into an all encompassing theme.

Application

68. The poetry was primarily concerned with what? (S.C)

Frame: "Lost love"

Comprehension

69. What's Annabel Lee about? (S.C) Since deductively drawing conclusions doesn't work, I'm hoping that inductively she can break down the specific themes into broader categories.

Application

70. What literary device does Poe use in all of his poems? (S.B) 
Frame: A refrain in all of his poetry

Application 71. Why do you think Poe does that? (S.A)

Frame: The repetition

Comprehension 72. Had anybody ever really done this before Poe? (S.B)

Frame: Although Annabel Lee is romantic it's not Gothic.

Application

73. ... on the other hand, what's "The Raven" like? (S.A)

Frame: Poe's short stories revenge theme; poetry lost love

Application

74. Where does Dickinson fit in to all of this? (All students)

Comprehension

75. She was around then right? (S.A)

Application

76. What did she do with the ideas of Hawthorne and Poe? (S.C)

Comprehension 77. Unrequited means what? (S.C)

Application

78. Why did shy write about unrequited love? (S.C) Here, I am trying to reinforce the previously discussed role that her personal life had in shaping her writings.

Application

79. Why was she concerned with death? (S.C)

Frame: Dickinson's affair with the married preacher discussed. 
Comprehension 80. Do you think a preacher in the late 1800's would get a divorce and change their whole life situation? (S.A)

Application

81. Is it likely that the situation would ever change during her lifetime? (S.A)

Comprehension 82. So what was Dickinson waiting for? (S.B)

Frame: Postulation of reasons she wrote

Knowledge 83. Do you know what catharsis means? (S.C)

Comprehension 84. She was also considered a romantic because she talked about what in her poetry? (S.D)

Knowing the student internalized the idea of man in nature, here I am asking him to make the connection.

Comprehension 85. How man or woman, in this case, fits into ? (S.D)

Comprehension 86. Remember the poetry where she talks about things being ripe? (S.E)

Comprehension 87. Wasn't it a bird she uses as a metaphor? (S.E)

Application 88. At first, when he (her lover) leaves, she thinks ? (S.B)

Comprehension 89. At the end of her life, what idea were her poems totally concerned with? (S.C)

Comprehension 90. Do you think she was looking forward to it, at that point? (S.D)

Early thought of death lead to later thoughts of her 
place in nature, the student attempts to quantify.

Comprehension 91. What was her primary purpose for living, as an adult? (S.A)

Frame: Students speak of her lack of job or career and living at home.

Application

92. She was able to do this because she came from what kind of a family background? (S.D)

Frame: All authors thematic ideas are reviewed here.

Application

93. About the same time period as Dickinson and Hawthorne we start to see the emergence of a couple of philosophers: (S.D)

Frame: Emerson and Thoreau

Comprehension 94. Their idea was what? (S.E)

Comprehension 95. Are they romantic writers? (S.B)

Correctly points out that Thoreau spent time in nature.

Application 96. If so, why? (S.C)

Comprehension 97. What broader genre of writing are they working in?

(S.A)

Application

98. Non-fictional because the subject matter was ? (S.D)

Comprehension 99. If Emerson laid out the plan, what did Thoreau do? (S.E) 
Comprehension 100. Who goes out and does it? (S.B)

Comprehension 101. Where does Thoreau go to live? (S.A)

Application 102. What kind of conclusions does he come up with, based on his experiences there? (S.C)

Comprehension 103. Who do you need to consult, in order to make correct decisions in life - according to Thoreau? (S.E)

Frame: The geographical regions of all the writers is recapped.

Application

104. What does Twain talk about? (S.A)

Frame: "If Poe, Hawthorne, and Dickinson are concerned with the dark side of life..."

Comprehension 105. Where's Twain thematically? (S.A)

Points out Twain's comedic nature.

Comprehension 106. Twain wrote about what (subject matter)? (S.C)

Frame: "If Poe and Dickinson are pessimists and Twain an optimist..."

Comprehension 107. Where do Emerson and Thoreau fit in? (S.D)

Application 108. Along with John Fennimore Cooper, Twain was one of our first ___ in this country? (S.E)

Comprehension 109. Because he wrote what two famous novels? (S.B)

Comprehension 110. Was that all Twain wrote? (All students) 


\section{Comprehension 111. What other genres of writing did he work in? (S.A)}

\section{Lesson Twelve Summary:}

Though the nature of this study was to improve my questioning skills- while moving up and down Bloom's Taxonomy-always edging closer to the analysis, synthesis levels with all students, I had the epiphany that- I did take these students to the higher-order thinking abilities that I wished to endow them with.

On the other hand, I was only able to instill (read remediate) a modicum of change in their respective abilities to: read critically, overcome and incorporate new vocabulary, and improve their written organizational and articulatory skills. They became much more adept at critical, sensible, thinking (since they now had a rubric to apply)- but the paradigm shift (read apathy) towards learning reading, writing, and vocabulary skills had not changed significantly. 


\section{Chapter Six: Daily Reflections}

\section{Introduction}

The intent of this chapter is to explicitly acknowledge all of the various criterion that were considered, from the federal (Praxis III), district (Pathwise), and building (Watkins Memorial High School administrators use a state generated form) level assessors up front- prior to discussing my conclusions in the proceeding chapter. For a complete reconciliation of all criteria please see the complete assessment guides located in Appendix B.

\section{Framing the Context}

Time was taken each day, with the daily journal quotes to:

1. Relate the quotation to previous material covered

2. Frame knowledge constructively, by asking students to paraphrase sections of text covered.

3. Engage students by analogizing to a situation they can relate to.

4. Lay out concepts, such as "oppression" (textbook questions) at the end of each literary excerpt.

5. Create a logical coherent lesson by constructively layering a cause and effect relationship in the unit - and by layering national trends and thoughts (based on technological, political and economic advancements) in as well.

6. Hone skills in these taxonomic areas:

- A. Paraphrase (comprehension-level 2)

- B. Interpret meanings (application- level 3)

- C. Analyze and test concepts- level 4 on each excerpt relating authors and their works, one to another, - and -

- D. Evaluate the quality of ideas, complexity of ideas (authorial intent) as well as, how successful, or comprehensible/accessible the author was. 


\section{Question Distribution}

1. Questions are always rotated to all students, but modifications (the level of comprehension) are tempered to hit the specific level of comprehension that each student is at (or near) and thereby work progressively up the taxonomy from there.

2. Students are always encouraged to take risks and speculate - as long as the text is being used as support.

3. Students are praised for finding support for their answers within the text; incorrect answers are remediated by asking students where they are (what specific passage) basing their ideas on.

4. Off task behaviors (unengaged students) are re-directed based on the above (\#3) and by reminding/ reiterating the skills and objectives that the course guide requires them to know (i.e. the class exams/ proficiency tests will ask for evidence of these skills that are stated and taught).

5. All students are being monitored for skill and concept attainment either through in-class discussions or written (essay) assignments to assess the exact working level of knowledge (level of taxonomy mastered).

\section{Level of Taxonomy Addressed}

1. Analogies are custom tailored to each student based on known interests of students: Student E interested in sports cars and wants to go to law school;

Student $A$ - is an abstract thinker needing less concrete grounding who can place herself within the context of the protagonist (higher functioning);

Student $B$ - needs a little situational (real world analogies) prompting to discover connections/correlations with literature (usually based on her volleyball interests);

Student $D$ - thinks abstractly, but must always be shown the relevance (the stakes involved) of an issue to engage in analysis and evaluation, and wants to know authors' life situations as their (the author's) motivation;

Student $C$ - needs an issue of injustice in order to go back and look at the concrete tangibles leading up to an outcome. Many analogies, for her, were of work, school, or family situations. 
2. Every question attempts to challenge students to be concise/precise with their answers - at the highest level of cognition (usually beginning in this Jr./Sr. level course, with application/interpretation).

3. Each lesson begins with a concept(s) in literature attainment. Skills, however, such as paraphrasing, interpreting, analyzing, and evaluating literary genres (and their authors') are ongoing integral parts of the lesson plan design.

\section{Authors/Texts chosen}

The rubric for evaluating and judging these American authors is based upon the articulatory ability of those authors confined within their ability to craft the characters, plot, dramatic suspense, and illustrate other literary devices- as well as to what degree these seminal authors helped define/refine the respective genres they were working within.

\section{Lesson Design}

\section{Each lesson is designed with two overarching considerations in mind:}

1. Each lesson/activity is designed to show the prevailing (concerns) social consciousness of America during the time period and genre that the author was writing in. Therefore, cognitive mastery is an ongoing objective, though mastery of central key ideas and concepts is achieved on a daily moment to moment basis.

2. Students, at the end of a lesson or unit- if designed well- can predict the outcome of individual fiction/non-fiction writings as well as the types of themes that are developed by individual authors (e.g. Dickinson's preoccupation with death).

\section{Lesson Modifications}

1. Since the goal of nearly all of the lessons was to reach consensus on comprehension of the concept (i.e. attainment), and questioning was the means to that stated end, modifications came only in the form of moving up and down the taxonomic level that the original query was designed to elucidate.

2. Lesson plans were continually modified and changed, primarily in terms of the questions anticipated by me and then re-directed towards the students.

3. Lessons were only modified if consensus, the end concept was not attained, (i.e. the next lesson 
would then begin exactly with that previous concept attained or not attained yet).

4. Time scheduled concepts were monitored and built upon, but concept attainment (consensus of) was a realistic goal considering the class size (only five students).

5. Strong points of each lesson usually came in the form of the instances wherein a question was phrased/framed in a manner in which the student was able to make the Gestalt connection to concept and instant comprehension was attained. Weak points, therefore, were defined as incomprehensible questions leading to greater confusion rather than situational clarity. 


\section{Chapter Seven: Findings and Implications}

\section{Introduction}

The purpose of this chapter is to reconcile the findings of my classroom performance assessment as witnessed by the two Praxis III assessors, the district Pathwise assessor, and the two building administrators with my criteria based paradigmatic frame of departure; each assessor's frame of reference will likewise be speculated upon, along with possible reconciliations of my own criteria with broader educational (and political) standards (read I will answer research question number one). Ultimately, this chapter drives at the essence of curricular alignment of all teacher performance standards by suggesting specific solutions on the national, state and local levels that would facilitate higher order thinking, reading, and writing skills.

\section{Reconciling Multiple Assessment Rubrics}

Research question \# 1: Can Pathwise (district), the State of Ohio (proficiency tests/learning outcomes), and PraxisIII standards be reconciled into one functional cover-all assessment device that can be reflected upon daily?

Since the scope of this action research project was an amalgamation of personal desires to improve my methodological delivery while attempting to meet administrative edicts in the four (Praxis III) domains, in this section, I will discuss to what extent those ends were met.

The Educational Testing Service created the Praxis III authentic classroom assessment device to augment the already existing Praxis I pre-service portfolio assessment (in place in most teacher education programs) and the Praxis II National Teacher Exam (the comprehensive paper/pencil test). The purpose of the Praxis III is to determine if the first year rookie teacher can evince satisfactory skill levels in each of the four following domains: (A) ORGANIZING CONTENT KNOWLEDGE FOR STUDENT LEARNING; (B) CREATING AN ENVIRONMENT FOR STUDENT LEARNING; (C) TEACHING FOR STUDENT LEARNING and (D) TEACHER PROFESSIONALISM.

Throughout the remainder of this section, I will be using emboldened letter abbreviations to the left of the paragraph(s) discussing each particular section. I will designate the Praxis IIIP., followed by the Domain A.-D., then the subsections will be given numbers 1; hence Praxis III, Domain A, subsection one, would be designated P.A.1.

P.A.1 In domain (A), under "Organizing Content Knowledge..." comes subsection number one; becoming familiar with relevant aspects of students' background knowledge and experiences. There is a direct correlation between this assessment criterion and classroom videotaping, since it becomes readily 
apparent (on tape) when a teacher has done his/her homework in gaining personal insight into student interests, motivation, and familial SES. When student " $\mathrm{D}$ " is asked to relate a literary analogy to a similar skill used as an attorney, or student " $\mathrm{C}$ " is asked to relate a philosophical concept to a team mentality applied in sports, the evidence of this advanced preparation becomes a tangible factor.

P.A.2 Under subsection two, Articulating clear learning goals for the lesson that are appropriate for the students, the intended area being assessed becomes slightly nebulous- since, what is clear to an evaluator or even a rookie teacher may not be clear to a student (on the particular day of evaluation) being observed- as satisfactory evidence of the teacher meeting this criteria.

Here videotaping multiple lessons in a unit becomes a decided advantage when working with thematic concepts such as "Romanticism" which may not become crystallized until mid-way through or nearing the end of a unit. Since the weight of national certification is resting on only two days (one class period per visitation) worth of classroom snapshots (Praxis III assessments), the teacher must either choose, lower order, simplified concepts for the instructional period or interrupt the larger educational portrait (being strategically created and orchestrated in segments designed to come to fruition as an epiphany by students).

Furthermore, students may have a very vague conception of how the rules of a genre apply to a heretofore unseen work; therefore- not until they actually have interacted with said illustrative texts, does that semantic differentiation validate reader pathos and become a worthy abstract concept retained. Likewise, the word appropriate conjures up images of Piaget, Erikson, Dewey and a host of other educational theorists that ask teachers to constantly evaluate the readiness of a student to grasp an abstract concept. However, as Vygotsky and Benjamin aptly pointed out, sometimes it is necessary to immerse a pupil in a new concept in order to create the "gestalt" from the new construction- where no prior visible evidence existed that the pupil was ready. Without question, videotaping multiple lessons can produce far greater evidence of an accurate student prognosis than can a simple preliminary interview question lightly probing the topic.

\section{P.A.3 In subsection three, Demonstrating an understanding of the connections between the} content that was learned previously, the current content, and the content that remains to be learned in the future, we also see a clear advantage in creating a running commentary- even if for only one class period. When the triangulation of the first Praxis III: Record of Evidence (APPENDIX F) suggested a decent 2.5 (or "C') rating of my American Literature Revolutionary Period Unit and a second observation (different assessor) score of 3.0 on my Poe Unit, I began to realize just how accurate my misgivings about single observation assessments were. After two subsequent viewings of each lesson assessed, wherein multiple references of the part (the author) to whole (the course) picture connection was stressed, my hypothesis- based on my own student teacher assessments of pre-service 
teachers is that both assessors were keyed into only the initial introduction of the lesson segment, not the examples and clarifying questions that were interspersed throughout each observation period.

P.A.4 Regarding subsection four, Creating or selecting teaching methods, learning activities and instructional materials or other resources that are appropriate for the students and that are aligned with the goals of the lesson- biases, training and teacher philosophy strongly affect. During both post-observation interviews with the respective Praxis III assessors, it was made manifest that not only teaching style preferences and philosophy were divergent, but also my overall political ideology was being scrutinized. The first assessor (came in Fall '99'), an older male high school teacher of English from a parochial school, shared many of my Thomistic and Neo-Platonic views of education, though not necessarily my Socratic method. He, responding favorably to my conservatism, rated the delivery of my Revolutionary Unit intro a solid 3.0, which I genuinely think needed to be improved (see A1 in Appendix B).

Conversely, the second assessment (Spring 2000) was performed by an older, decidedly liberal, female middle school teacher that clearly preferred student centered learning activities- not as strictly related to the text and issues. Total misalignment of ideology, methodology, and the culpability/accountability (needed on the student's part) ensued. An educational divorce court would have proclaimed our irreconcilable differences; yet, I believe that I accurately judged, by my own rubric, the Spring 2000 observation lesson's delivery as a stellar performance when compared to the first observation in the Fall. As an aside, and to bring the building Pathwise mentor teacher into the fray (also included in APPENDIX F), she too, using the identical Praxis III rubric, wanted to see differing (from Socratic) methods and activities relating to lesson delivery. Concomitantly, I later learned from a district curriculum coordinator, she too was given an administrative edict to stress alternative teaching styles to match diverse learning styles. Without bemoaning the ramifications, suffice it to say, I see 11th grade literature courses as needing to be firmly grounded in the textual transcript written on the page- not vague generalities unsubstantiated- and Socratic Methodology delivers the empirical subtleties specifically.

Additionally, reading and writing skills can not be taught without sticking close to the printed word published. A home economics teacher, with no formal assessment training, given a dictum to follow does not warrant teaching efficacy introspection on my part. For the record, this was her only formal teaching suggestion, though she was a helpful affable resource for other general school related procedural task explanations (read, helpful colleague).

P.A.5 Dovetailing with subsection four, subsection five Creating or selecting evaluation strategies that are appropriate for the students and that are aligned with the goals of the lesson, delineates many of the underlying issues present when using the single observation; if there is no formative evaluation being pressed into service during this very brief snapshot (less than 40 minutes), it presupposes then you are deemed uninformed as to the rate of student progress. By focusing on the level of Bloom's 
Taxonomy addressed, the professional educator is constantly analyzing such disparate factors as student schemata internalized (broad categorical conceptualizations) with the rate of retention being constructively layered upon. Socratic discussion formatively measures summative skills and cognitive internalization incrementally (i.e. again, I take issue with the accuracy of rating overall teacher competency using this ill-conceived category).

P.B.1 Upon closer inspection of Domain B, "Creating an Environment for Student Learning” again we find politically correct labels given to highly subjective, poorly measured, subsections. For example, subsection one, Creating a climate that promotes fairness, seams straightforward and innocuous enough; I interpreted this, based on the Praxis III guidebook, as giving (in fact I require) all students an opportunity to participate in every facet of the classroom instruction taking place. To a great extent, in fact, this was part of my aim for improving instruction in each student's zone of proximal development (see Pedagogical Skills Honed section of this chapter).

Given that the first assessor understood, and appreciated, my methodology (i.e. working from the student's highest level of current comprehension [the question's aim] to the next level of cognitive abstraction in the zone of proximal development), it was not surprising that I received a just 3.0 score on my questioning. Since the first lesson was only three days into the semester and course, I felt I was not only genuinely focussed on my personal questioning objectives, but that, upon viewing the taped segment, I also was fairly rating my own ability to be metacognitive; which was a boon to the initial project undertaking.

After almost a hundred (93) viewings of the lessons leading up to my second assessment and countless minute changes to my questioning techniques, somehow, paradoxically, I was given only a mediocre 2.5 rating by the Spring 2000 assessor. Possible explanations? The first reaction to most disappointments normally are not empirically sound observations, so I discounted pop-culture/correct politics in favor of attempting to understand the assessors point of departure for this subsection.

Given that she had zero prior information of any of the students previous classwork or working knowledge regarding each student's cognitive ability to articulate their own thoughts, let alone a thorough understanding of all of the research on questioning - nor the dynamic already in place amongst this cast (my class), my intuition interpreted this anomaly as an attempt on her part to protest the three girls operating at a lower level of cognitive abstraction. Her protest was seemingly (to the casual observer) a clearly laid out educational axiom; you must have a minimum 90 second wait time, and possibly as much as three minutes, before rephrasing the question or moving on to the next student. I do not doubt the validity of this research applied to the context it was designed for- checking student comprehension of clearly conceptualized concrete concepts that could easily be culled from listening in class or reading passages wherein no new vocabulary or terminology was introduced.

I, do however, take issue with applying this research carte blanche to all questioning situations in light 
of the following overarching concerns: 1. Incorrect overgeneralizations (misunderstanding the part to whole relationship) create slightly more than ignorance embellished with a better vocabulary and confuse the other students and themselves. 2. The students unable to, at least, apply the knowledge (fact memorized) to their own schemata (read, relevance and constructivist relationship to other concepts) will gain nothing from guessing without these guidelines.

Therefore, students need this higher order thinking modeled first or they will only be overly stressed by experiencing the failure. Yes, on earlier questioning attempts I did wait.

Just as no coach would ask a beginning basketball player to dribble between the legs while runningwithout first mastering the essentials of dribbling in place, I will not set students up for clear failures by asking them to perform operations three steps beyond their ability -without first asking them to master the next sequential level of critical thinking difficulty. *For a reasonably complete overview of the seminal research on questioning strategies see the "Questioning Strategies" research reviewed in chapter two.

P.B.2 Establishing and maintaining rapport with students, subsection two amounts to a footnote and off the cuff comment by the assessor that I hesitate to even review, due to its nature. Tersely stated, I don't believe this category should be observable as part of a pre-planned observation. If a teacher is focussed on instruction (and a question distribution category already exists) then in-class discussions of students' outside-of -class interests shouldn't be taken up as instructional time. How would a one shot observation possibly capture all of the hours spent speaking to students about personal quandaries in the hallways before, during, and after school bells ring? Furthermore, the fact that 153 identifiable videotaped analogies directly related to an existing rapport with all students that already (and were easily singled out) is documented exists- only strengthens my position that a videotaped portfolio should be the cornerstone of certification/licensure level teacher assessments.

P.B.3 Communicating challenging learning expectations to each student, subsection three, is not only readily apparent when viewing any given videotaped lesson segment, but is substantiated during each round of questioning with minute by minute "challenges". Ironically, the second assessor here rated my "probing question" at a higher 3.0 mark than did my more methodologically aligned first assessor (2.5). Here, he tertiarily observes my questioning of an unprepared student who has not read the selection being explicated whereas the second observer notes "actively asks". Somewhere along the line, teacher intent, motives and classroom activities must converge into a tangibly observable product... Like a cross-examination from an overzealous prosecuting attorney hell bent on getting to the facts, my Socratic intent screams "challenging"; I therefore discount these superficial facile attempts at measurement as inappropriate for my, or any, purposes.

P.B.4 Establishing and maintaining consistent standards of classroom behavior, referred to in subsection four, similarly must be interpreted within the context. In a Socratic Dialogue, the observable 
essential truths are sought as a foundation for creating a detailed, well-documented, blueprint of knowledge- centered around an issue. Erroneous beliefs can not be ferreted out and dealt with unless students feel "intellectually safe" to pursue these ends. Considering the scope of this heading, and the fact that both assessors keyed into the students behavior as telling evidence, this category needs to be either rephrased as percentage of students "off-task" or the assessors need to focus on teacher actions that truly affect students.

I can promote and maintain consistency via my own actions, but, as the dearth of research on public school videotaping tends to indicate, this (teacher assessment) is truly an area to fear administrative abuse in. Where do we begin discussing, at what age (given the rights of adults) children are to be held culpable for their own actions- and how much of this appropriate behavior should parents be held liable for? I had no behavior problems- all students were engaged- though I expressly accept only limited credit and liability for either appropriate or inappropriate student behavior.

P.B.5 Subsection five, Making the physical environment as safe and conducive to learning as possible, though it should not have been evaluated (I was a floating teacher at the time), since I couldn't affect any physical change of the surroundings- nonetheless is an area where videotaping could possibly lead to uncovering a potential safety hazard. Though one would tend to think that a careful periodic check of safety considerations would yield an accurate analysis of potential student hazards, it might be fruitful to see human subjects moving about within the confides of the area to isolate unforeseen ergonomic considerations.

P.C.1 Section C, “Teaching for Student Learning”, subsection one, Making learning goals and instructional procedures clear to students is generally less subjective than previous categories, easier to quantify, in terms of specific actions performed by the teacher and behaviors illustrated by studentsall of which lends itself to stop-action video analysis. If interpreted literally, this component of instruction has two natural outcroppings: 1. Directions stated by the instructor, and 2. Modeling the appropriate response being requested of the pupil.

Verbal directions given to students can be endlessly honed by the instructor- if one were to videotape, and then watch the same set of instructions being stated to, several groups at the same developmental level during different time (or class) periods. Applied to this situation, a goal oriented reflective teacher could continually refine his/her vocabulary (synonyms easily understood) as well as developmentally appropriate analogies that relate to the paradigm (SES, geographical, etc...) that the particular group of students is working from. Unfortunately, due to the nature and limits of this experiment (since instructions for heretofore unheard directions only happened once during the course before moving up to a more complex task) the project did not lend itself to this goal.

On the other hand, modeling the appropriate responses being sought can be observed for clarity of both example and non-example of the task by introspectively breaking the task down into its component 
parts. For instance, in lessons (videotapes) five through eleven there is an explicitly stated underlying reference to the "five paragraph essay structure" which continually is refined via the sieve of abstract conceptualization, practiced both in student essays (summatively graded) and examples of paragraphs (to be included in future essays) generated by students; which I repeatedly modeled on the chalkboard. After considering the level of student ability to recreate the layout (purpose driven) of each individual paragraph, as it pertains to the intent of their own thesis statement or topic sentence, the videotaping yielded a decided advantage here (in specifically reviewing each example generated and its commensurate level of effectiveness) which in turn could be re-created during the subsequent lesson.

P.C.3 Making content comprehensible to students, the aim of subsection two, was an integral component to my own instruction aims, hence the labeling of each cognitive level of "Bloom's Taxonomy". Interestingly, though the Praxis III guidebook also aims to assess this higher order thinking phenomena, in neither the Fall nor Spring assessment were either assessor concerned with anything more than mere very concrete questions of fundamental comprehension. As such, both assessors rated my skill at disseminating knowledge a 3.0 - but neither was concerned with the student's ability to accurately articulate something other than an oversimplified generalized gist of the differentiations being sought.

Ergo, if the criteria here was, could a student generate an answer generally related to the question (in their own imprecise vocabulary), once I framed an analogy in their paradigm- then I was accurately assessed. If the criteria was inversely applied to read, could students repeat specialized words relating to literary terms/devices, skills, or concepts on cue (without comprehending the meaning of their answers) then I was similarly treated fairly.

However, in the first scenario, if students are simply responding to egocentric questions about their own life's issues, without empathizing and relating to the parallel drawn out (in the literature under discussion) or using the appropriate terminology, then what have they learned or I accomplished? The second scenario, I liken to learning the words to a song without comprehending its meaning; Don McLean's “American Pie" lives on (like great literature) though few remember its original intent as homage to Buddy Holly; "bye, bye, Miss American Pie..." most college students could complete the lyric. However, the real question in critical thinking is, could the apt pupil describe what "...but the levy was dry..." represents metaphorically?

Though many of the earlier assessment questions I have currently placed under indictment for overstepping the boundaries of what can accurately be empirically assessed-in this category, I see the intent of this measuring instrument (content comprehension) being misaligned with the end result desired (critical thinking); in summary, none of the four domains in the Praxis III rubric are designed to differentiate between rote recitation/vague generalization and abstract levels of analysis- which videotaping facilitates. * A more in-depth discussion of this misnomer will occur in the Pedagogical Skills Honed 
section of this chapter.

P.C.4 Though the next subsection makes an attempt to capture the essence of critical thinking, Encouraging students to extend their thinking, it doesn't define what end result is supposed to be achieved. Specifically stated, "extend" and refine are not synonymous. Extend has no result in mindonly the idea of continuation is expressed. This is not a semantical difference when assessors key on words like "add" and "think" (see C3 summary in APPENDIX F) rather than phrases like "break it down further", "categorize", "evaluate" which I use in these lesson segments to refine generalizations. If we want specifics to be measured, we need to create categories designed to measure specifics that- at minimum- differentiate between the appropriate time/place to use analysis (break it down on your own), synthesis (generate new/unheard examples) and evaluation (create new categories, of your own to use in measuring effectiveness) -and not the more simplistic knowledge (memory), comprehension (uncontextualized definitions) and application (repeat an example already stated) levels of knowledge. The only danger here, which I will address in terms of responsibility/accountability is, were this category to be more specifically phrased (with the commensurate assessor training), it might be temping to the assessor to do as they've done in previous categories and measure student responses, rather than the level of questioning attempted by the teacher. This current administrative thinking (holding only teachers accountable for results) is totally incongruent with all current research showing the myriad factors that influence educational outcomes. Essentially, a students prior training and current ability are mediated by such disparate factors as SES, mother's level of education, and, as Aristotle pointed out two milleniums ago- internal motivation! Current US Department of Education literature revolves around getting the third party (parents) involved in the educational process.

P.C.4 Again subsection four, Monitoring students' understanding of content through a variety of means, providing feedback to students to assist learning, and adjusting learning activities as the situation demands, leaves me wandering what "the situation" is referring to. Are we simply asking if the stated lesson plan's objectives are being met (today's small piece of the pie) -or- do we make our transitory lesson goals subservient to (the end of course results in) this moment by moment revisionary process? I opt for the latter. Understandably, any evaluator must look at stated lesson objectives as a barometer against which to gage effectiveness, but here's where overarching knowledge of course goals and methodology must be considered by the evaluator (i.e. another subject specialist must fully comprehend my Socratic methodology, Thomistic Philosophy and the end result of the course- to improve students' abilities to think critically, first orally- then epistolarily).

If all of the aforesaid considerations are not firmly entrenched in the evaluator's mind then what ensues is a measure of how well your methodology, philosophy, and overarching course goals meet their conception. Which- in the case of a home economics or middle school teacher trying to evaluate complex thinking process and a student's ability to clearly articulate those concepts on paper- becomes 
a totally subversive farce to the entire process of teacher improvement; for it asks you (the instructor with advanced methodological training) to revert to oversimplifications and redundancies to accommodate the uninformed, somewhat pedantic, assessor's deficiencies in your methodological area of expertise. This is ridiculous!

Even in the case of my previously described, reasonably aligned (first Praxis) assessor, personal beliefs and stigmatisms did influence his analysis: Was I covering the authors whose thinking and craft he valued? No. Was I trying to present the information in a way that would easily facilitate student memorization of key facts? No. Did I give positive feedback to clearly off-track student responses to my queries? No. Did I present the same information in the same manner that he would have presented it? No. Was I trying to accomplish any of these objectives? No. Was I being judged by my own lofty standards? No. Again, I argue for trying to accomplish the stated course objective; students should be able to break down complex issues via critical thinking and evince that knowledge by creating clearly lucid (specific to author/theme/genre) essays which convey the intricacies of those conceptual ideas.

If the classroom 'read throughs' (students read aloud/we discuss seminal ideas) were not observed by the assessor (step one), but the classroom discussion- designed to aid in essay organization (step two) is- without considering the final product, the essay (step three), then how can any mention of assisting or adjusting of learning activities be justified? Would a coach make any drastic changes to the player lineup on the football field if they were temporarily losing this game, but the same lineup proved unbeatable in every prior game during the season? Videotaping provides a tremendous boon to sequential task analysis in terms of having the entire course context in mind (by frequently reviewing all tapes in a series).

P.C.5 Using instructional time effectively, is the focus of subsection five. This category is easily assessed by the casual and infrequent observer, as well as through self-analytical videotaping. For my purposes, isolating the appropriate times and points of instruction in which to foster critical thinking at the higher levels of the taxonomy, I chose to create an interaction analysis chart borrowing from the selfanalysis conceptualization of Gunter and Reed (see page 23 of chapter two).

Although rough numerical statistics stating this number of level four (analysis), five (synthesis), and six (evaluation) questions (all higher order questions) is slightly less than 10 percent $(9.75 \%)$ of the total volume of questions- the more telling statistic is the fact that all of these higher order questions required far more time, skill, and articulatory ability in an effort to fashion an answer (i.e. these were student, not teacher framed responses). Considering about five minutes is lost per class period doing administrative/ organizational tasks, and I spoke approximately $53 \%$ of the time on average, the length of response time is clearly increasing as the level of the taxonomy increases (i.e. there exists a positive correlation). *See tables on page 149 .

P.D.1 Section D "Teacher Professionalism” is more of a post-session information-gathering category 
for the Praxis assessor than a tangible measurement of effective classroom practices- and therefore only has limited use to the practicing teacher/self-assessor. However, even though segments of this domain were covered by myriad other subsections falling under other domains, subsection one, Reflecting on the extent to which the learning goals were met, does ask the assessed teacher to label specific segments of their lesson design with concretely conceptualized educational terminology to their respective evaluator.

Table 1: Student Response Elaborations

Taxonomic Level

of Questions $\quad$ Number of Questions

Per Level Total Response Time (min.) Duration of Response Per Question (sec.)

$\begin{array}{llll}\text { Knowledge } & 91 & 5.63 & 3.2 \\ \text { Comprehension } & 413 & 48.11 & 6.99 \\ \text { Application } & 311 & 114.13 & 22.02 \\ \text { Analysis } & 60 & 38.21 & 38.21 \\ \text { Synthesis } & 11 & 5.13 & 28.0 \\ \text { Evaluation } & 15 & 13.79 & 55.16\end{array}$

Table 2: Instructional Emphasis of Lesson

$\begin{array}{llll}\text { Lesson } & \text { Purpose } & \text { Lesson } & \text { Purpose } \\ 1 & \text { Review } & 7 & \text { Read/Review } \\ 2 & \text { Review } & 8 & \text { Introduction } \\ 3 & \text { Essay Dev. } & 9 & \text { Read/Review } \\ 4 & \text { Introduction } & 10 & \text { Read/Review } \\ 5 & \text { Essay Dev. } & 11 & \text { Essay Dev. } \\ 6 & \text { Introduction } & 12 & \text { Review }\end{array}$

* When the nature of the lesson is considered as being conducive to higher order critical thinking, such as essay development, then the statistical breakdown of time spent on task is an even more meaningful statistical expression (compare to Table1).

P.D.2 There is a clear responsibility here, on the teacher's part, to master the vocabulary of the professional assessor- if one wants to be viewed as a professional instructor familiar with the language of their craft. Some of the terms that I used during the post-assessment evaluation were: formative/ 
summative, verbal feedback, theoretical constructs, observations, reflections, metacognition, student groupings, student activities, skill competency, consensus, methodology, pedagogical philosophy, etc... all of which favorably affected the assessors summative evaluation of my, Demonstrating a sense of efficacy (subsection two).

P.D.3-4 The last two subsections of the domain are as follows: Three, Building professional relationships with colleagues -and- Communicating with parents or guardians about student learning, are areas which have no clear correlation to videotaping classroom instruction due to the focus on affective intangibles outside the classroom; these are assessments (again unjustly included) based solely on the post-observation interview.

Therefore, research question \#1. Can Pathwise (district), the State of Ohio (proficiency tests/ learning outcomes), and PraxisIII standards be reconciled into one functional cover-all assessment device that can be reflected upon daily? - is not a realistic possibility, considering the diverse points of instructional reference and measurement devices.

\section{Multiple Assessment Implications}

The obvious implication in reconciling multiple assessment rubrics is that there can be no agreed upon criteria between the teacher being assessed and the assessor if their is no dialogue clarifying conceptualizations of categories to be assessed prior to these observations. The second offshoot to this same issue of misalignment comes in the form of norming the assessment device to clearly defined methodology that is alignment with teaching styles and philosophical beliefs regarding the nature and delivery of classroominstruction.

Simply stated, these outside assessors must have advanced pedagogical training in the area methodological teaching styles and the underlying philosophical tenets thereof- before evaluating an orange on the qualities of a Kumquat! Once this issue is addressed, and the major teaching methodological camps are represented with separate evaluation criterion- then other issues such as the ethics of measuring teachers- based on student actions and behaviors- can be disentangled before the teachers (unions) and administrators square off in court, and finally decide whether ETS really is the "God" of education (or just a thinly masked administrative teacher compliance governing body designed to push only "liberal" educational aims).

\section{Educational Administration Aims}

Research question \#2: Is public school teacher videotaping an effective method of self-assessment documentation with regard to administrative educational aims? In this section, the focus of videotaping 
classroom instruction will be dwelt upon as either being in concert with administrational concerns, of no benefit (or neutral), and, in a few cases, possibly a hindrance to the process of keeping teachers aligned with chain of command hierarchy. Unfortunately, the principal of the high school was unable- even after repeated invitations- to come into my American Literature course (being videotaped) and instead chose to evaluate a creative writing course that I was also teaching during the same semester; therefore no triangulation with his perspective of my own metacognitive assessment (of the videotaped American Literature course) exists. However, the following are all valid reasons that educational administrators in secondary public education should strongly consider, at least piloting (for further study), teacher video taping:

1. Set of dialectical notes (running commentary on student progress) which allows speculation about solutions; for instance, vocabulary reticence as a result of whole language instruction is now documented on videotape - lesson one.

2. Allows specific student skill deficiencies to be identified such as reading comprehension (discussed as a running commentary from lesson one).

3. Connections of inter-related skills such as reading comprehension, vocabulary assimilation, critical thinking and writing skills - lesson one.

4. Observation of student posture, attitude and attentiveness (can be clearly observed - lesson one and three) in relationship to analogies (question frames).

5. Specific teacher frustrations can be isolated and discussed with administrators (student discipline issues to apathy) - lesson one.

6. Balanced positive and negative reinforcement can be shown within context to head off parental criticism-lesson two.

7. Instructors can check and re-check earlier prognosis with later epiphanies (once new conceptualizations become crystallized) - lesson two.

8. Likewise, larger orchestration (longer time periods) can be viewed as a whole; like an orchestra leader saving the crescendo for the finale - lesson two.

9. Instruction can be individualized much easier than memory alone - based on video - lesson two, three, and six.

10. Specific methodology (Socratic questioning in this case can be proven either effective or ineffective) - lesson two.

11. Evolving dynamic group changes (learning conceptualizations can be easily identified) - lesson three.

12. Links to specific educational research dynamics can be easily pinpointed-lesson three.

13. Student connection to personal issues (emotions) can be identified as motivational factors to build on - lesson four.

14. Student trust in the teacher can be easily documented at critical junctures where new skills are being 
honed and old inaccurate ideas are dispelled - lesson four.

15. Components of difficult, sequentially progressive conceptualizations can be schematically mapped (and diagnosed if faulty) - lesson five.

16. Unclear instructional phrasing can be easily ferreted out and changed prior to teaching similar lessons - lesson five.

17. Pacing of correctly phrased questions, answered correctly shows student confidence in taking risks (critical thinking) - lesson five.

18. Specific teacher training (classroom practices) can be traced by identifiable oral or written teacher commentary - lesson six.

19. Basic student academic behaviors, such as patience, can be fostered by keeping previous lessons fresh in the students' minds - lesson six.

20. A greater sense of trust in the students to develop their own conceptualizations (mastery on their own) - lesson seven.

21. Inductive and deductive lessons can be contrasted for situational effectiveness - lesson eight.

22. Teachable moments (reinforcement of previous learning, such as literary terminology) can be more easily identified - lesson eight.

23. Repetition, re-teaching, needs can be gauged - lesson eight.

24. Modeling of specific skills can be continually honed and revised-lesson ten.

25. Multi-grade level concerns can be tracked more easily - lesson eleven.

26. All of the information gleaned from videotaping can be used to custom tailor continuing teacher training-lesson eleven.

27. State learning goals and student performance outcomes can be specifically documented by teachers and verified by administrators - lesson twelve.

I mention the creative writing course to illustrate several, what I believe to be, telling considerations in administrative assessment: First, are there any student (leading to), parent (calling), board of education member (calling), superintendent (calling), principal concerns? After speaking to a plethora of administrators in public education over the past five years (many in my own education administration classes at the graduate level), one thing is crystal clear; lawsuits scare the hell out of all administrators!

The second, well known, factor along the same economic continuum is test scores. Test scores dictate state and federal dollars that benefit and also, when high scores have been attained, allow a modicum of autonomy from the state to be maintained. I don't mean to oversimplify or trivialize the tediously difficult job of being a public school administrator. I respect sensible, effective administrators orchestrating divergent factors tremendously, but I also realize that a teacher's classroom practices are seldom scrutinized without an underlying economic reason. Principals envision their job as seeing to it that the school runs smoothly, from heating system and maintenance to teaching and students, while keeping their 
eye on the larger financial picture.

With the administrative paradigm squarely defined, I can confidently say that even though the principal came in as part of a regularly scheduled visit, his intent was to see if I was meeting the minimum acceptable standard of my job performance- including whether I was able to effectively teach highly abstract skills and concepts through sophisticated questioning techniques; clear evaluation procedures, providing frequent feedback to students, encouraging learning environment, and independent student thinking were all singled out as commendable areas of my administrative evaluation. However, all other categories were checked off as being effective (see appraisal form in APPENDIX F).

Conversely, the principal is also concerned with monitoring, evaluating, and keeping the teacher in compliance with other areas not associated directly with instruction, such as: Staff Relations, ParentCommunity Relationships, Professionalism, and Personal Qualities, since teachers must work as team within the building; many of these categories were checked as unobservable.

Under: Personal Qualities, "is reliable in performing non-instructional duties"; under Professionalism, "Performs assigned duties and complete reports accurately and on time", "Serves on district and building committees"; under Parent- Community Relationships, "Supports school and/or community activities" "Communicates positively with the community about the school, the district, and the educational program"; and under Staff Relationships, "Accepts and profits from supervision”, "Assumes fair share of responsibilities for schoolwide activities", "Works cooperatively with colleagues and administrators" - are all illustrious examples of the types and kinds of activities that administrators are concerned with- not directly related to instruction.

When the Southwest Licking Local Schools' standard teacher appraisal form creates only one page of categories relating to instruction -and two defining other non-teaching duties assigned the teacher, it is fairly easy to assume, 1) that administrators are concerned with teachers doing administrative work more than teaching and 2) that due to the shear volume of administrative tasks and concerns, they wouldn't be all that receptive to spending any more time evaluating teachers than the law mandates. Considering the request to glean administrative input was asked for prior to the school year, in fact during the interview process before being hired, I felt that I made it very clear that this project was an important consideration in my accepting the position. Nonetheless, after the school year was over, I found myself in the unenviable position of having no administrative evaluation of any of my videotaped lessons. The assistant principal finally acquiesced in early June 2000 to view one of the American Literature videotapes and write up the standard evaluation form (previously described).

Though she tacitly states that she feels the videotaping lacks enough clear contextualization of the educational situation (in the classroom)- she doesn't check off unobservable in the following categories: Sound knowledge of subject, prepares instructional activities to meet individual differences, provides clear explanations and instructions, uses varied and adaptable teaching techniques, provides frequent 
feedback to students, provides an environment that encourages learning, respects, understands and likes children, maintains professional rapport with students, and promotes respect among students towards learning. She even checks commendable for, maintains a consistent and fair approach in dealing with students, plus the encourages independent thinking and problem solving category.

Objectively speaking, classroom videotaping- though it meets or exceeds many of the aims of classroom instruction frequently dwelt upon by teachers and outside assessing agencies (focussed on instruction)- does not offer any significant time/money advantage to the administrator (in fact it does the opposite) and therefore shouldn't be counted on as a possible source of support for this type of assessment- though many educators concerned with improving instruction (and thus test scores) may not oppose this extra effort on the teachers part.

\section{Educational Administration Implications}

Research question \#6: How will my conclusions affect my administrator's plans to implement this technology as a staff development project? The most obvious implication to be addressed with regard to future teacher/ administrator alignment on issues of instruction is for administrators to be clear about their economic concerns and teachers to be equally clear about their instructional concerns. If administrators are viewing their school buildings simply as another business, with employees to be manipulated toward economic ends, while teachers are concerned with issues of student comprehension of concepts and skills mastered- there is an obvious curriculum misalignment here.

The beginnings of addressing this problem would be for school districts to stop their promotional mentality from being extended to future administrators who lack any in-depth pedagogical knowledge of diverse methods of delivering instruction (i.e. stop promoting physical education teachers who are good with discipline, but lack in-depth multi-discipline teaching knowledge).

Secondly, school districts need to be clear about their overall outcome (the quality of the students produced) by administrators asking themselves whether they want to run scared from liberal parents and teachers threatening lawsuits (which have a stranglehold on middle school methodology) or resign themselves to delivering test results (which the majority of elementary and high school curriculums revolve around). If administrators simply wish to avoid lawsuits, then holding teachers accountable for results becomes a ludicrous undertaking considering keeping parents and students happy and entertained is the reality and learning the joke.

On the other hand, if district level administrators are willing to make proactive curriculum choices that meet with success- then two essential ingredients must be in place:

1. Every grade level must be assigned an equitable portion of the educational pie; this means most of the current middle school "student centered" practices must be re-evaluated to reflect parity within the 
larger student final product (no whole language, reading comprehension and writing must be taught, and student responsibility gets stressed equally at every level, etc...)

2. Teachers who are working towards that final educational goal must be rewarded with, at minimum, a positive evaluation. Teaching, not administrative duties, here need to be focussed on; this can only be accomplished by knowledgeable (in terms of classroom instruction) administrators genuinely understanding a teacher's personal classroom aims and then assisting that instructor in that method of delivery. Support, then, of these individual teachers working towards a common goal- becomes a natural outcropping when parents or students rebel against the higher standards (and they will until solidarity is achieved).

Furthermore, and directly to the point of this study, videotaping provides more- not less- information (a movie) central to improving classroom instruction than does the occasional administrative evaluation (a snapshot). Deanna L. Nekovei's (1997) 24 teacher study entitled, Assessment of Beginning Teacher Performance Utilizing Video Technology, clearly specifies, "In sum, it appears that videotape performance assessment that uses a holistic scoring scale is a viable and cost effective method of teacher evaluation". The only caveat here is, as I stated, the administrators must be familiar with differing methods of instructional delivery involved in effective clinical supervision in order to be capable of reaching the same teacher ends (i.e. student outcome). *See examples of teaching styles in the definitions section. Therefore, research question \#6, How will my conclusions affect my administrator's plans to implement this technology as a staff development project? - remains an inconclusive finding considering the various interpretations of the time and effort versus money continuum.

\section{Pedagogical Skills Honed}

Research question \#3: Can my own questioning and framing skills be honed and improved to target higher order thinking skills, in light of the constraints that the assessment and outcome rubrics (\#1\&2 from above) place on my lesson plan designs?

With questioning and framing (of questions) skills firmly anchored as the focus of this study, the most appropriate method of explicating my pedagogical ends is by viewing the larger critical thinking spectrum (Bloom's Taxonomy only labels the components) in terms of its dimensions and end result aspirations. As is the case with all learning, critical thinking too asks the learner to build sequentially on component skills mastered before moving on to a more complex procedure (skill) or concept and eventually to mastery that holistically showcases this learning.

Considering the larger overview, just stated, one of the most elementary of the critical thinking skills I began working with, early on in the course, was distinguishing the tacitly stated fact from opinion and 
vice versa; in the case of the former, students were asked to recall pertinent clearly germane information from the texts read versus remembering summative generalizations regarding a character's behavior (within a story) for instance. Because character analysis requires both an ability to cite facts plus make a reasonable generalization about that character- here is where a large portion of the course time was spent.

With only minimal prompting, students were able to make generalizations about what they had read by ruminating the essence of the details just passed over. Conversely, the opposite was not true. Without digressing into multitudinous factors of this fact, suffice it to say that, the students had not, along their educational journey, been asked to provide any proof to support unfounded generalities; this was the beginning.

One of the effective strategies that I employed was to ferret out the root of student thinking Socratically. Since the advent of the "MTV generation" students, more often than not, tend to view the world through a sociocentric pop-culture lens that stresses instant gratification. Independent "freethinking" is therefore a seldom asked for (by parents running to and from work, etc...) until educational requirements, such as creating a clearly thought out, articulately phrased essay, demand this skill. Unfortunately, many steps must be taken en route to developing confidence in reason over social propaganda. Initially, this Socratic process involved exploring underlying feelings associated with the issues being embraced by this course.

If refining generalizations and avoiding oversimplifications was the macro ability, what were the skills leading up to this ability? Essentially these skills boiled down to clarifying and analyzing the meanings of words or phrases (yes, they needed to understand the new vocabulary), developing criteria for evaluation (e.g. how do these characters rate in terms of moral consensus?), evaluating the credibility of one character's feelings towards another (perspective), questioning the significant issues raised in didactic texts, and comparing and contrasting ideals with actual practice; all of this, taken collectively required "questioning everything" as a starting point.

If "MTV" is not the authority in terms of rational reasonable thought based on meritocracy, then conceptualizing this type of thinking is best accomplished, in this course, by looking at the American authors that epitomized this "enlightened, Age of Reason" empirical process. Once the shaping contributions of these seminal authors' thoughts were contrasted with the neveau rich mentality, then a thorough breakdown of egocentric perceptions could be contrasted with reality; whereas Jefferson and Franklin modeled clear headed open hearted thought for all-mankind, Emerson and Thoreau illustrated the schism between group-think and free-thinking (self-reliant) models.

By the mid-point of the course, the post-modernist chaos mantra, "I should get anything I want, simply based on my wants" was en media res being replaced by a tolerance of rational meritocratic axioms. Not only were the students' own ideas and vague platitudes repeated, but the incipient thought 
processes were vague conceptions of my ideas as well. By now, the skill of being able to accurately diagnose student educational needs was quickly being replaced with a prognosis for connecting thought to feeling.

For any aspiring educator reeling from the divergent factors that influence the classroom practices the professional educator must be adept with, let me now draw psychological skills into the admixture. Without understanding the pervasive egocentric "I WIN-YOU LOSE" mentality present at Kohlberg's (Webb, 1996) fourth level of morality, Piaget's concrete (read literal interpretations) stage, or Erikson's (Webb, 1996) conceptualization of progressive stages of intellectual development, then I wouldn't begin to apply reality therapy to a high school English course. Concomitantly, were I not willing to describe these roadblocks as resistance to educational change, on the students' part, then I would be in need of therapy.

When, throughout school the public school system, teachers ask students to memorize only the absolutely essential information covered (which teachers provide with little student effort), parents take little time with their children to augment the educational process (due to current economic and social conditions), and children likewise are allowed to run free (seeking only their own immediate gratification) without having to work for/at anything given to them, then it's no great surprise that they don't want to think for themselves. Nonetheless, without student thought, any student essay is nothing more than a pre-fabricated teacher conceptualization of an issue.

How then do we get students to suspend judgement and re-think conclusions constructively-based on new evidence that controverts the old? One effective method to expose these irrational ideas is via teacher restatement of student sentiment. Often this technique alone has netted impressive results wherein students frequently chortle aloud at their own ridiculous incongruencies. However, for more deeply held irrational beliefs, a tightly focussed discussion of group benefit vs. consequence needed to be concretely labeled; in these pursuits, I frequently (and sometimes a student) would play devils advocate.

During the height of defending their erroneous beliefs and feelings toward other groups, I would apply their self-same standard to the other party. For example, when students would fail to provide specific examples from the text that illustrated their essay thesis, when queried, they would reply, "I don't know". Coming out of their own mouths, this statement sounds right at home. Applied to the adult world, parents, teachers, employers- all the students agreed, was unacceptable. My analogy (and thus mirror of) to them was, "So, when you ask me what your grade is, It's okay if, I don't know"? Consistent principles modeled by my classroom demeanor coupled with continually requiring a sustained systematic student effort ultimately, after better than half a semester, allowed these initially concrete thinkers to move into the realm of abstract thought- and thus begin crafting self-directed essays designed to unmask authorial intent in a given work. 
Even with shaky intellectual confidence in place, students were now able to generate their own essay ideas based on myriad themes that had been explicated during the process of 'read throughs'. Once the genesis of the concept was of their own schemata (related to personal knowledge constructs), I began the process of supporting the thesis generalization by breaking the statement into at least three key points illustrative of the generalization (and subsidiary student point of view). Next, the three pieces of evidential support were fashioned into topic sentences relating back/supporting the thesis. From here, students were asked to provide examples to support their constructivist conceptualization (i.e. quotes were needed).

With quotes, paragraph topics, and an idea to glue it all together came the arduous task of asking students to draw from our in-class Socratic discussions to deductively arrange facts under their subsidiary generalization and articulate these ideas in a comprehensible manner-using the English Language properly. Yes, it's true, up to this point in the semester, I hadn't asked students to write but a few times (three)- but, up to this point, students weren't internally motivated to share their own personal perspective. Therefore, students didn't really care whether the ignorance of the proper use of the language detracted from their own voice as a writer because, it wasn't their ideas being voiced.

Up to this point, videotaped lesson segment were tremendously beneficial to me in terms of gauging my prowess at discourse against the student's existing frame of reference, but once the concept of essay layout congealed in the students mind, their own epiphanies provided the impetus for expression through the written word. All proceeding student leaps in ability were subsequently measured in written articulatory responses (the essay format became the focus of the last third of the course).

Now that students believed they had something important to say, and an empirical method of doing so (via the Socratic dialogues) other tertiary issues at the sentence level could be dissected and broken down into easily digestible parts. Subject specific vocabulary here becomes simply a question of whether the terms (and corresponding ideas) have been used continually throughout the course- even though the vocabulary, literature, and for that matter, the course text has been approached in a heretofore largely apathetic manner.

Reinforcing the Socratic mode of questioning now becomes the basis for individual sentences designed to convey specific hierarchical relationships illustrating the part to whole nature of the entire document. The payoff for asking for proof of ideas along the way, comes now if the student has been astute in noticing the repeated words (or similar synonyms) used as past illustrations (key quotes) supporting themes. Usually, at the initial stages of essay development, I will have asked students to write down at least three key quotes that are obvious examples of the authors theme (and intended messages). Now the students have a basis of judging a quality example that draws its strength from the facts it makes clear- rather than second hand information, opinion or a mis-leading statement from another character in the text. 
Nearing the end of the course, the process of developing ideas, formatting them, and sticking to the objectives could then be simply referred to periodically as the student was in the various stages of developing the piece. Viola! More time spent early in the course on fundamental thinking skills and clarifying concepts equals less teacher effort in generating answers (that students can simply memorize) and greater student achievement at the end, in terms of self-styled conceptualizations- since they now posses the tools necessary to learn on their own.

Therefore, research question \#3, Can my own questioning and framing skills be honed and improved to target higher order thinking skills, in light of the constraints that the assessment and outcome rubrics (\#1\&2 from above) place on my lesson plan designs? - yes, my questioning and framing skills were improved though, many of the external constraints placed on my lessons were made subordinate to my own pedagogical concerns.

\section{Pedagogical Implications}

The clearest implication to this section comes in the form of the personal responsibility needed on the part of every teacher to understand that learning is a sequential process of building up skills connected to more and more abstract concepts. Therefore, not only should teachers understand each underlying skill needed to perform at the next progressive level of instruction, but teacher education programs should put greater focus on the diagnostic abilities that their graduates should possess. Meaning, we should be training student teachers to diagnose the larger semantical breakdowns in terms of the highest cognitive abilities that students clearly possess (i.e. don't expect students to write paragraphs if they are not competent at the sentence, or, worse yet, the word level).

\section{Videotaping Considerations}

Research question \#4: What physical ways will I have to amend my teaching (e.g. classroom movement and voice projection) in order to work effectively within this video medium? The most fundamental of all considerations in any endeavor to improve one's self is a clear conceptualization of what you hope to achieve. Once this objective is known, then an exploration of personal beliefs must be forthcoming; if you don't understand your current ideological ends, then improving skills towards those ends becomes an exercise in futility. An objective (appropriate for a rookie teacher) might be as simple as improving the clarity of verbal instructions given, provided that the teacher his/herself had a clear conceptualization of how a clearly phrased explanation was measured. If it was measured according to an ideological perspective defined, say, through a speech course, then vocal inflection, body posture, rate and clarity (word speed and choice) might be isolated as factors to look for; if the measurement followed current educational trends, perhaps pupil ability to demonstrate mastery of the specified skill would be targeted. 
Here, I wish to illustrate a paramount consideration; pupil performance in a group situation, where oral or kinesthetic factors are being observed can be an affective information gathering tool and possibly it could be used as a summative assessment- but educational change needs to be measured academically as the professional endeavor that it is; document your philosophy, methodology, and specific pedagogical ends you are working towards ahead of time or you will be held to somebody else's standard.

With the caveat given, once a teacher understands exactly what end result they are aspiring to, and the measurement thereof, an advanced organizer of specific actions or behaviors needs to be created as a focal point. Now come the tangibles such as camera angle, point of focus, volume, etc... Initially at least, regardless of the intended unit of measurement chosen, a teacher must see themselves in action (even if student behavior/actions are deemed more important)- there may be a surprising effect to seeing yourself in action.

Research question \#5: What technical problems will I face/troubleshoot that might be beneficial to other educators wishing to replicate my research undertaking? To videotape yourself, I recommend "blocking" the scene as if on a theatrical stage: First, mark the edges of the area of the classroom that you normally travel. If generally you know you are going to be presenting a great deal of information on the chalkboard, then place X's on the floor at the edges of the area and then have someone close to your approximate height walk between the marks while you adjust the focal point of the videorecorder from the back of the room. Usually, you'll want the tripod height set between three and four feet for an eye level camera angle. With this type of setup, the automatic focus feature (present on most modern cameras) will keep the picture clear as long as you make no rapid movements (walking and writing stay in focus). The only conceivable problem here could come from the less emphatic, soft-spoken oration on the teachers part, since the built in microphone is going to be affected by proximity.

The second useful camera angle to include in your repertoire would be the side angle shot that captures all of the action in the classroom- both student and teacher. The obvious drawback to this focal point is the reasonably distant horizon line; you will probably need a minimum of 10 feet (probably 15) of unobstructed space from the subjects to the camera in order to affective use this shot. If you can move all of your students into the last three rows of a thirty-foot wide classroom- this shot will give a clear depiction of both teacher actions and student reactions. Again, I recommend blocking off the scene and adjusting the camera (ready to go, set on pause) prior to filming the lesson.

The last camera angle can also be useful if simply observing student behavior during a lesson; the "Podium" front view gives the teacher an opportunity to specifically tailor the camera view to the specific subject(s) being observed. Normally, less than a third of the students attempt to answer all of the questions staying actively engaged, but if you wished to observe the unnoticed behavior of other students, this pre-determined camera angle could be beneficial.

* For all other videotaping assessment considerations refer back to the section of the same name found in chapter two. 


\section{Reconstructing the Project}

The following are the progressive levels of this project's development:

1. Ibecame interested in improving classroom instruction via questioning/framing

2. I collected background information through my graduate level professors

3. I researched Questioning/framing and related areas (see chapter two)

4. I began to reconcile my own educational beliefs and methods with the research

5. I conceived a hypothesis that included my beliefs and the existing research

6. I created a short questionnaire to test my hypothesis on a small sample group

7. From the pilot study, I conceived a study to measure the intangibles in question

8. The conceptual paradigm (prospectus) was refined and modified by committee

9. The appropriate approvals were garnered and consent was given via IRB

10. The lessons were strategically videotaped to illustrate all facets of the study

11. I continued to research, reconcile my beliefs and practices throughout,

12. While outside assessors were brought in to triangulate (validate) my paradigm

13. Upon completion of the information gathering stage, I began to review journal

14. Daily journal entries were stitched together to create emergent patterns

15. From the patterns, categories for my concluding discussion were fashioned

16. Feedback from committee mentors was sought on the layout of write-up

17. The final product (dissertation) was laid out in sections according to purpose

18. Drafts were drawn, revisions made, conclusions presented before

19. Pre-printing (final edit) approval from a key mentor was given

20. The final draft was printed, research defended successfully and...

21. Technological changes were met before the degree was conferred 


\section{Work Cited}

American Educational Research Association. (1992). Ethical standards of the American Educational Research Association. Washington, DC: Author.

American Educational Research Association, American Psychological Association, National Council of Measurement in Education. (1985). Standards for educational and psychological testing. Washington, DC: APA.

American Federation of Teachers, National Council on Measurement in Education, National Education Association. (1990). Standards for teacher competence in educational assessment of students. Washington, DC: Author.

Barrett, J. (1970). Individual Goals and Organizational Objectives. Ann Arbor, MI: University of Michigan, Institute for Social Research.

Bloom, Benjamin S., \& Krathwohl, David R. (1956). Taxonomy of Educational Objectives: The Classification of Educational Goals, by a committee of college and university examiners. New York, Longmont, Green, 1956.

Blumberg, Arther. (1980). Supervisors \& teachers: A private cold war, (2 $2^{\text {nd }}$ ed.). Berkeley, CA: McCutchan Publishing Corporation.

Blumberg, A., \& Jonas, R.S. (1987). Permitting access: The teacher's control over supervision. Educational Leadership, 44(8), pp. 58-62.

Bonwell, Charles C., \& Eison, James A. (1991, September). Active Learning: Creating Excitement in the Classroom (Report No. RI88062014). Washington, DC: George Washington University. (ERIC Document Reproduction Service No. ED 340 272).

Brumbaugh, Robert S. (1982). Whitehead, Process Philosophy, and Education. Albany, SUNY Press, 1982.

Buck, Rachel. et al. (1992). Teachers' Goals, Beliefs, and Perceptions of School 
Culture as Predictors of Instructional Practice (Report No. SP034243). San Francisco, CA:

American Educational Research Association. (ERIC Document Reproduction Service No. ED352359).

Bussis, Anne., \& Chittenden, Edward. (1971). Open Education: Research and Assessment Strategies (Report No. PS005408). Minneapolis, Minn: National Association for the Education of Young Children. (ERIC Document Reproduction Service No. ED060932).

Butroyd, B. (1997). Are the Values of Secondary School Teachers Really in Decline? Educational Review, pp. 49, 251-8.

Cardellichio, T. L., \& Field, W. (1997). Seven strategies that encourage neural branching . Educational Leadership, 54, 33-6.

Carnegie Forum. (1986). A Nation Prepared: Teachers for the Twenty-First Century. Carnegie Forum on Education and the Economy's Task Force on Teaching as a Profession.

Clearing House. (1993, August). Teacher Questions and Schema Activation. The Clearing House, 66 (6), pp.349. Retrieved December 14, 1999 from EBSCO database (Masterfile) on the World Wide Web: http://www.ebsco.com

Clyde, Glenda. et al. (1994). Assessment is Epistemic and Heuristic: The Role of Video Tape in the Public Speaking Course (Report No. CS508843). New Orleans, LA: Speech Communication Association. (ERIC Document Reproduction Service No. ED380826).

Denner, Peter R., \& Rickards, John P. (1987). A Developmental Comparison of the Effects of Provided and Generated Questions on Text Recall. Contemporary Educational Psychology, 12 (2), pp. 135-146.

Dobson, Russell, \& Dobosn, Judith. (1983). Teacher Beliefs-Practice Congruency. Viewpoints in Teaching and Learning, 59 (1), pp. 20-27.

Dwyer, Francis. (1971, July) Effect of Questions on Visualized Instruction. Journal of Psychology, 78, pp. 181-183.

Galas, C. (1999). The never-ending story? Questioning strategies for information age. 
Learning and Leading with Technology, 26 (7). pp. 10-13.

Garner, Ruth., \& Alexander, Patricia. (1982). Strategic Processing of Text: An Investigation of the Effects on Adults' Question-Answering Performance. Journal of Educational Research, 75 (3), pp. 144-148.

Grasha, Anthony F., \& Yangarber-Hicks, Natalia. (2000, Winter). Integrating Teaching Styles and Learning Styles with Instructional Technology. College Teaching, 48 (1). pp. 2-11.

Gray, Dennis. (1988). Socratic seminars: Basic education and reformation. Basic Education Issues, Answers, and Facts, 4 (3). p.23.

Gunter, P. L. \& Reed, T. M. (1996, March). Self-evaluation of instruction: A protocolfor functional assessment of teaching behavior. Intervention in School and Clinic, 31, p. 225.

Instructional Innovation. (1987, September). The Use of varied interactive questioning strategies with feedback in improving posttest Time efficiency during visualized instruction. Journal of Instructional Psychology, 24 (3), pp.207. Retrieved December 14, 1999 from EBSCO database (Masterfile) on the World Wide Web: http://www.ebsco.com

Jensen, Rita. et al. (1994). Fear of the Known: Using Audio-Video Technology as a Tool for Reflection in Teacher Education. St. Louis, MO: American Teachers of English.

Leming, James S. (1995). Reflections on Thirty Years of Moral Education Research. Moral Education Forum, 20 (3), pp. 1-9, 15.

Lickona, Thomas. (1991). Educating for Character. How Our Schools Can Teach Respect and Responsibility (Report No. ISBN-0-553-07570-5). New York, NY. (ERIC Document Reproduction Service No. ED337451).

Martin, E. \& Mayerson, E. (1985, November). Video interviewing: An effective technique for aspiring job seekers. Journal of Education for Business, pp. 57-59.

Martin, Jack. (1979). Effects of Teacher Higher-Order Questions on Student Process and Product Variables in a Single-Classroom Study. Journal Educational Research, 72 (4), pp. 183-187. 
Nekovei, Deannal L. (1997, November). Assessment of Beginner Teacher Performance Utilizing Video Technology. Research in Education.

Rosenshine, Barak. (1976). Recent Research on Teaching Behaviors and Student Achievement. Journal of Teacher Education, 27 (1), pp. 61-64.

Slavin, Robert E. (Ed.). Educational Psychology: Theory and Practice. (5 ${ }^{\text {th }}$ ed.). Needhan Heights, MA: Allyn \& Bacon.

Smith, D. (1996). Peer coaches' problems with videotape recording for teacher observation. Action in Teacher Education, pp. 18-27.

Smylie, M. A., and Conyers, J. G. (1991, winter). Changing Conceptions of Teaching Influence: The Future of Staff Development. Journal of Staff Development, 12 (1), pp. 12-16.

Veuglers, Weil, (1995). Teachers, Value Stimulation and Critical Thinking. Chicago, IL: American Educational Research Association.

Vygotsky, L. S. (1978). Mind in society. M. Cole, V. John-Steiner, S. Scribner, \& E. Soubermant (Eds.). Cambridge, MA: Harvard University Press.

Wager, Walter, \& Mory, Edna. (1992). Feedback, Questions and Information ProcessingPutting It All Together (Report No. IR015775). Iowa: Convention of the Association for Educational Communications and Technology. (ERIC Document Reproduction Service No. ED348038).

Webb, L. Dean, et al. (Eds.). (1996). Foundations of American Education. (2 $2^{\text {nd }}$ ed.). Englewood Cliffs, NJ: Prentice-Hall, Inc.

Wylie, R. C. (1974). The self-concept, revised edition. Lincoln, NE: University of Nebraska Press.

Zirkle, P. A. (1996). The Law of teacher evaluation: A self-assessment handbook. Topeka, KS: National Organization on Legal Problems of Education. 
APPENDIX A: PILOT STUDY 


\title{
APPENDIX A
}

\section{Teacher Attitudes Towards in-class Videotaping: An Action Research Project}

\author{
By Al Alberts
}




\section{RETURN TO AL ALBERTS' MAILBOX - 604 ALLEN HALL}

BACKGROUND: Over the past ten years videotaping students, student teachers, and even veteran teachers has become a more accepted method of collecting classroom performance data; From self-analysis using set criteria, to peer review, to supervisory assessment and longitudinal studies, videotaping, for all of its inherent strengths, still has not met with widespread acceptance in the classroom as a teacher assessment device. It is legal to videotape in a public arena. It is increasingly being used to identify and prosecute students endangering other students- on this basis alone, it will certainly become a more prevalent practice. The questionnaire that follows is designed to capture teacher attitudes concerning the use of classroom videotaping. Moreover, I personally plan to follow through on any emergent pattern coming out of the results of this questionnaire in developing my doctoral thesis.

\section{TEACHER VIDEOTAPING: effective classroom assessment tool?}

Using the Likert scale: 1 . Very negative 2 . Somewhat negatively 3 . Neutral 4 . Somewhat positively 5 . Very positive, please complete the following inventory from this frame of reference; How would unobtrusive videotaping affect (or relate to) your performance in the folowing areas:

1. Your ability to raise standardized test scores?

2. Your ability to create consistent classroom standards?

3. Your ability to improve your administrators future evaluation?

4. Your ability to accurately describe immoral/illegal student behaviors to administrators and parents?

5. Your ability to quantify subjective areas of teaching?

6. Your ability to identify discriminatory practices?

7. Your ability to defend your classroom practices to parents, the public or media?

8. Your ability to target students for academic intervention (i.e. remediation/tutoring)?

9. Your ability to further individualize instructional strategies?

10. Your ability to share (workshop) "best teaching" practices with peers?

11. Please characterize your political outlook (1 being very liberal - 5 being very conservative).

12. How many years have you taught?

13. What is your age?

14. Please circle: male/female

15. Please describe the level you teach at.

* In the space provided below, or on the back of this paper, please add any further questions or comments that might improve or validate this research instrument. 


\section{Rationale}

As a doctoral student in curriculum and instruction interested in maximizing teacher effectiveness, it seems blatantly logical to create opportunities for teachers to improve their own instructional techniques; In the past, this has been accomplished solely from editorial commentary generated by administrators and/or students. The problem with this system is twofold: 1 . Memory becomes selective after a period of time (and therefore more subject to immediate emotional contextualization). 2 . This critique does not take into consideration, nor delegate the responsibility to, the respondent teacher in terms of stylistic conceptual approaches. Self-analytical teacher videotaped assessment addresses both the need for immediate feedback as well as empowers that teacher to refine his/her own teaching persona- before presenting the results of this effort to their respective administrator. The added boon to adopting this method of self-evaluation lies in the concrete images created, that may later be workshopped as "Best Teaching Practices". Towards these ends, my exploratory inventory on teacher attitudes' concerning the effectiveness of this metacognitive technique seeks to isolate and identify specific areas of resistance to and aesire for such a system.

\section{Questions}

The questions for this interest survey were generated by carefully reviewing the available current literature (articles published within the past 15 years) and gleaning the essential areas of accepted usage as well as the resistance (legally and ethically) to said usage - hopefully framing these legal/moral issues (in question form) in the process. All ten of these issue-oriented questions (1-10) additionally have been identified by The Harvard Law School's educational law division as being definitional in defending the legality of this practice. Questions 11-15, on the other hand, were designed to be exploratory descriptors that might, at some point in the future of this research endeavor, be given the causal status role of dependant variable. * The entire questionnaire appears as an addendum to this document (see back page).

\section{Methods}

Rather than relying on others' innate interest in this topic of research or the tenuous lationship request for the compliance of professional acquaintances, in $95 \%$ of all of the 46 questionnaires returned, I prefaced my request with "could you take just a couple of minutes to fill out this questionnaire on teacher attitudes toward videotaping for me now?'While respondents filled out the survey, I busied myself with other activities in an attempt not to be obtrusive or influential. Since the questionnaire neither asked for names nor reasoning behind the answers given, I feel my physical proximity did not create any undue anxiety affecting my respondents. The research alluded to in this text was 
performed during the last two weeks of November and the first two weeks of December 1998. Once I felt I had adequate representation from both genders, public and higher education, rookie and veteran teachers, I examined the frequencies for each question and began looking for the mediating effects of questions $11-15$ on questions 1-10. The final comparison grouping of the data will be fundamentally explicated in the "Interpretation" and "Conclusion" sections of this essay.

\section{Results}

Beginning with the demographics to greater conceptualize the responses:

$\mathrm{N}=27$ female respondents (\#14) with 11.6 years average teaching experience (\#12). The median age of these respondents was 39.2 years of age (\#13) with the following teaching background (\#15): four taught elementary, three taught at the secondary level, and 20 taught in higher education.

$\mathrm{N}=19$ male respondents (\#14) with 12.4 years average teaching experience (\#12). The median age of these respondents was 47.4 years of age (\#13) with the following teaching background (\#15): eight taught at the secondary level and 11 taught in higher education (none taught at the elementary level).

In response to question $\# 11$, I have averaged the male central tendency $=3.3$ and the female central tendency $=3.0$ to illustrate the older, more conservative nature of the males' answers; The complete frequencies of response (including \#11) appear below:

$\mathrm{N}=19$

$\begin{array}{lccccc}\text { Males } & 1 & 2 & 3 & 4 & 5 \\ \text { Likert: } & \text { very negative } & \text { negative } & \text { neutral } & \text { somewhat } & 50 \text { very posit }\end{array}$ Likert: very negative negative neutral somewhat pos. very positive

\begin{tabular}{|c|c|c|c|c|c|}
\hline QUESTION & RESPONSE & RESPONSE & RESPONSE & RESPONSE & RESPONSE \\
\hline$\# 1$ & 0 & 2 & 11 & 5 & 1 \\
\hline$\# 2$ & 0 & 0 & 6 & 8 & 5 \\
\hline$\# 3$ & 1 & 2 & 5 & 5 & 6 \\
\hline$\# 4$ & 0 & 0 & 3 & 8 & 8 \\
\hline$\# 5$ & 1 & 2 & 4 & 10 & 2 \\
\hline$\# 6$ & 0 & 1 & 4 & 11 & 3 \\
\hline$\# 7$ & 0 & 0 & 1 & 12 & 6 \\
\hline$\# 8$ & 1 & 1 & 8 & 7 & 2 \\
\hline$\# 9$ & 1 & 4 & 6 & 5 & 3 \\
\hline$\# 10$ & 0 & 1 & 2 & 8 & 8 \\
\hline$\# 11$ & 2 & 1 & 8 & 6 & 2 \\
\hline
\end{tabular}

- For layout purposes, so that a side by side comparison may be made, the female response table appears on the proceeding page. 
$\mathrm{N}=27$

\begin{tabular}{|c|c|c|c|c|c|}
\hline $\begin{array}{l}\text { Females } \\
\text { Likert: }\end{array}$ & $\begin{array}{c}1 \\
\text { very negative }\end{array}$ & $\begin{array}{c}2 \\
\text { negative }\end{array}$ & $\begin{array}{c}3 \\
\text { neutral }\end{array}$ & $\begin{array}{c}4 \\
\text { somewhat po }\end{array}$ & $\begin{array}{c}5 \\
\text { very positive }\end{array}$ \\
\hline QUESTION & RESPONSE & RESPONSE & RESPONSE & RESPONSE & RESPONSE \\
\hline$\# 1$ & 1 & 2 & 20 & 4 & 0 \\
\hline$\# 2$ & 0 & 1 & 12 & 11 & 3 \\
\hline$\# 3$ & 0 & 4 & 5 & 13 & 5 \\
\hline$\# 4$ & 0 & 2 & 5 & 9 & 11 \\
\hline$\# 5$ & 0 & 1 & 11 & 12 & 3 \\
\hline$\# 6$ & 0 & 0 & 5 & 14 & 8 \\
\hline$\# 7$ & 0 & 1 & 3 & 17 & 6 \\
\hline$\# 8$ & 1 & $\overline{0}$ & 11 & 12 & 3 \\
\hline$\# 9$ & 2 & 0 & 9 & 14 & 2 \\
\hline$\# 10$ & 0 & 0 & 3 & 15 & 9 \\
\hline$\# 11$ & 1 & 10 & 7 & 6 & 3 \\
\hline
\end{tabular}

\section{Interpretation}

Out of this admittedly limited data set come several trends that warrant further study with greater numbers to determine the validity of this pilot study. However, for the purpose of identifying patterns of responses, I will base my interpretations on the top two most positive categorical responses (i.e. 4 and 5 on the Likert scale) that relate favorable approval for the practice stated within the question.

Based on the fact that the females in general were younger and more liberal than the male participants, they tended to be slightly higher in approving of using this technology ( $82 \%$ responded either 4 or 5 ) to identify discriminatory practices in the classroom (question \# 6) -Vs- the males combined total of only $74 \%$, using the same top two categories. Likewise, the female respondents were also a shade more willing to share "best teaching practices" (question \#10) at $89 \%$ than the males $84 \%$ approval - though both responded very positively to this practice.

Conversely, the older, more conservative males were more willing to use the videotape technology to identify immoral student behavior (question \# 4) at $84 \%$-Vs- the lower female approval of 76\%; Ironically, I see questions \# 6 and \# 4 as two sides of the same inappropriate behavior continuum separated only by the nature of the transgression.

Age, political outlook, and gender issues aside, both the males and females felt, at an identical $85 \%$ rate, that this technology could be well used to defend classroom practices (question \# 7). Other than \# 4, \#6, and \# 10, none of the other questions (and practices questioned therein), received an approval rating over $67 \%$. Still, the least favorable approval of practices identified in these questions bears exploration as well. 
Both males and females failed to generate positive answers regarding raising test scores (question \# 1); The males rated $31 \%$ and the females only $15 \%$. Whether this means that they don't see an application of technology towards this objective, simply a negative outlook on this practice, or both, this was the most apathetic answer (with both males and females scoring very high numbers in the neutral category).

The next poorly received project for the females dealt with consistency (question \# 2) gleaning a lowly $51 \%$ approval Contrastly, the males scored this usage at a much higher $68 \%$ rate of approval. The next inost coolly received practice for the males was question \# 9 dealing with individualizing instruction at $42 \%$. Inversely, the females had fewer problems with this application at $59 \%$ (though they too rated this usage far from the top of their respective agendas).

\section{Conclusion}

Whether the trends I have identified are justifiable conceptualizations or not, are and will be, subjects of conjecture until greater statistical significance is created through validation of a larger data base isolating dependant variables. Concomitantly, I also feel very strongly that gender oriented paradigms have increasingly (over the past 20 years) colored our collective objectivity in ways that can't be ignored by education or society at large. Hopetully, by isolaung and identifying these gender variances towards the same educational end, we can all use this, now commonplace, technology to hone our collective teaching skills - and in the process come to realize that the classroom can no longer be thought of as an isolated area to conduct educational experiments. As teachers we must have professional growth that reflects the inetacognitive process involving feedback; From this growth, the art of teaching as a performance will gain professional respectability and maybe in the long run the commensurate pay that it deserves. 
APPENDIX B: AMERICAN LITERATURE COURSE GUIDE 


\section{A TRRCAN ITHERATURS I}

Credit: $\quad 1 / 2$

Length: Semester

Grade Levels: 11 and 12

Prerequisites: English 10

\section{Course Description}

This course includes American literature from the Early Native Americans to the Civil War period. Students will be provided with integrated language arts opportunities to improve skills in reading, writing, listening, visual literacy and oral communications. Short story, essay, poetry, drama, and the novel will be explored, interpreted, and analyzed. In addition, students will complete a variety of writings, such as narrative, expository, and persuasive, based on the literature. Instruction and practice in language structure and usage are included.

\section{Coure Objectives and Content Outime}

\section{A. Reading}

The student will:

1. read, interpret, analyze, and discuss various literary forms (short story, poetry, essay, novel) which include but are not limited to the following authors and their time periods:
a.Puritans
1 .Smith
2. Bradstreet
3.Edwards
4.Taylor
b. Revolutionaries
1.Franklin
2.Jefferson
3.Henry
c. Romantics
1.Whitman
2 .Dickinson
3 .Poe
4. Hawthorne
d. Transcendentalists
1.Emerson
2.Thoreau 


\section{e . Pre-Civil War \\ 1.Twain \\ 2.Crane}

2. assess the validity of ideas and the quality of writing of a literary selection.

3 . read to facilitate content learning.

4. read to develop an awareness of contemporary issues and relate them to issues of historical significance through their presentation in literature.

B. Writing

The student will:

1. write as a response to the literature using the following writing types:
a persuasive
b. expository
c . narrative

2. display a knowledge of gathering research and evidence from the novel or other outside sources to support interpretations and analyses of literature.

3. use correct mechanics, usage, grammar, and spelling in written assignments.

4. display increased knowledge of a building vocabulary, much of which is obtained from the literature in the course.

5 . determine patterns of organization appropriate to a writing topic.

6. develop organized pieces of writing which contain strong voice, clear theses, and well-developed ideas.

7 . assess personal/peer revisions to a piece of writing.

8. apply an appropriate recursive writing process as suggested by the writing task.

9. write in various domains.

C. Listening /Visual Literacy

The student will:

1. listen to and view a wide variety of genres.

2. expand vocabulary through listening to and/or viewing varied media.

3 . listen and view critically to facilitate learning across the curriculum.

4. participate and be involved in individual, small-group, and whole-group listening and viewing activities.

\section{Oral Communication}

The student will:

1. participate in the following activities that are related to the readings in the class:
a . discussion
b.drama 
c . debate

d .speech/ public speaking

2 . use oral communication for a variety of purposes and audiences.

3 . be involved in individual, small-group, and whole language activities.

\section{Bvalution}

Evaluation of the student may include, but not be limited to, the following.

participation in oral reading, listening, and class discussions. work done by the student, including homework, tests, quizzes, exams, projects, and reports. 


\section{PERPORANCE OBJECTIVES}

\section{ANTARCAN IHTEATURS I \\ $x=$ strongly emphasized areas of course}

-1. After reading a complete work of literature, the student will respond in writing, demonstrating an acceptable level of understanding of the material, as evidenced in part by the capacity to:

a. relate a personal experience or the experience of another, gleaned through literature, to the literary work;

b. compare and contrast the literary work to another which has been studied;

c. determine structural elements of the literature, including such areas as theme, characters, plot, setting, mood, and point of view;

d. recognize and interpret organizational patterns of writing to teacher satisfaction.

2. Presented with appropriate nonfictional selections, the student will demonstrate comprehension, as evidenced in part by the capacity to:

a. find major concepts by identifying stated or implied thesis, then differentiating between details that support the thesis and those that do not;

b. differentiate statements based on fact from statements based on opinion;

c. make predictions about whether certain information is likely to be included in material;

d. compare and contrast facts and events from one selection with facts and events from other selections,

to teacher satisfaction.

3. Presented with everyday/functional reading materials, the student will identify, locate, and use information from libraries and other sources, to the teacher's satisfaction, as evidenced in part by the capacity to:

a. follow multiple-step directions;

b. develop directions for completing a basic task;

c. select and use appropriate reference sources and illustrative materials.

4. The student will respond to a variety of texts, including complete works, by generating interpretations using background knowledge and literary elements to determine responses, to the teacher's satisfaction.

5. When presented with a prompt designed to elicit narrative writing, the student will generate writing appropriate for the purpose of narration that demonstrates competence in the development of content and use of language, as evidenced in part by the capacity to:

a. develop a response that is related to the prompt;

b. prepare a fully developed beginning, middle, and end; 


\section{APPENDIX C: SAMPLELESSON PLANS}




\section{APPENDIX C}

April 10, 2000

American Literature I $\quad 2^{\text {nd }}$ Period

\section{Monday:}

\section{A Objectives, RLO\# 2 \& 4, PPO\# 1}

Procedures: Begin reading Poe's “Cask of Amontillado," identify elements of plot, setting, characterization, foreshadowing, and irony JN: "Man is unjust, but God is just; and finally justice triumphs" H.W.L.

Text/Materials: pp. 208-212

Evaluation: Formatively discussed

\section{Tuesday:}

A Objectives, PPO \#1, RLO \#2 \& 4

Procedures: Finish "Cask of Amontillado" noting the dialogue between Montressor \& Fortunato

$\mathrm{JN}$ : "The ability to discriminate between that which is true and that which is false is one of the last attainments of the human mind." J.F.C.

Text/Material: pp. 212-221

Evaluation: Formatively discussed

\section{Wednesday:}

C Objectives, PPO \#10, 11, 17, LLO \#3 \& 4

Procedures: Explicate, on board, setting, plot and characterization as they affect mood and tone of "Cask of..." $\mathrm{JN}$ : "It is more dangerous that even a guilty person should be punished without the forms of law than that he should escape." T.J.

Text/Material: based on pp. 208-221

Evaluation: Note taking observed 


\section{Thursday:}

C Objectives, PPO \#10, 11, 17, LLO \#3 \& 4

Procedures: Finish explication of plot, using the five-act plot diagram, drawn on the board: then review essay format

JN: "Nothing brings more pain than too much pleasure..." B.F.

Text/Materials: based on previous story

Evaluation: Note taking observed

\section{Friday:}

B Objectives, PPO \#1, 5, 8, WLO \#7, 8

Procedures: Individually workshop essay drafts of "A Cask of Amontillado" carefully noting the points developed in each body paragraph on plot, characterization and setting.

$\mathrm{JN}$ : "Courage is resistance to fear, mastery of fear - not absence of fear." Mark Twain

April 24, $2000 \quad$ American Literature I $\quad 2^{\text {nd }}$ Period

\section{Monday:}

D Objectives, PPO \#4, 11, 17, LLO \#2,3,4, OLO \#4

Procedures: Discuss text questions on "The Raven." Collect textual evidence (cite text) of the speaker losing his lucidity.

Text/Materials: pp. 226

Evaluation: Written answers summatively graded

\section{Tuesday:}

D Objectives, PPO \#4,11,17, OLO \#4

Procedures: Discuss genres of writing covered thus far: essays (Jefferson \& Paine), autobiography 
(Franklin)- non-fiction, short (horror) stories (Hawthorne \& Poe)- fiction, and

subject matter of the Romantic - vs - Transcendentalists

Text/Material: p. 254 and notes on the board

Evaluation: Observed notes taken

\section{Wednesday:}

\section{A Objectives, PPO \#2, RLO \#2,4}

Procedures: Begin Emerson's "Self-Reliance" essay reconciling his personal spiritual "transcendental" philosophy with common public perceptions then and now

$\mathrm{JN}$ : The true test of civilization is, not the census, nor the size of the cities, nor the crop - no, but the kind of man the country turns out." R.W.Emerson

Text/Material: pp. 250-257

Evaluation: Class discussion

\section{Thursday:}

\section{A, D Objectives, PPO \# 6,8,10,11,17, OLO \#4}

Procedures: Discuss Emerson's ideas and how they might be applied (questions on p. 258).

$\mathrm{JN}$ : "Whatever course you decide upon, there is always someone to tell you that you are wrong." R.W.Emerson

Text/Material: p. 258

Evaluation: Formative discussion

\section{Friday:}

D Objectives, PPO \#4,11,17, OLO \#4

Procedures: Classroom discussion: free thinking "Self-Reliance"- vs - ostracism and isolationism

Text/Material: Based on text questions 


\section{APPENDIX D: PARTICIPANT CONSENT FORMS}


WesthrginitaLriversity

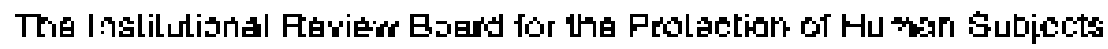

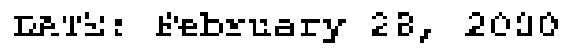

WOTICE OF APEFOHA EOE PEOTOCOL H.S. ̈̈147G4

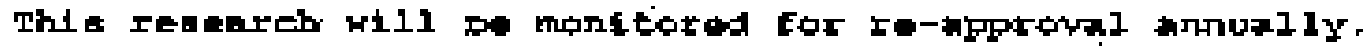

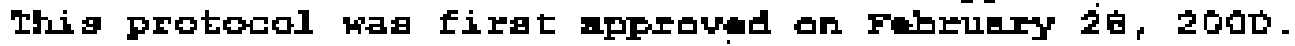

To: Allér hlbarte

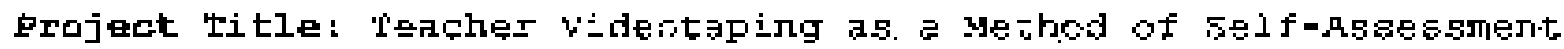

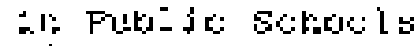

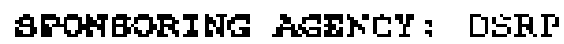

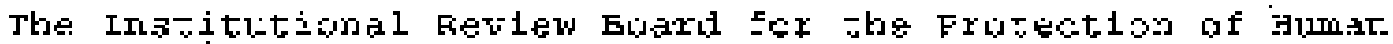

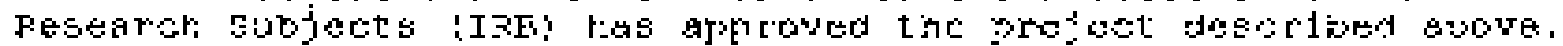
Apperval was saset on the iescriptive raterial and profediras you

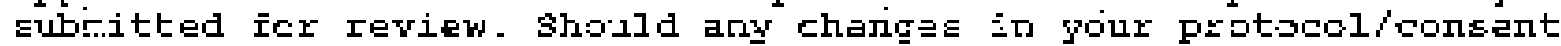

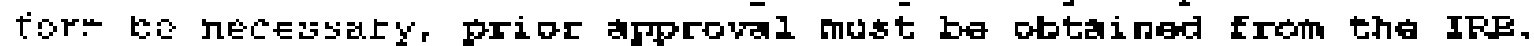

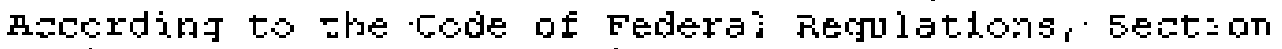

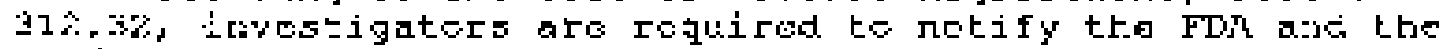

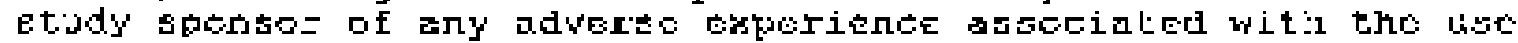

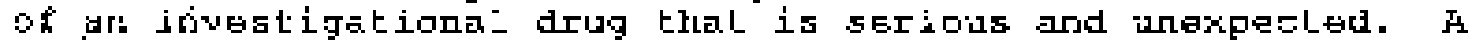

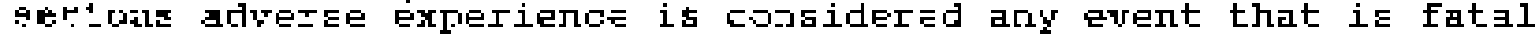

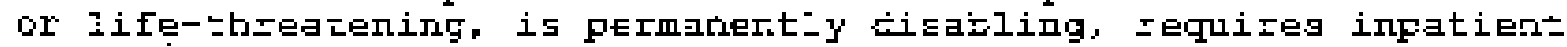

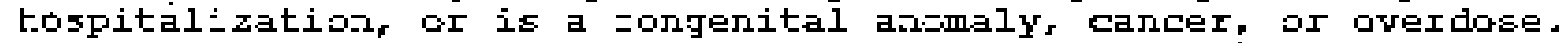

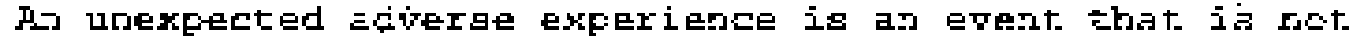

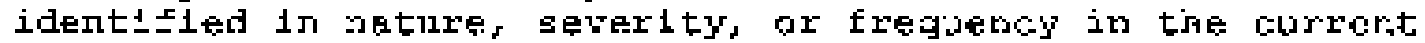

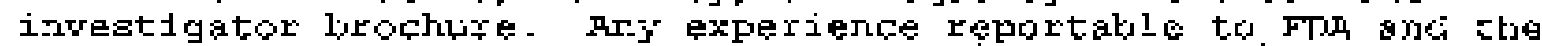

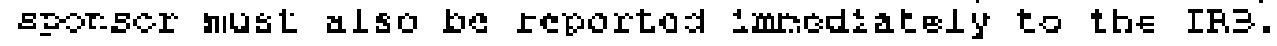

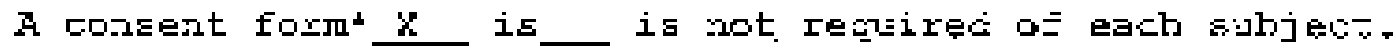

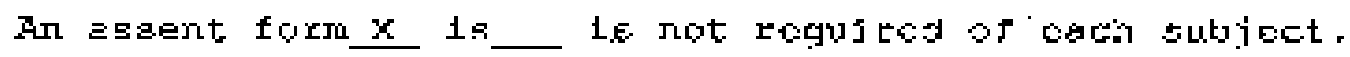

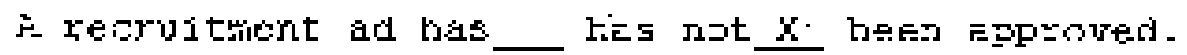

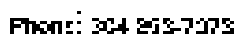
Fos out ejs icte.

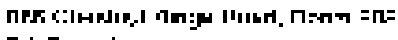

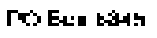

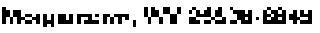

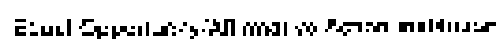


Page 2-

\section{Alberts}

HS \#14704

February 28, 2000

* Only copies of the consent and/or assent form with the IRB's approval stamp may be used with human subject research. It is the responsibility of the investigator to submit a revised consent form for the IRB's approval should funding be obtained. This stamped consent form must then be used for subjects enrolled. A copy of each subject's signed Consent/Assent Form must be retained by the investigator and accessible to federal regulatory authorities for at least three years after the study is completed.

Marzan J. Turner

IRB/ACUC Administrator

MJT/baw 


\section{WWestVirginiaUniversity \\ College of Human Resources and Education}

\section{Assent Form}

"TEACHER VIDEOTAPING as a METHOD of SELF-ASSESSMENT in PUBLC SCHOOLS"

Introduction. I, been explained to me by S. Alan Alberts II.

have been asked to be in this research study, which has

Purpose of the study. I have been told that the purpose of this study is for my teacher (Mr. Alberts) to improve his teaching ability by recording our class on videotape.

Description of procedures. This study will be performed at School. I will

be asked to behave appropriately focusing on the lesson (not the camera). I have been given an opportunity to ask questions regarding this research. I understand that the focus of this study is the instructor's teaching behavior and actions; we, the students, are not the primary focus of this research.

Discomforts. Some of the questions (during this American Literature I course) will be difficult and I may not enjoy trying to answer them.

Benefits. I understand that this study is not expected to help me., but what they learn from the study may help other people.

Confidentiality. I have been promised that anything they learn about me in this study will be kept as secret as possible.

Voluntary Participation. I have been told I do not have to do this. No one will be mad at me if I refuse to do this or if I decide to quit. I have been allowed to ask questions about the research, and all of my questions were answered. I will receive a copy of this form after I sign it.

I willingly agree to be in this study.

Signature of subject

Date

Signature of Investigator or Investigator's Representative

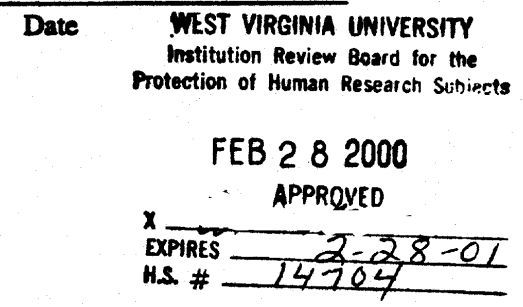

*version $\# 3$ 3/1/00 


\section{PARENTAL or GUARDIAN CONSENT FORM}

"TEACHER VIDEOTAPING as a METHOD of SELF-ASSESSMENT in PUBLIC SCHOOLS" Introduction. I , have been asked to allow my child Virginia University, he has explained the study to me.

Purpose of the study. The purpose of this study is to learn more about public school teachers improving their own classroom teaching performance by assessing themselves in action using a videocamera to record the lesson.

Description of Procedures. This study will be performed School. My child will be asked to behave appropriately focusing on the lesson (not the camera). I have been given an opportunity to ask questions regarding this research. I understand that the focus of this study is the instructor's behavior and actions; the students are not the primary focus of this research.

Risk and Discomforts. There are no known or expected risks from participating in this study, except for mild frustration, sometimes associated with performance when initially exposed to the videocamera. Alternatives. I understand that my child does not have to participate in this study.

Risks and Benefits. I understand that this study is not expected to be of direct benefit to my child, but the knowledge gained may be of benefits to others.

Contract Persons. For more information about this research, I can contact Mr. Alberts at (614) or his supervisor, Dr. Perry Phillips, at (304) 293-3637 ext. 6.

For information regarding my child's rights as a research subject, I may contact the Executive Secretary of the Institution Review Board at (304) 293-7073.

Confidentiality. I understand that any information obtained as a result of my child's participation in this research will be kept as confidential as legally possible. I understand that these research records, just like hospital records, may be subpoenaed by court order or may be inspected by federal regulatory authorities. In any publications that result from this research, neither my name nor that of my child nor any information from which might be identified, will be published without my consent.

Voluntary Participation. Participation in this study is voluntary. I understand that I may withdraw my child from this study at any time. Refusal to participate or withdraw will involve no penalty or loss of benefits for me or my child. I have been given the opportunity to ask questions about the research, and I have received answers concerning areas I did not understand. Upon signing this form, I will receive a copy.

I willingly consent to my child's participation in this study.

Signature of Parent or Guardian

YIEST VIRGINIA UNIVERSITY Institution Review Board for the

Signature of Investigator or Investigator's Rerecentive

Signature of Investigator or Investigator's Representative Protection of Human Research is:biects

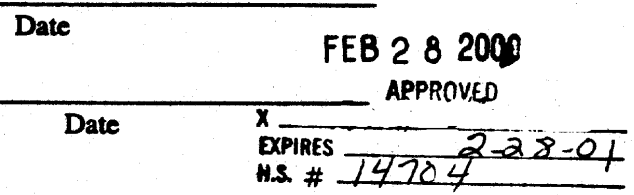

*version \#3 3/1/00 


\section{APPENDIX E: REFLECTION GUIDE}




\section{Master List of Daily Criteria to be reflected upon:}

\section{Framing the Context}

1. Connecting to past class lessons with relevance stated?

2. Framing questions that relate to student knowledge?

3. Are students engaged in the issues of concept?

4. Are concept and skill attainment goals clearly laid out?

5. Is there a logical coherent lesson structure?

6. Is the whole (unit) to part (lesson) sequenced in a way that leads to analysis/synthesis of the concept using the identified skills?

\section{Question Distribution}

1. Are questions being equitably distributed around the room?

2. Are students encouraged to take risks and speculate?

3 Are students given positive reinforcement for genuinely attempting the questions?

3. Are negative (off task) answers being modified without derailing the lesson?

6. Are students at the top and bottom of the cognitive range being formatively monitored for concept and skill attainment? 


\section{Level of Taxonomy Addressed}

1. Are analogies specifically addressing each responding student's cognitive ability?

2. Does each follow up question attempt to address the next cognitive level?

3. Does the lesson activity begin at a concept and skill mastery level?

4. Does the lesson activity/unit culminate in a higher level of cognitive mastery?

5. At the end of a lesson/unit, can students predict the outcome?

\section{Lesson Modifications}

1. Were the lesson goals met?

2. If the desired skill or concept was not evidenced by a skill or concept attained, were lesson plans changed?

3. What modifications were made to the lessons planned?

4. Were clear, time scheduled, concepts attained as planned?

5. What were the strong and week points of this lesson?

* This rubric was only used as a guide. 


\section{APPENDIX F: ASSESSMENT REVIEWS: PRAXIS III, PATHWISE AND LOCAL SCHOOLS}


ntral Ohio Regional Coordinator for Praxis III

(O) 614

(H) 614

1. candidate profile (pages 65 - 66 of OG) completed and forwarded to Ohio Department of Education

2. assignment letter sent to Praxis III Assessor with copy of candidate profile

3. letter sent to EYT (Fntry-Year Teacher) with name of assessor and copies of:

- class profile (pages $67-69$ of $O G$ )

- instructional profile (pages $71-73$ of $O G$ )

4. assessor calls to arrange a mutwally convenient time for visit

5. EYT, with copies to the principal and regional coordinator, receives confirmation letter regarding date and times for visit

6. for visit, EYT must have following prepared:

- class profile (pages $67-69$ of $O G$ ) on form sent by regional coordinator

- instructional profile (pages $71-73$ of $O G$ ) on form sent by regional coordinator

7. day of assessment visit (purpose of which is to gather data) requires:

- $\quad 30-45$ minutes for assessor to independently review:

$\checkmark \quad$ class profile

$\checkmark \quad$ instructional profile

- $30-45$ minutes for pre-observation interview (pages 75 - 77 of OG): EYT and assessor

- 35 - 60 minutes (one complete class period) for observing a class selected by EYT (pages $79-80$ of OG): EYT, assessor and students

- $30-45$ minutes for post-observation interview (pages $81-84$ of OG): EYT and assessor

- assessor leaves with NO feedback to EYT, mentor teacher or principal

8. following the assessment visit:

- assessor independently completes a record of evidence based on all of the data gathered, using the scoring rules described at the end of each criterion (pages 85 - 96 of OG)

- completed record of evidence is forwarded to the Ohio Department of Education with copy to the regional coordinator

- Ohio Department of Education prepares final report of summary statements and ratings and sends rannert dirartly to FVVT 


\section{State of Ohio Department of Education}

Professional Development and Licensure

Marilyn Troyer, Interim Director, 65 South Front Street, Room 1009, Columbus 43215-4183, (614) 466-2761

\section{MEMORANDUM}

To: Ohio Beginning Teachers

Participants in Entry Year Program

From: Rae Harriott-White. PRAXIS Program Administrator

Division of Professional Development and Licensure

Robert Hite, PRAXIS III Regional Coordinator, Central Region

Re: PRAXIS III Assessment Schedule/Materials

Date: Fall/Winter 1999

We hope your new teaching position is one that has been rewarding and that you are gaining confidence with each day. We appreciate your willingness to be a part of this Entry Year pilot program.

You should be working with your district mentor each week. and using him or her to support and assist you. As a part of this Praxis III pilot study, we will be having two assessments of your classroom teaching this year. This will NOT impact your state certificate, nor your district contract. Please view it as an opportunity for professional growth.

Enclosed are the Class Profile (gray), and the Instructional Profile (beige) that you will need to complete for your assessor prior to the pre-observation interview. After your assessor

contacts you. please make arrangements to complete these two forms for the observation day.

Your assessor will be contacting you to set a mutually convenient appointment. Your assessor has been given a copy of your Candidate Profile and will be contacting you for an appointment and observation. Should you have any questions or concerns, please call Robert Hite, your Praxis III Regional Coordinator, at (614) 236-6135 or e-mail rhite@capital.edu

Thank you for your involvement in the Entry Year Program with the Praxis III assessment and commitment to the education of Ohio's students.

cc: Mentor 


\section{State of Ohio Department of Education}

Professional Development and Licensure

Marilyn Troyer, Interim Director, 65 South Front Street., Room 1009, Columbus 43215-4183, (614) 466-2761

\section{MEMORANDUM}

To:

From: , Praxis III Assessor

Re: Entry Year Beginning Teacher Assessment Confirmation

Date: January 3,2000

We appreciate your commitment to the Ohio Department of Education Entry Year Pilot Project and look forward to observing you on this round using the ETS PRAXIS III Teacher Assessment Strategies. You should have received two forms that relate to this observation: the Class Profile and the Instruction Profile. Please prepare these for the teaching activity for the day of observation and arrange to either mail them directly to me, or have them available in the office prior to our meeting.

We need to have a Preobservation and Postobservation interview (25-45 minutes) in a location that is free from interruption and interference from the routine activity of the school day. During the interviews you will need to have release time from your normal classroom duties. Together we can arrange this with your building principal. Our schedule for the day of observation is as follows:

Date: Wednesday, January 19, 2000

$6: 45$ Arrival at School Site/Report to Office

$6: 50$ Preobservation Teacher Interview (25-45 minutes)

8. 10 Classroom Teacher Observation (30-60 minutes)

9. 30 Postobservation Teacher Interview (25-45 minutes)

10:15 Report to Office/Depart School Site

Should you have any questions or situations that relate to our observation, please contact me at:

Thank you for your assistance.

$\mathrm{cc}:$ Principal , Regional Coordinator 


\section{Praxis III Observation Confirmation Form}

This form needs to be returned with your hard copy of the ROE to your Regional Coordinator. (NOTE: You will need the college/university information when you submit the Record of Evidence via Internct in fulure this will be on the Candidate Profile.)

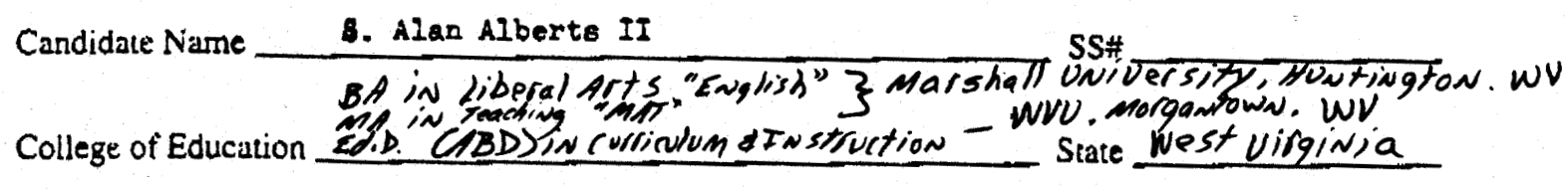

Assessor Name RPDC $\# 01$

Date of Observation January 19, 2000

Check one: $\square$ First Observation $\square$ Second Observation

Please check that these events have occurred:
G Pre-Observation Incerview
$\checkmark$ Class Observation
I Post-Observation Interview

\begin{tabular}{lll} 
Signature: & Entry Year Teacher & January 19, 2000 \\
Signature: & Praxis III Assessor & January 19, 2000 \\
\hline Date
\end{tabular} 
PRAXIS III: RECORD OF EVIDENCE

Candidate Name: S. Alan Alberts

\section{Candidate ID\#: \\ Assessor ID\#: RPDC \#01 District: \\ District: \\ Subject(s): American Literature} Assessor Name: -

School:

Grades: $11^{\text {th }}$

Date of Obs. 01-19-00
Start Time of Obs. 8:17 AM End Time of Obs. 8:57 AM

\section{[A] ORGANIZING CONTENT KNOWLEDGE FOR STUDENT LEARNING}

A1. Becoming familiar with relevant aspects of students' background knowledge and experiences Evaluation [2.5]

SUMMARY STATEMENT: The teacher demonstrates understanding of the importance of becoming familiar with students' background experience (The teacher has identified $80 \%$ of the students in the class to be in the average range; $10 \%$ above average and $10 \%$ below; 1 student has a learning disability), describes procedures for obtaining this information (The teacher claims to have learned about the students in this class through earlier reading comprehension practices in class), and has some familiarity with the background knowledge and experience of many students in the class. ( $T$-"I know some students from previous classes I have taught." And "I know students outside of class in many different settings.")

A2. Articulating clear learning goals for the lesson that are appropriate for the students Evaluation [2.5]

SUMMARY STATEMENT: The teacher articulates clear learning goals, appropriate for the students (T-"Students will gain an awareness of the social context that prevailed in Colonial America that led the Founding Fathers to revolutionary sentiment.")and offers an explanation of why they are important for the students ("This is the introductory lesson, seminal to the document under study, and the beginning of a chronological study.".)

A3. Demonstrating an understanding of the connections between the content that was learned previously, the current content, and the content that remains to be learned in the future

\section{Evaluation [2.5]}

SUMMARY STATEMENT: The teacher accurately explains how the content of this lesson relates to the content of previous lessons (T."A brief overview of Crevecoeur's economic, academic, and social status was given as a contextual preface."), and fits within the structure of future lessons ( $T$ - "This introduction/overview establishes a baseline paradigm for the 'Founders' Writing") ( $T$ - "What the students know from previous discussions connects socially and politically to the times.")

A4. Creating or selecting teaching methods, learning activities and instructional materials or other resources that are appropriate for the students and that are aligned with the goals of the lesson Evaluation [3.0]

SUMMARY STATEMENT: The teacher chooses methods, activities and materials (T- "Since the class is exceptionally small, a Socratically oriented discussion will be generated regarding the social and economic climate of the time period.") (T-"We will work through previously 
written text questions, identify four social strata divisions, and locate specific passages from the essay.") (T-"I will use text, chalkboard and notes.") are related, aligned with the goals of the lesson and appropriate to the students in general. (T-"Text questions [1] seem to delineate the pattern of social classification, breakdown [2] stratification further to relate present social conditions; and relate specific information to both [1] and [2].") These methods, activities and materials seem to allow a differentiated learning experience for individuals. (T-"Small group size makes Socratic style most productive in seeing student understanding and consensus is possible.")

A5. Creating or selecting evaluation strategies that are appropriate for the students and that are aligned Evaluation [2.0] with the goals of the lesson

SUMMARY STATEMENT: The teacher has a plan for evaluating student learning (Discussion is based on size and lesson plan grouping) that is aligned with the goals of the lesson and appropriate to the students. (Small group size offers the ability to use Socratic, consensus method.) (T-"Verbal evaluation today, a summative assessment is incorporated into the essay assignments.")

\section{[B] CREATING AN ENVIRONMENT FOR STUDENT LEARNING}

B1. Creating a climate that promotes fairness Evaluation [3.0]

SUMMARY STATEMENT: The teacher appears to be fair in the treatment of students (The teacher uses both direct and indirect questioning to include all students.), encouraging positive as well as fair treatment (e.g. S-"Native Americans." T-"You've created a new category I didn't think of, good!") and actively promotes general faimess among students throughout the lesson. (While taking information for a chart on the chalkboard, T-“....including?..." [all students respond] "Okay, one at a time.")

B2. Establishing and maintaining rapport with students Evaluation [2.0]

SUMMARY STATEMENT: The teacher establishes a basic level of rapport with students (T"r. " write the quote on the board.") (The teacher speaks to one student, "What do you think? Do you agree? Can you add anything?") and shows evidence of interest in students involvement in class. (The teacher asks a question... waits...student responds, T-"You're right, you are absolutely right!") (T-"You wouldn't want the president to be an $8^{\text {th }}$ grade dropout?!" Students laugh.)

B3. Communicating challenging learning expectations to each student Evaluation [2.5]

SUMMARY STATEMENT: The teacher does nothing to communicate to any student that he or she is incapable of meeting learning expectations; and in fact makes attempts to encourage participation. (The teacher addresses . , who has entered the class on his first day of this new course: T-"I know you didn't read it, but what do you think?") 
B4. Establishing and maintaining consistent standards of classroom behavior Evaluation [2.5]

SUMMARY STATEMENT: The teacher makes generally appropriate attempts to maintain appropriate behavior in ways that demonstrate respect for the students. (T-w do you have your book? S-"I have a book." T-"I gave it to you yesterday." S-"Uh-huh.") (The students have good posture in class, enjoy a comfortable atmosphere and participate throughout the class.)

B5. Making the physical environment as safe and conducive to learning as possible Evaluation [2.0]

SUMMARY STATEMENT: The teacher creates a physical environment that is safe and does not intentionally interfere with learning (The teacher travels to several classrooms. The classroom for this lesson is used for a large Health class. The teacher's American Literature class has six students. While they stayed in one section of the room, the teacher did not attempt to more them closer together nor closer to the chalkboard.)

\section{[C] TEACHING FOR STUDENT LEARNING}

C1. Making learning goals and instructional procedures clear to students Evaluation [2.0]

SUMMARY STATEMENT: The teacher provides students information about the instructional procedures of the lesson (The teacher explains the format of quotations and discussion) (T-"I hope you see, by the way, I am drawing this [chart] up on the board as a way to have information to start you thinking about things for writing later.")

C2. Making content comprehensible to students Evaluation [3.0]

SUMMARY STATEMENT: The content is accurate and appears to be comprehensible to the students. (T-"Read the quote, are there any ideas from yesterday?") (T-"Summarize ideas; what is the main idea?") (The teacher also repeats, restates and clarifies student answers.) (T-"Is that what we are saying?") The lesson as a whole was logical and had a coherent structure. (The teacher created a data chart while students answered; and the teacher asked every student to respond.)

C3. Encouraging students to extend their thinking

\section{Evaluation [3.0]}

SUMMARY STATEMENT: The teacher uses activities or strategies that are designed to actively encourage students to think independently, creatively, or critically about the content being taught. (T-" read question \#1; What do you think, 2. .?" "Anything to add ") (T-"So you believe what Jefferson says? - you did not read, I know, but what do you think?") (The teacher goes to the board, writes classifications. The teacher invites and adds student input.) (T"Who do we not have?" "What does the author think, " ?") 
C4. Monitoring students' understanding of content through a variety of means, providing feedback to students to assist learning, and adjusting learning activities as the situation demands

Evaluation [2.0]

SUMMARY STATEMENT: The teacher monitors students' understanding of the content. (T"Anything to add?" "Do you think this is the case today?") The students receive feedback as necessary. (T-"Good point, good point; explain.") (The teacher writes all student data on the board. T-"That's right" nods in agreement as student talks.)

C5. Using instructional time effectively

Evaluation [2.5]

SUMMARY STATEMENT: The teacher provides students with activities of instructional value during the majority of the instructional time (The teacher provides quotations, procedures for answering questions and discussion opportunities.), and paces them appropriately. (Opening quote creates discussion, use of board chart illustrates for students the categories for discussion.) Non-instructional procedural matters do not occupy an excessive amount of time. (The small class size enables the teacher to keep students focused and to keep them engaged from bell to bell.)

\section{[D] TEACHER PROFESSIONALISM}

D1. Reflecting on the extent to which the learning goals were met Evaluation [3.5]

SUMMARY STATEMENT: The teacher accurately identifies strengths (T-“Overall students stayed on task; the discussion had its own dynamic." "The verbal feedback was good. The evidence provided support, substantiation of theoretical constructs."), and weaknesses (T-“At times the students had ideas I hadn't figured on.") of the lesson in relation to the learning goals and describes in general terms how he could use the experience from the lesson in future instruction (T-"Perhaps I could use a stronger advanced organizer, though the Crevecoeur essay provides a good synopsis."). In addition, the teacher supports his judgments with specific evidence from the observation reflection. (T-"Students were able to come to consensus before moving to another issue." "I anticipated that once there were categories on the board students would fall in, indicating they stayed with the text.") (T-"The text framed issues fairly well and created a baseline.") (T-“Group size is an asset, a larger group would not likely have reached consensus; skill competency would be lower.")

D2. Demonstrating a sense of efficacy

Evaluation [3.0]

SUMMARY STATEMENT: The teacher suggests specific, practical actions that he intends to take to help specific students who are not meeting the learning goals. (T-"From her non-verbal cues, I think she might have a better chance to express herself in the essay. It will help if I help pick out differences of opinion she might have with other students.") (T."I think _... is simply bored with these issues on which he has already conceptualized.") (T-"I will follow up with each student as much as possible to customize the essays to reflect the facets of their interests.") 
C4. Monitoring students' understanding of content through a variety of means, providing feedback to students to assist learning, and adjusting learning activities as the situation demands

\section{Evaluation [2.0]}

SUMMARY STATEMENT: The teacher monitors students' understanding of the content. (T"Anything to add?" "Do you think this is the case today?") The students receive feedback as necessary. (T-"Good point, good point; explain.") (The teacher writes all student data on the board. T-"That's right" nods in agreement as student talks.)

C5. Using instructional time effectively

Evaluation [2.5]

SUMMARY STATEMENT: The teacher provides students with activities of instructional value during the majority of the instructional time (The teacher provides quotations, procedures for answering questions and discussion opportunities.), and paces them appropriately. (Opening quote creates discussion, use of board chart illustrates for students the categories for discussion.) Non-instructional procedural matters do not occupy an excessive amount of time. (The small class size enables the teacher to keep students focused and to keep them engaged from bell to bell.)

\section{[D] TEACHER PROFESSIONALISM}

D1. Reflecting on the extent to which the learning goals were met Evaluation [3.5]

SUMMARY STATEMENT: The teacher accurately identifies strengths (T-"Overall students stayed on task; the discussion had its own dynamic." "The verbal feedback was good. The evidence provided support, substantiation of theoretical constructs."), and weaknesses (T-"At times the students had ideas I hadn't figured on.") of the lesson in relation to the learning goals and describes in general terms how he could use the experience from the lesson in future instruction ( $T$-"Perhaps I could use a stronger advanced organizer, though the Crevecoeur essay provides a good synopsis."). In addition, the teacher supports his judgments with specific evidence from the observation reflection. ( $T$-"Students were able to come to consensus before moving to another issue." "I anticipated that once there were categories on the board students would fall in, indicating they stayed with the text.") (T-"The text framed issues fairly well and created a baseline.") (T-"Group size is an asset, a larger group would not likely have reached consensus; skill competency would be lower.")

D2. Demonstrating a sense of efficacy

Evaluation [3.0]

SUMMARY STATEMENT: The teacher suggests specific, practical actions that he intends to take to help specific students who are not meeting the learning goals. (T-"From her non-verbal cues, I think she might have a better chance to express herself in the essay. It will help if I help pick out differences of opinion she might have with other students.") (T-"I think _... is simply bored with these issues on which he has already conceptualized.") (T-"I will follow up with each student as much as possible to customize the essays to reflect the facets of their interests.") 


\section{MEMORANDUM}

To: Stephenclelente, Entry Year Teacher

From. , Praxis III Assessor

Re:' Entry Year Beginning Teacher Assessment Confirmation

Date:

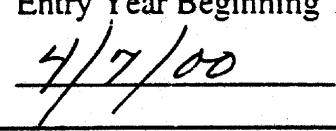

We appreciate your commitment to the Ohio Department of Education Entry Year Pilot Project and look forward to observing you on this round using the ETS PRAXIS III Teacher Assessment Strategies. You should have received two forms that relate to this observation: the Class Profile and the Instruction Profile. Please prepare these for the teaching activity for the day of observation and arrange to them ave them available in the office prior to our meeting.

We need to have a Preobservation and Postobservation interview (25-45 minutes) in a location that is free from interruption and interference from the routine activity of the school day. During the interviews you will need to have release time from your normal classroom duties. Together we can arrange this with your building principal. Our schedule for the day of observation is as follows:

Date: apsil 12,2000/ Wed,

7 oo AM Arrival at School Site/Report to Office

$7 \cos ^{A M}$

8. 15 A Classroom Teacher Observation (30-60 minutes)

$9: 15$ AM Postobservation Teacher Interview (25-45 minutes)

__.___ Report to Office/Depart School Site

Should you have any questions or situations that relate to our observation, please contact me at:

(614)

Thank you for your assistance.

cc: Principal

Regional Coordinator 


\section{State of Ohio Department of Education

John E. Nichelson

Administrator

Educator Preparation

Ohio Departments Building, Room 1009, 65 South Front Street, Columbus 43215-4183, (614) 752-9447

M E M

To: Beginning Ohio Teachers

Participants in PRAXIS III Pilot study

From:

Rae Harriott-White, PRAXIS Administrator

Center for the Teaching Profession

Re: Evaluation Results

Date: Spring/Summer 2000

Enclosed please find the Record of Evidence based upon your second evaluation. Please excuse the delay in your report due to computer problems. The four domains are outlined as are the nineteen specific criteria areas. Take this opportunity to review those domains in which you still may wish to concentrate improvement for next year, again sharing it with individuals with whom you are comfortable. It is your decision as to how you wish to share your results. Should you have any specific guestions related to the results, you may call me or speak with your mentors or area coordinator.

Since the school year has drawn to a close, there will be no additional observations by an assessor, but we hope that your work with mentors and colleagues will continue next school year. Enciosed is a inal evaluation form for you to complete.

Thank you for your involvement in the PRAXIS III pilot program. We hope you have found it has assisted you professionally. 


\section{Stephen Alberts}

$1 / 19 / 2000$

\section{Domain A Scores and Summary Comments}

A1 Score: 2.0

Summary:

The teacher describes some understanding of why it is important to become familiar with students' background so that he can encourage them to bring their own life experiences as analogies. He describes one procedure (informal class discussions) that he uses to obtain

information and has some familiarity with the background knowledge (writing skills) and experiences of his students.

A2 Score: 2.0

Summary:

The teacher articulates clear learning goals that are appropriate for the students.

A3 Score: 3.0

Summary:

The teacher accurately explains how the content of this lesson(outline) relates to the content of previous lessons (authors already read) and future lessons (use the generalizations and interpretations of the text to write a rough draft of an essay). The lesson addresses Poe's writing within the historical overview of American Literature.

A4 Score: 2.5

Summary:

The teacher chooses methods (Socratic lecture), activities (students

contribute and copy notes from the board). and materials (graphic organizer of notes) that are aligned with the goals of the lesson and are appropriate to the students in general.

A5 Score: 2.5

Summary:

Teacher has a plan for systemically evaluating student learning (looking at draft and inal copy) that is aligated with the goals of the lesson and appropriate to the students. However he does not indicate how he will use the results of this evaluation for future planning.

\section{Domain B Scores and Summary Comments}

B1 Score: 2.5

Summary:

Teacher calls on every student during the discussion, although he frequently does not allow enough time for a student to respond before calling on another student for the answer. Since other students often answered a question before the called upon student had a chance to respond, there is no evidence that the teacher actively encourages fairness among students.

B2 Score: 2.5

Summary:

Teacher establishes a basic level of rapport with the students and permits a relaxed, casual atmosphere.

B3 Score: 3.0

Summary

T expects students to extend their thinking by asking probing questions during discussion and actively encourages students to meet challenging learning experiences.

B4 Score: 3.0

Summary:

The students' behavior during the lesson is consistently appropriate.

B5 Score: 2.5

Summary:

The teacher creates a physical environment in which learning takes place and some provisions are made to accommodate students' need for a informal setting. 


\section{Stephen Alberts}

\section{$1 / 19 / 2000$}

\section{Domain C Scores and Summary Comments}

\section{C1 Score: 3.0}

Summary:

Siudents receive and seem io understand the learning goals. They receive clear and accurate infomation about the instructional procedures and how they relate to the next assignment.

C2 Score: 30

Summary:

The teacher conveyed content of the lesson through a logical and coherent sintcture. It was accurate and comprehensible to most of the siudent:.

C3 Score: 2.5

\section{Summary:}

Tencher encourages sludents to think independently and creatively on the content being studicd by using open-ended question, but seems to be pressured by time constraints to quickly give the ansuer in the form of noter for studenls to copy.

C4 Score: 70

Summary:

Teacher monitors students' understanding with continuous questions related in the content. Stutequtis revive substantive feedback tarnuth additional commemts relating to the content.

C.5 Score: 2.5

Sammary:

Although the pacing sizems to allow little time for retlection, the leacher provides students with an activity of instwetional vatue the entire class time and doninsteuctional duties were pstrormed effictently.

\section{Domain D Scores and Summary Comments}

D1 Score: 3.0

Summary:

Teacher describes the strengths and weaknesses of the lesson in relation to the

leaming goal and says that he would use the same Socratic Questioning

method because if works wilh a small group of students. He said he would

focus bis questioning on nore concrete questions because some students had

difficulcy making the 'jumn .. co abstract answers.'

\section{D2 Score: 1.5}

Summary:

Teacher makes no attempt to find ways to help specilic students who were nol meeting the learning goals that day because he believed the reason was that

those two students had been absent and had not read the assigned short story.

I might mot try anything different in the future because if they are prepared

they perform the sime:

Dạ Seore: 2.0

Summary:

Teacher demonstrates knowledge of resqurees and attempts to consult with colleagues when necessary on manets rílated to learning and instruction.

D4 Score: 3.0

Summary:

Teacher demonstrales knowledge of forms of communication stelephone. personal contact en opel house, and considered using letters), that he uses to cotanumicale with parents or guardians and describes sittations ('If a student

is not performing in class, is in danger of nol passing. or receiving a $D$ average ") in which he would ise theste strategits. 
[3)

ENTRY YEAR aO of 7007

(A) Entry Year Program

(1) The Entry Year Progtam shall be surcessfully completed prior to issuarce of a professionat license to a teacher or principal. Completion of the entry year as an assistant principal meets the Entry Year Program requirements tor the principal license.

(2) The Entry Year Program shall include both a formal program of support, including mentoring to foster professional growth of the individual, and assessment of the performance of the begiruning teacher or principal.

(3) A candidate for the Entry Year Program shall hold a provisional license issued pursuant to paragraph (A) of Rule 3301-24-05 of this chapter for a teacher; ar paragraph (B) of Rute 3301-24-05 of this chapter for a principat.

(4) The Entry Year Progratn shall be one academic year in length which sthall indude a minimum of one hundred twenty school days. In those instances when the teacher or principal is employed atter the beginning of the school year, the Entry Year Progran shati be a minimum of one hundred twenty schoot days. Teachers or principals may attempt to complete the Entry Year. Program requirements no more than two times under the provisional license. Failure to complete the entry year requirements successfully after the second attempt will result in loss of the provisional license until such time as the candidate completes additional coursework, supervised field experiences, and/or clinical experiences as designated by a college or university approved for educator preparation, and is recommended by such college or university.

(5) The Entry Year Program shall be developed by school personnel, a majority of whom shall be practicing classroom keachers, following guidelines established by the Ohio Departenent of Education. School districts, chartered nonpublic schools, or consortiums of schools desiting to participate in the Entry Yeat Program shall engage in collaboration with colleges or universities preparing teachers. The entry year does not replace employment evaluation. Entry year assessment is exclusively used for licensure determination.

(6) Districts and chartered rongublic schools shatl provide entry year teachers or principals full salary as determined by appropriate placement on the school distrint or sinol salary schedule.

(B) Entry Year Assessment

(1) Ал assessment of skills and abilities appropriate to the field of licensure shall be used to assess the ertry year teacher or principal.

(2) Assessment of the skills and abilities of the entry yeak teacher or principal shall be prescribed with the involventent of the profession, shall be adrninistered urder the authority of the State Boand of Education, and shall:

(a) Encompass the perfortunance-based licensure requirements specified in Rule 3301-24-02 of this chapter for beginning teachers, with approptiate roodifications for principals; and

(b) Be conducted throughout the entry year period.

(C) Upon successful completion of the Entry Year Program and assessment, the individual shall be deemed to have met the requirements for professionat licensure.

NEEII Praxis III = certification 
SCHOOLS

CHECKLIST FOR TEACHER EVALUATION

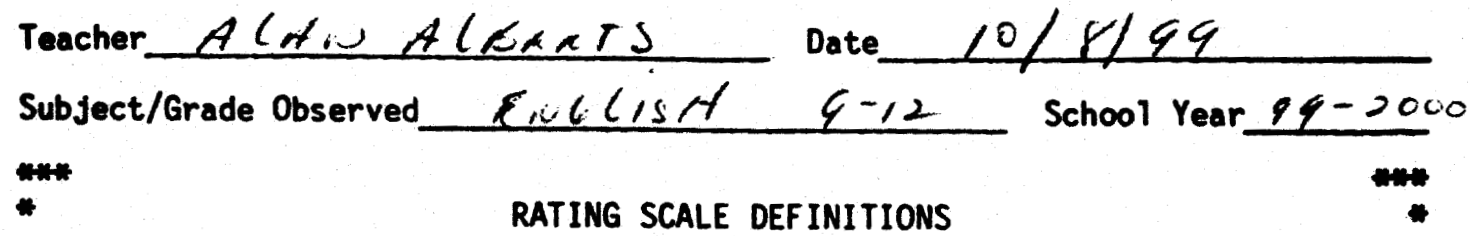

COMMENDABLE - Above what is routinely expected of all staff

EFFECTIVE - At the level of performance that is routinely expected of all staff

NEEDS IMPROVEMENT - Generally of acceptable quality, but in some espects improvement is needed

NOT SATISFACTORY - Generally below what is routinely expected of all staff

NO OPPORTUNITY TO OBSERVE - Evaluator has not been able to observe this particular area enough to make a judgment

$*$

*⿻*从一

\section{INSTRUCTIONAL EFFECTIVENESS}

1. Possesses and demonstrates a sound knowledge of subjects taught.

2. Prepares lesson plans which follow district guidelines and curriculum guides.

3. Plans and prepares instructional activities to meet individual differences.

4. Maintains organized lesson plans and adequate records of students' progress.

5. Establishes instructional objectives and goals for dally lessons and long range units.

6. Provides clear explanations and instructions.

7. Uses varted and adaptable teaching techniques.

8. Has clear evaluation procedures.

9. Provides frequent feedback to students.

10. Provides an environment that encourages learning.

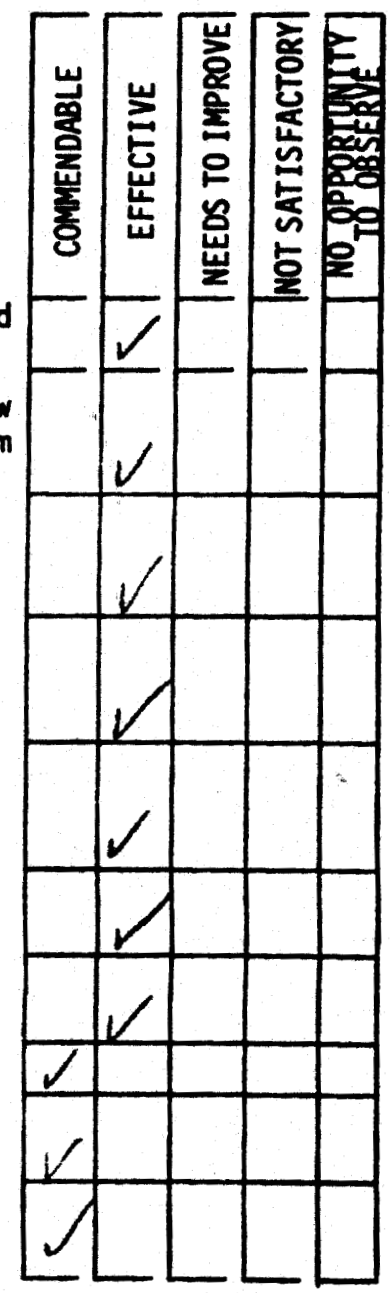

APPRAISAL RECORD, FORM 2 


\section{RELATIONSHIP WITH PUPILS}

1. Respects, understands, and likes children.

2. Maintains professional rapport with students.

3. Maintains established classroom and school discipline policies.

4. Promotes respect among students and towards learning.

5. Maintains a consistent and fair approach in dealing with students.

6. Encourages independent thinking and problem solving.

\section{STAFF RELATIONSHIPS}

1. Works cooperatively with colleagues and administrators.

2. Assumes fair share of responsibility for schoolwide activities.

3. Accepts and profits from supervision.

PARENT-COMMUNITY RELATIONSHIPS

1. Demonstrates willingness to communicate with parents about students' educational experiences.

2. Communicates positively with the community about the school, the district, and the educational program.

3. Supports school and/or community activities.

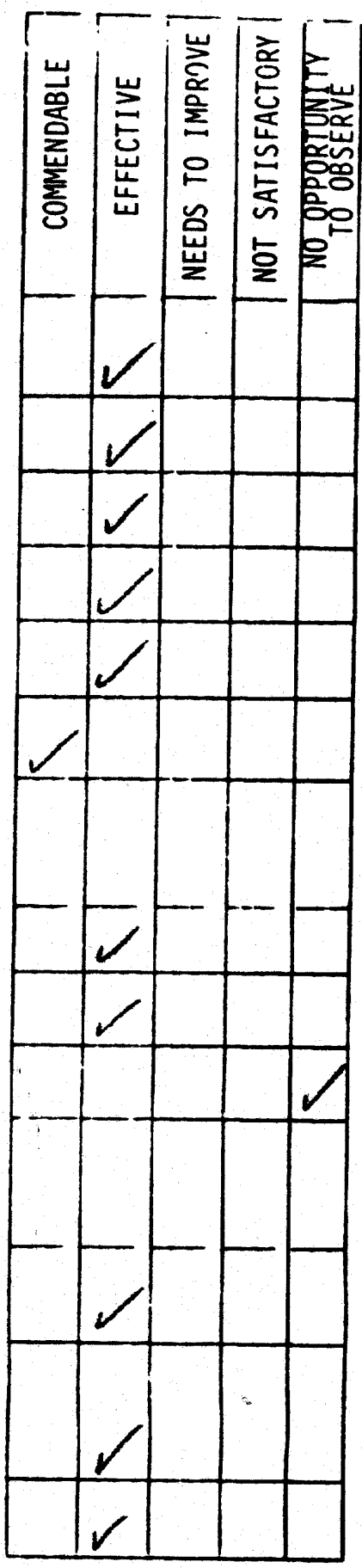

COMMENTS

APPRAISAL RECORD, FORM 2 


\section{PROFESSIONALISM}

1. Observes district and building policies, regulations, state and federal laws, statutes, and minimum standards.

2. Follows ethical standards of the teaching profession.

3. Models consistently professional behavior.

4. Seeks professional growth and development opportunities.

5. Maintains memberstitp in professional assoctations.

6. Serves on district and building comnittees.

7. Performs assigned duties and complete reports accurately and on time.

8. Uses correct English and approprlate language as part of professtonal responsibility.

\section{PERSONAL QUALITIES}

1. Exhibits positive attitude toward teaching.

2. Exercises self-control.

3. Is prompt for work.

4. Is regular in attendance.

5. Is reliable in performing noninstructional duties.

6. Maintains sound, mature emotional Judgment.

7. Dresses appropriately - is neat and well groomed.

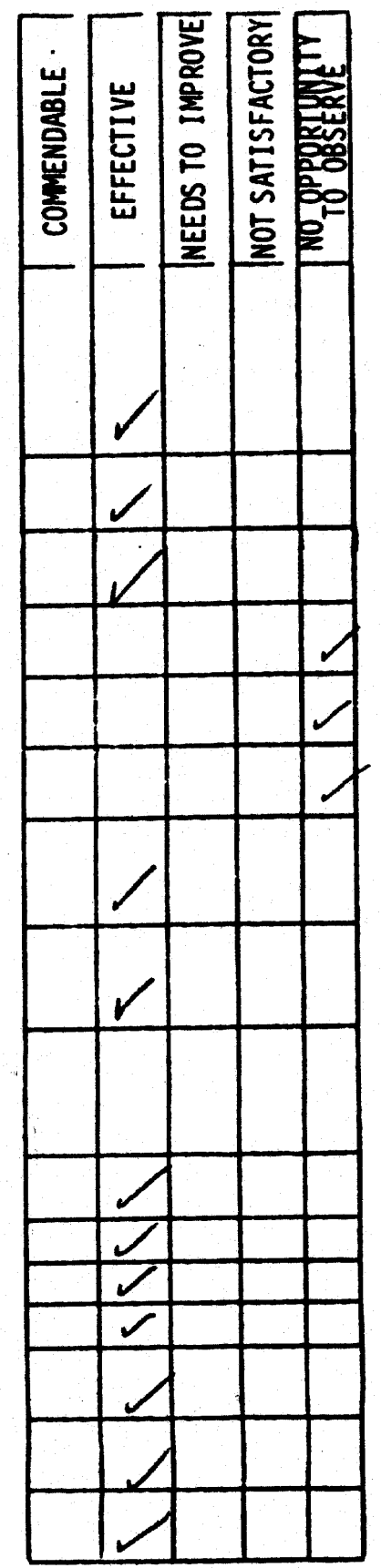

COMMENTS

APPRAISAL RECORD, FOPA 2 


\section{WHAT EXTENUATING CIRCUNSTANCES EXIST?}

\section{AREAS OF STRENGTH:}

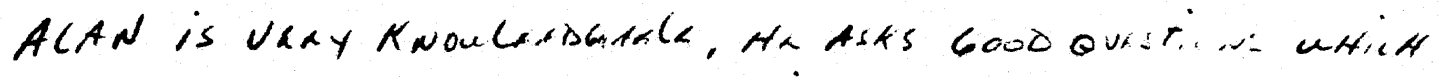

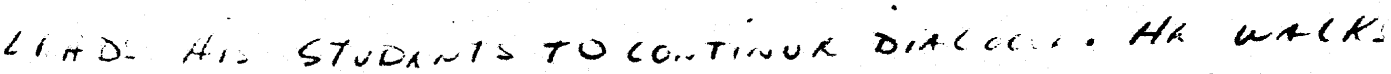

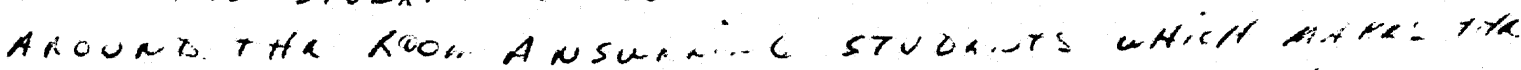

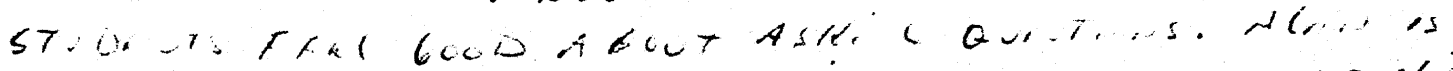

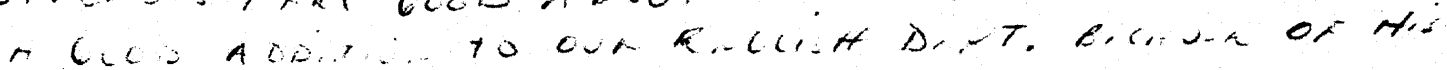

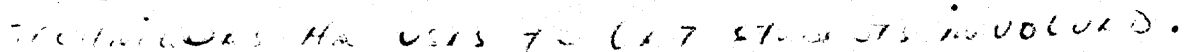

AREAS NEEDING IMPROVEMENT, SUGGESTIONS FOR IMPROVEMENT, AND PLANS FOR SUPERVISORY FOLLOW UP:

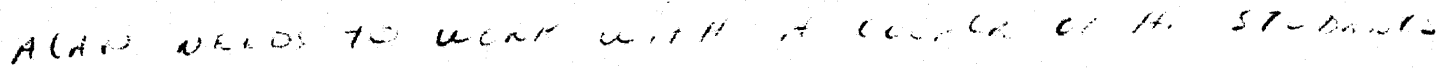

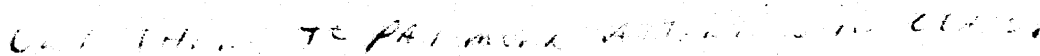

COMMENTS BY TEACHER:

AfCilinte asseoonent

I have received a copy of all of this appraisal record that has been completed to date and I wish to have any additional statements of my own included with this record at this time.

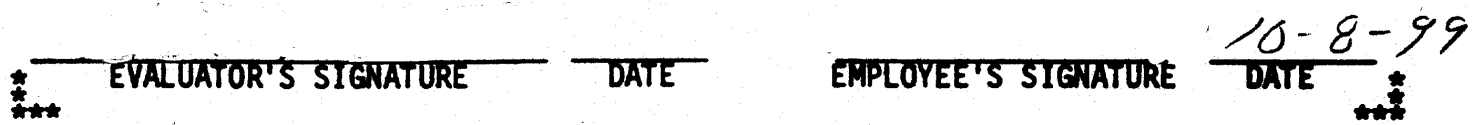

APPRAISAL RECORD, FORM 3 


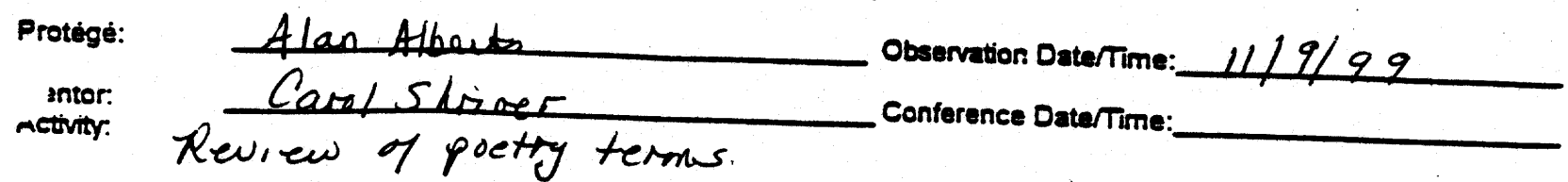

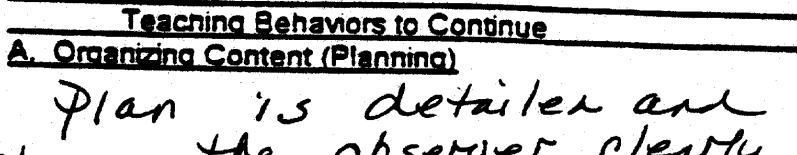
shews tho observer cleary whor will be covered on the ibservation arr detils the vhy are how as evell.

\section{B. Environment} students ar called on randemly (faimess). Classmoles are revileuer as necenessary (bringin book to claw, shtypery pencil Expeclation are. statei do ctues clearly with student repeding Yhese expectatione stedene fillow procelues $\alpha$ routine for poumep writiop (beginury of cther pueal)

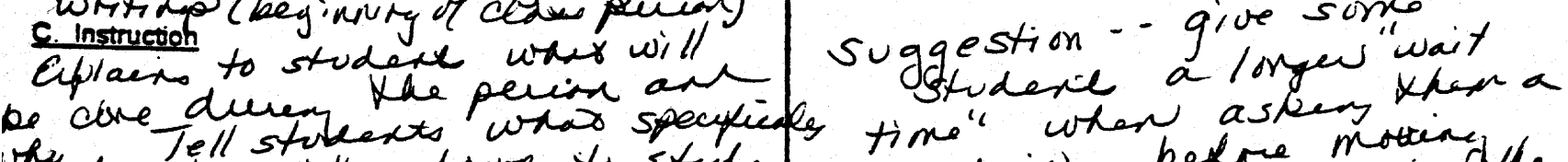
vey 'to be writter down to stidy

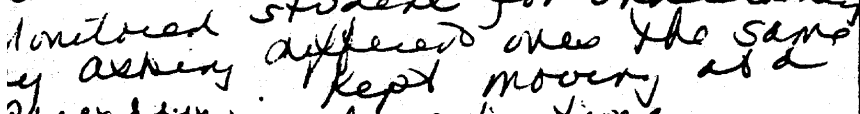
peeclum the entipe tions Geich yace

wae the other Erglon teachers to cinged wede (If)

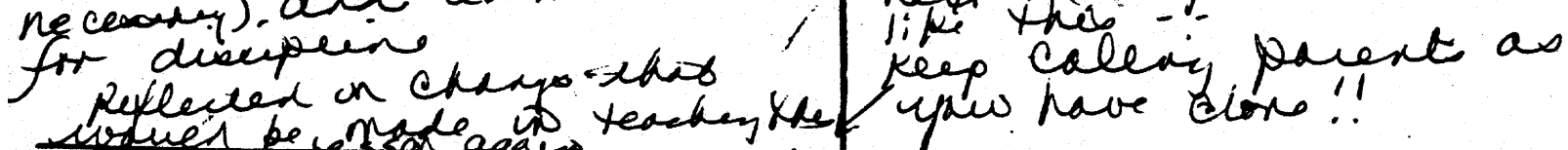
Goars:

None notel - noxe noted - teep up
the grend wock

nore noter -
you notel mary chayglo in to rest isdeclest fridth arower. has you now tereh a lesson lipe the iver calla parest as 
SCHOOLS

CHECKLIST FOR TEACHEK EVALUATION

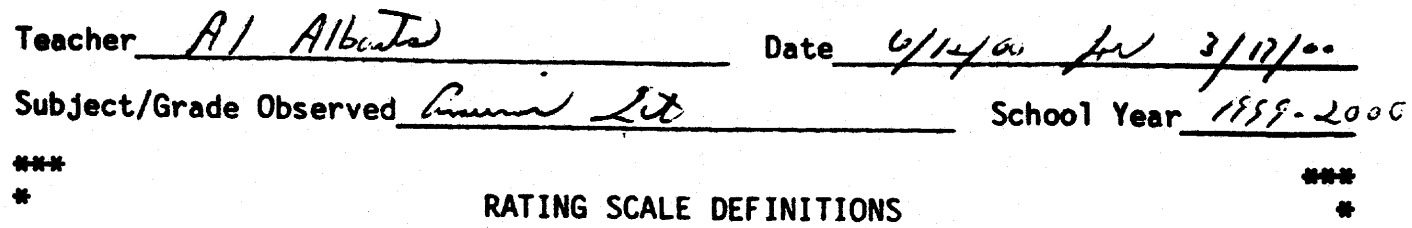

COMMENDABLE - Above what is routinely expected of all staff

EFFECTIVE - At the level of performance that is routinely expected of all staff

MEEDS IMPROVEMENT - Generally of acceptable quality, but in some aspects Improvement is needed

MOT SATISFACTORY - Generally below what is routinely expected of all staff

NO OPPORTUNITY TO OBSERVE - Evaluator has not been able to observe this particular area enough to make a judgment

nin.

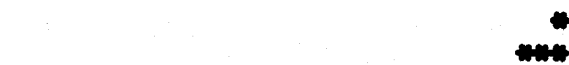

\section{INSTRUCTIONAL EFFECTIVENESS}

1. Possesses and demonstrates a sound knowledge of subjects taught.

2. Prepares lesson plans which follow district guidelines and curriculum guides.

3. Plans and prepares instructional activities to meet individual differences.

4. Maintains organized lesson plans and adequate records of students progress.

5. Establishes instructional objectives and goals for dally lessons and long range units.

6. Provides clear explanations and instructions.

7. Uses varied and adaptable teaching techniques.

8. Has clear evaluation procedures.

9. Provides frequent feedback to students.

10. Provides an environment that encourages learning.

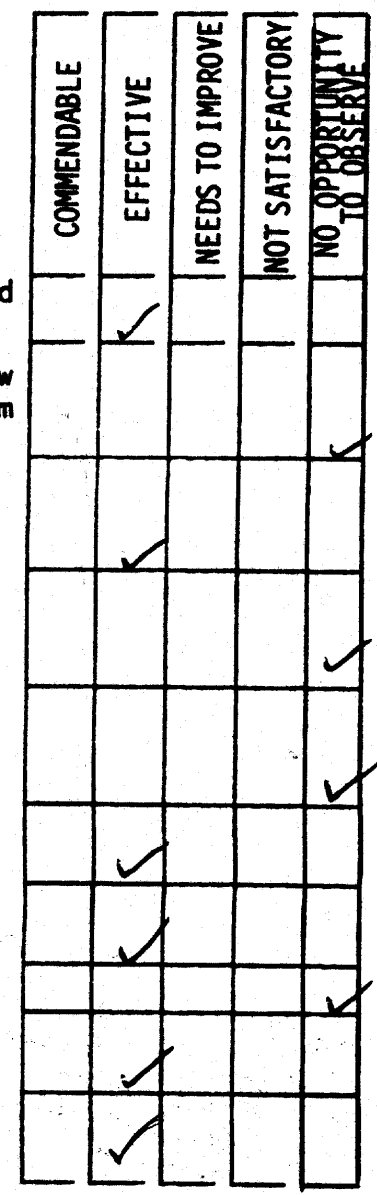

APPRAISAL RECORD, FORM 2 


\section{RELATIONSHIP WITH PUPILS}

1. Respects, understands, and likes children.

2. Maintains professional rapport with students.

3. Maintains established classroom and school discipline policies.

4. Promotes respect among students and towards learning.

5. Maintains a consistent and fair approach in dealing with students.

6. Encourages independent thinking and problem solving.

\section{STAFF RELATIONSHIPS}

1. Works cooperatively with colleagues and administrators.

2. Assumes fair share of responsibility for schoolwide activities.

3. Accepts and profits from supervision.

\section{PARENT-COMMUNITY RELATIONSHIPS}

1. Demonstrates willingness to communicate with parents about students' educational experiences.

2. Communicates positively with the community about the school, the district, and the educational program.

3. Supports school and/or community activities.

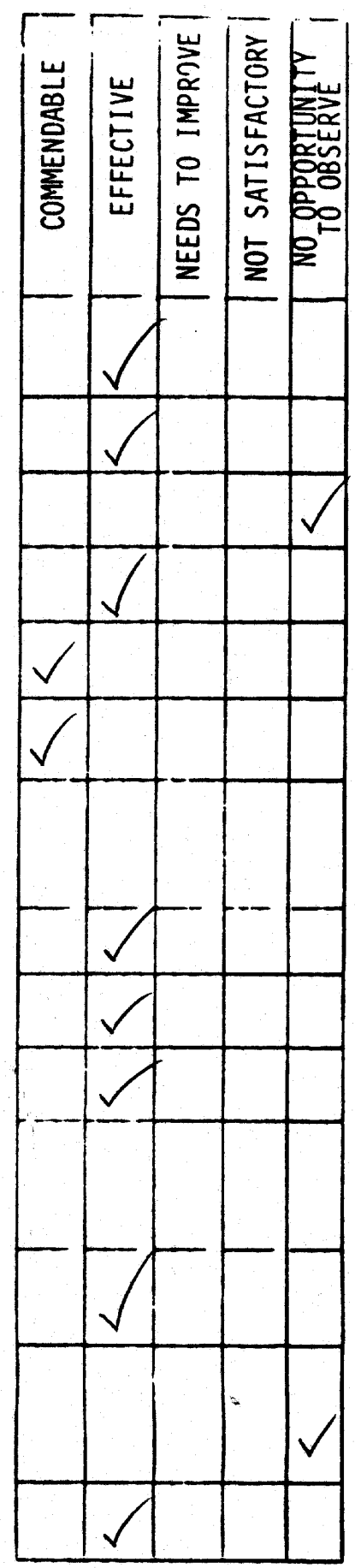

COMMENTS

APPRAISAL RECORD, FORM 2 


\section{PROFESSIONALISM}

1. Observes district and building policies, regulations, state and federal laws, statutes, and mintmum standards.

2. Follows ethical standards of the teaching profession.

3. Models consistentiy professional behavior.

4. Seeks professional growth and development opportunities.

5. Maintains memberstip in professional associations.

6. Serves on district and building committees.

7. Performs assigned duties and complete reports accurately and on time.

8. Uses correct English and appropriate language as part of professional responsibility.

\section{PERSONAL QUALITIES}

1. Exhibits positive attitude toward teaching.

2. Exercises self-control.

3. Is prompt for work.

4. Is regular in attendance.

5. Is reliable in performing noninstructional duties.

6. Maintains sound, mature emotional Judgment.

7. Dresses appropriately - is neat and well groomed.

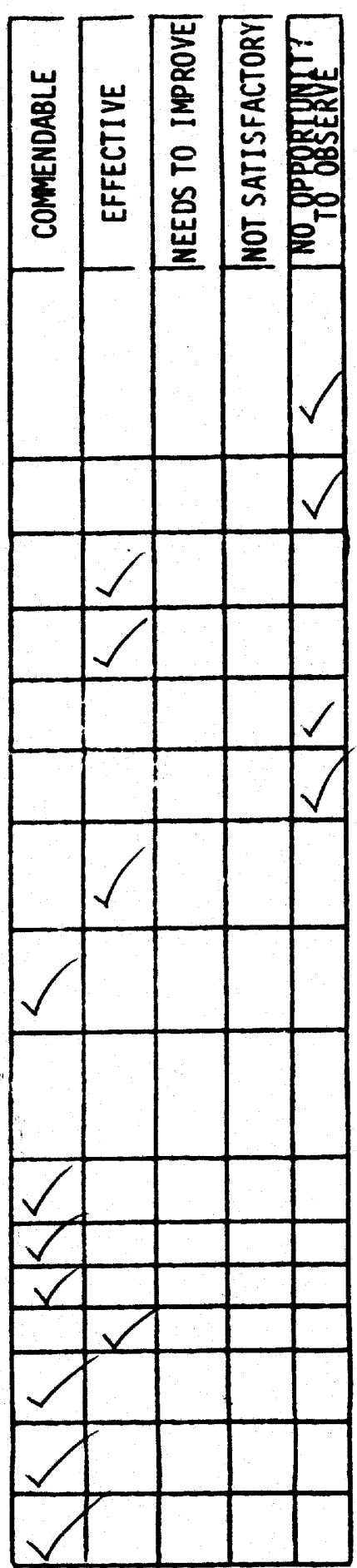

APPRAISAL RECORD, FORM 2 
WHAT EXTENUATING CIRCUMSTANCES EXIST?

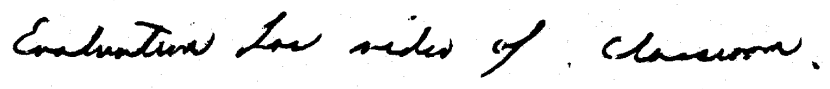

AREAS OF STRENGTH:

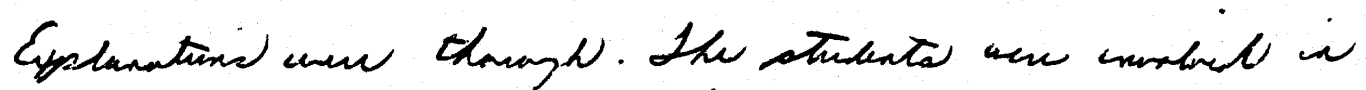

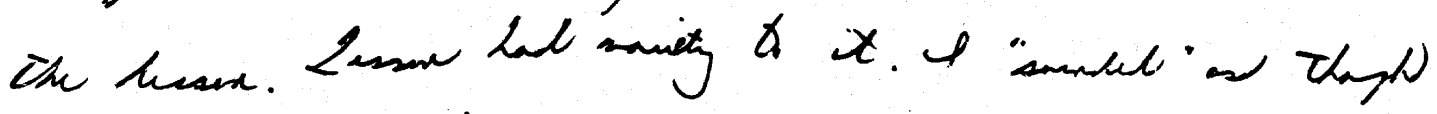
the stentiats ween hetaving.

AREAS NEEDING IMPROVEMENT, SUGGESTIONS FOR IMPROVEMENT, AND PLANS FOR SUPERVISORY FOLLOW UP:

COMMENTS BY TEACHER:

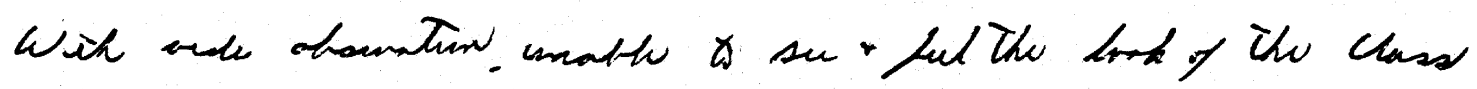

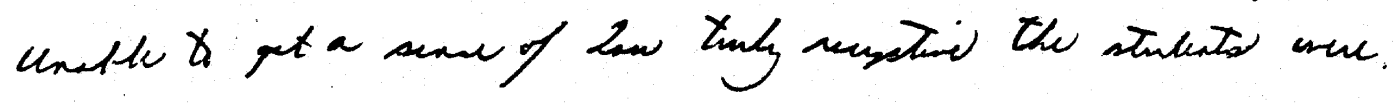

* I have received a copy of all of this appraisal record that has been completed to date and I DO / DO NOT included with this record at this time.

* EVALUATOR'S SIGNATURE $\frac{6 / 22 / 00}{\text { DATE }}$ ERPLOYEE'S SIGNATURE $\frac{6-12-00}{\text { DATE }}$

APPRAISAL RECORD, FORM 3 
June 12,2000

Observations for Al Alberts

Direct Observations vs. Video Observations

My name is

School. We are not only thrilled to have Mr. Al Alberts as part of our staff, but are likewise thrilled with his desire to involve new and innovative ways of doing what we have always done the same way! Al spoke with me early in the school year about his plans for video taping his classes. His idea at that time was to not only use it as a way that he would be able to observe himself and make adjustments with his presentation and mannerisms, but to also allow the Principal and myself yet another tool to use in the observations of teachers. Throughout the school year, Al was able to tape his classes and make his own personal adjustments. the Principal, observed $\mathrm{Al}$ on a number of occasions. I was not able to do such an observation. If I had been, perhaps I would have been able to make more use of the video classroom.

With making this tape the initial observation and having no baseline data observed in a direct way available, the video taping was not inclusive enough for an administrative observation. Again, had I observed Al teaching personally, I would have found the taping to be much more advantageous. As it was, I was not able to observe the classroom atmosphere, the student reaction, and the learning environment. This three areas are crucial in the overall observation of a teacher.

However, such tapping can be tremendously advantageous to the classroom teacher. How wonderful such a tool could be if the teacher is willing to put in the time and energy to not only make such tapes, but review the tapes and make necessary adjustments. Al has indeed demonstrated such an eagerness to take such a challenge. Al has also ignited such a spark in several other teachers! We are planning on allowing $\mathrm{Al}$ the opportunity to enlist other "recruits" in this arena during In-Service opportunities in the coming school year. 
APPENDIX G: STAFF DEVELOPENT: VIDEOTAPING (MODEL) 
APPENDIX G

\title{
THE MIRRORED EYE ON ME
}

\author{
EDLS 331 \\ Summer Session 1999 \\ Principles of Supervision \\ Staff Development Committee:
}

Al Alberts

Bernie Boice

Glenna Clutter

Joseph Oliverio 


\section{Mirrored Eye on ME}

I. Introduction: Our school was selected by the county to field test the practice of videotaping instruction in order to improve teaching. We have decided to conduct the initial in-service during a full day faculty senate meeting in October. The in-service day(s) set aside in August will be changed to a general meeting, building administrator meetings and teacher prep day(s).

\section{A. Title: Mirrored Eye on ME}

B. Description: A timely seminar on the metacognitive reflection of classroom techniques as they relate to your own personal teaching style.

C. Rationale: Every instructor can benefit through a physical, psychological, and situational analysis in their delivery of instruction.

D. Target Group: All classroom professionals. No prerequisite skills needed. A positive attitude towards self-improvement is desired.

E. Objectives:

1. All teachers will discover their philosophical outlook.

2. All teachers will analyze their teaching style.

3. Receive literature associated with philosophy and style for contrast and comparison.

4. Improve teaching skills, techniques, and methods through synthesized video taped self-analysis.

5. Learn to value the collaborative model by sharing results and information learned from the video taping experience.

F. Assumptions: Cost- $\$ 600-\$ 800$

Participation- Required for in-service, voluntary for implementation.

Knowledge- Some will have a working knowledge of topic. Presenter's Expertise: A trained administrator will present.

G. Location and Time: First full day faculty senate meeting in October. The in-service will begin at 10:00 a.m. and conclude at 2:30 p.m. The commons area will serve as the location. The training will be conducted at this time, due to the distractions involved with conducting seminars/training during the days before students return to school. Distractions include: getting room prepared, bulletin boards, copying various forms and papers, text book and locker issues, etc.

H. Preliminary Information: Since attendance is required, information sent prior to the meeting, will take the form of a graphic flyer describing the major 
tenets one week prior to the initial meeting. A general description of the inservice will be given during the building meetings in August.

I. Administrator support and involvement: A trained administrator will conduct the in-service. The same administrator will be involved in all follow-up activities.

II. The Plan

A. Overview:

10:00-10:40 Administer Philosophy Inventory (HUG model)

Discuss each of the five major categories

Provide literature to teachers in regard to their own results

10:40-10:55 Break

10:55-11:35 Repeat the process for administration of T.S.Q.

Discuss results

Provide literature

11:35-11:55 Discussion: How do the two inventories relate to each other?

11:55-12:55 Lunch

12:55- 1:25 Presentation on advantages of video taping for expressed purpose and self-evaluation.

Answer any questions.

1:25- 1:40 Give video handout. (See attached)

Show example of video taped teaching with teachers taking notes.

1:40-2:10 Discuss the tape and information recorded on the handout.

2:10-2:20 Demonstration of how to use video equipment.

2:20-2:25 Ask for two volunteers who are willing to video tape themselves and then share the information they learned at the next meeting.

2:25-2:30 Explain and distribute questionnaire. (See attached)

In-service complete.

B. Activities: The inventories are being done in order for the teachers to learn about themselves in regard to their teaching style and philosophy. $(\mathrm{Obj} .1,2)$ 


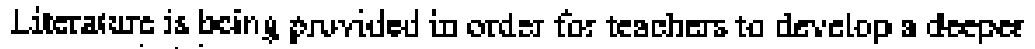

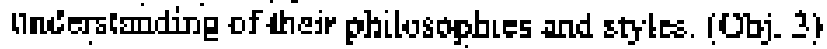

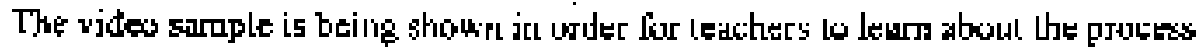

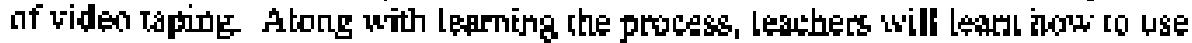
the infentralion gainat in imprntirg icsungtion. (0bj, 4)

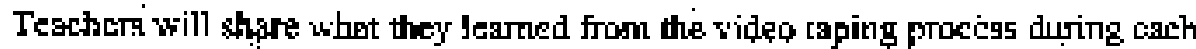

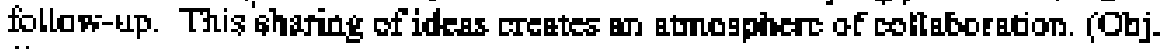
5)

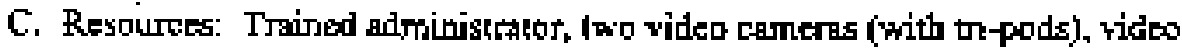

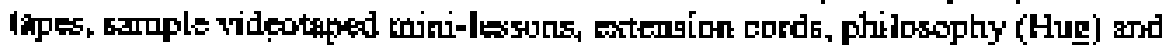

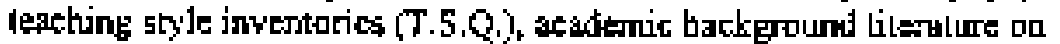
ptilogopby tod aty]es, Trit'

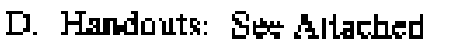

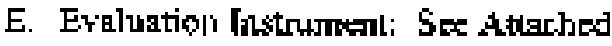

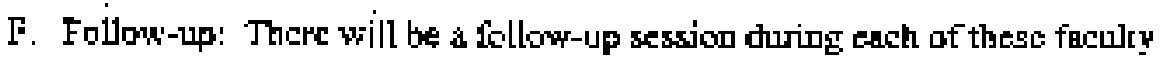

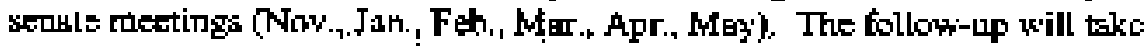

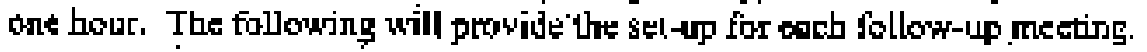

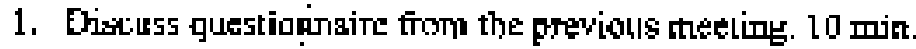

2. Porple who hate ued the viden tapisg will shire their experience (Y'stally. 20 min.

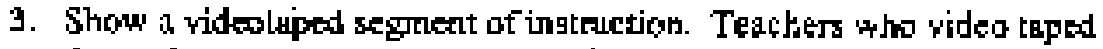

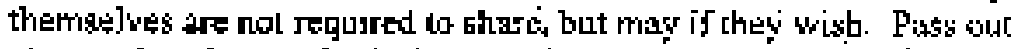
obsorrarion sheth. lí min.

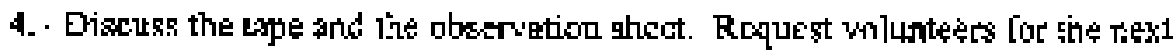
mosting- $] 5$ mijl. 


\section{Video Obserration Handout}

Pleasc pive feedback with regard to the following:

1. Teacher's belief or philosophy:

2. Teacher's teaching scyle:

Э. Teacher 2 classmoon climate: 


\section{Evaluation of In-gervice}

Pieasc answet the followitg lbree questions:

1. What tngights did you gain from the information prowided?

2. List three conterens you had conerning this in-sersice andior. the information prosented?

3. How do you plam on implementing this practice? 


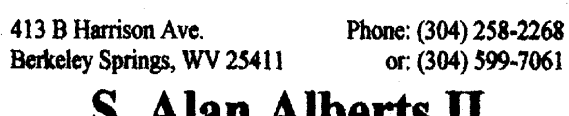

S. Alan Alberts II

Objective: To effectively communicate current educational

objectives/pedagogy/methodology and curricular theory to preservice teachers

\section{Professional:}

- Professionally NTE (Praxis) certified in English/LA 5-12

- Praxis III, domain driven classroom assessment trained

- Team member for district curriculum mapping committee

- Ed.D. action research: "Self-Improvement Videotaping"

- Researched an "On-Line" lap-top secondary school in WV

- $\quad$ Supervised graduate level (WVU) student teacher training

- Participant- Ed.D. workshop on grant preparation process

- Developed software evaluation scoring/usage rubric

- Familiar with state data programs WVEIS \& MOLE

- Prepared students for proficiencies; CTBS \& ACT to NTE

Education: Bachelor of Arts in English $1994 @$ Marshall University (WV) - 66 core hours completed in creative writing specialization Master of Arts in Teaching 1997 @ Marshall University (WV) -36 core hours in educational pedagogy $3.8 \mathrm{GPA}$

Ed. D. in Curriculum \& Instruction 2000 Ed.Ad. Minor @ WVU - 80 core hours beyond Master's completed 3.9 GPA

Experience: $\quad$ Three years as English 9-12 teacher (West Virginia \& Ohio):

Vinson H.S. 1997-1998 Huntington, WV

Watkins Memorial H.S. 1999-2000 Pataskala, OH

Berkeley Springs H.S. 2000-2001 Berkeley Springs, WV

Plus, one year supervising student teachers at WV University

West Virginia University 1998-1999 Morgantown, WV

\footnotetext{
- References and transcripts may be requested directly from: WVU Career Services Center. P.O. 6008, Morgantown, WV 26506-6008 Ph: (304) 293-2221
} 